\title{
Similarity Hypotheses for the Atmospheric Surface Layer Expressed by Non-Dimensional Characteristic Invariants - A Review
}

\author{
Gerhard Kramm ${ }^{*}, 1$ and Fritz Herbert ${ }^{2}$ \\ ${ }^{1}$ University of Alaska Fairbanks, Geophysical Institute, 903 Koyukuk Drive, P.O. Box 757320, Fairbanks, AK 99775- \\ 7320, USA \\ ${ }^{2} J . W$. Goethe-University, Theoretical Meteorology, Georg-Voigt-Strasse 14, D-60325 Frankfurt am Main, Germany
}

\begin{abstract}
In this paper, similarity hypotheses for the atmospheric surface layer (ASL) are reviewed using nondimensional characteristic invariants, referred to as $\pi$-numbers. The basic idea of this dimensional $\pi$-invariants analysis (sometimes also called Buckingham's $\pi$-theorem) is described in a mathematically generalized formalism. To illustrate the task of this powerful method and how it can be applied to deduce a variety of reasonable solutions by the formalized procedure of non-dimensionalization, various instances are represented that are relevant to the turbulence transfer across the ASL and prevailing structure of ASL turbulence. Within the framework of our review we consider both (a) MoninObukhov scaling for forced-convective conditions, and (b) Prandtl-Obukhov-Priestley scaling for free-convective conditions. It is shown that in the various instances of Monin-Obukhov scaling generally two $\pi$-numbers occur that result in corresponding similarity functions. In contrast to that, Prandtl-Obukhov-Priestley scaling will lead to only one $\pi$ number in each case usually considered as a non-dimensional universal constant.

Since an explicit mathematical relationship for the similarity functions cannot be obtained from a dimensional $\pi$ invariants analysis, elementary laws of $\pi$-invariants have to be pointed out using empirical or/and theoretical findings. To evaluate empirical similarity functions usually considered within the framework flux-profile relationships, so-called integral similarity functions for momentum and sensible heat are presented and assessed on the basis of the friction velocity and the vertical component of the eddy flux densities of sensible and latent heat directly measured during the GREIV I 1974 field campaign.
\end{abstract}

Keywords: Atmospheric surface layer, similarity hypotheses, dimensional $\pi$-invariants analysis, Buckingham's $\pi$-theorem, similarity functions, Monin-Obukhov scaling, Prandtl-Obukhov-Priestley scaling, integral similarity functions, surface layer turbulence.

\section{INTRODUCTION}

The idea on which dimensional analysis is based is very simple. It is inferred from the fact that physical laws do not depend on arbitrarily chosen basic units of measurements. In recognizing this simple idea, one may conclude that the functions that express physical laws must possess a certain fundamental property, which, from a mathematical point of view, is called the generalized homogeneity or symmetry [1]. This property allows the number of arguments in these functions to be reduced, thereby making it simpler to obtain them. As Barenblatt [1] pointed out, this is the entire content of dimensional analysis - there is nothing more to it.

Often, solutions for physical problems, especially in mechanics and fluid mechanics [1-8], blackbody radiation [9, 10], and cloud microphysics [11], can be found on the basis of similarity hypotheses that comprise all problem-relevant dimensional quantities and serve to possess the physical mechanisms of these problems. Such similarity hypotheses implicitly describe the functional dependence between these

*Address correspondence to this author at the University of Alaska Fairbanks, Geophysical Institute, 903 Koyukuk Drive, P.O. Box 757320, Fairbanks, AK 99775-7320, USA; Tel: +1 907474 5992; Fax: +1 907474 7290; E-mail:kramm@gi.alaska.edu dimensional quantities in a mathematical form. This does not mean that this functional dependence can explicitly substantiated by formulating a similarity hypothesis only. A similarity hypothesis will become successful if a generalized homogeneity or symmetry exists.

If similarity is hypothesized, its mathematical treatment can further be performed by the procedure of dimensional $\pi$ invariants analysis (sometimes also called Buckingham's $\pi$ theorem; for basic details see, e.g., [1, 4-6, 8, 10, 12]. By means of this mathematical treatment the relationship of subsets of the problem-relevant dimensionality quantities holds as a function of non-dimensional characteristic invariants, referred to as $\pi$-numbers. However, an explicit mathematical relationship cannot be obtained from a $\pi$-invariants analysis. Elementary laws of $\pi$-invariants have to be pointed out in accord with empirical or/and theoretical principles.

Various similarity hypotheses associated with the atmospheric surface layer (ASL, also called the Prandtl layer) have been discussed by Zdunkowski and Bott [7], but without a sufficient mathematical treatment of the $\pi$-invariants analysis. The same is true in the instance of Kitaigorodski's [3] paper, even though this contribution is by far the most complete one in the literature when the ASL is considered exclu- 
sively. Recently, Foken [13] gave a historical survey of "50 years of Monin-Obukhov similarity theory". Even though the notion Monin-Obukhov similarity theory is customary, here we only use the notion Monin-Obukhov similarity hypothesis and its result is called a Monin-Obukhov similarity law, in accord with Barenblatt [1].

In the following section 2, foundations of dimensional analysis of $\pi$-invariants are described in a mathematically generalized formalism. In section 3, the scope of the ASL physics is outlined, and the constant flux principles of the ASL are derived and assessed. For this layer the difference between complete and incomplete similarity is pointed out in section 4. Various prominent examples of ASL similarity laws are represented in sections 5 and 6, namely (a) MoninObukhov scaling for forced-convective conditions [14], and (b) Prandtl-Obukhov-Priestley scaling for free-convective conditions [15-17].

It is shown that in the various instances of MoninObukhov scaling generally two $\pi$ numbers occur that result in corresponding similarity functions. Such customarily called universal functions for variance and covariance terms depending on the Obukhov number, $\zeta$, are established using empirical or/and theoretical findings. In contrast to that, Prandtl-Obukhov-Priestley scaling will lead to only one $\pi$ number in each case; it is usually considered as a nondimensional universal constant. This kind of scaling is utilized here to derive the asymptotic solutions for freeconvective conditions.

For more practical purposes, various so-called integral similarity functions are presented in section 7 that are used to formulate flux-profile relationships. In this section, these integral similarity functions are assessed on the basis of the friction velocity and the vertical components of the eddy flux densities (hereafter simply called the eddy fluxes) of sensible and latent heat directly measured during the GREIV I 1974 experiment. These data, fully documented in [18], were not used in deriving the universal functions on which the integral similarity functions presented here are based.

\section{DIMENSIONAL SIMILARITY INVARIANTS ANALYSIS}

\subsection{Description of the Procedure}

The theoretical foundation of the procedure, described in this section, is linked to various sources, for instance, Kitaigorodskij [3], Barenblatt [1, 4-6], Herbert [19], Pal Arya [20], Sorbjan [21], Brown [11], and Kramm and Herbert [8, 10] which are devoted to characteristic scaling problems in fluid dynamics and turbulence, boundary layer meteorology and other physical disciplines. The description mainly follows the guideline of Kramm and Herbert [8, 10].

Let adopt that, associated with a certain physical problem, we can select a set of characteristic dimensionality quantities, for instance, $\mathrm{k}$ variables, parameters or/and constants, $Q_{1}, Q_{2}, \ldots, Q_{k}$ that unambiguously and evidently represent the arguments of a mathematical relationship. First this "law" is unspecified; therefore it is formally employed as a general postulate, commonly referred to as the similarity hypothesis of the problem, which may read

$$
F\left(\mathrm{Q}_{1}, \mathrm{Q}_{2}, \ldots ., \mathrm{Q}_{\mathrm{k}}\right)=0 \text {. }
$$

In its implicit representation Eq. (2.1) declares $\mathrm{k}-1$ free or independent arguments as well as a transformation of the full series of $Q_{j}$ for $j=1, \ldots, k$ to a series of $p$ nondimensional invariants $\pi_{i}$ for $i=1, \ldots, p$ in terms of a factorization by powers. Correspondingly, in that mind each $\pi_{\mathrm{i}}$-expression is defined by

$\pi_{\mathrm{i}}=\mathrm{Q}_{1}{ }^{\mathrm{x}_{1, i}} \mathrm{Q}_{2}{ }^{\mathrm{x}_{2, i}} \ldots . \mathrm{Q}_{\mathrm{k}}{ }^{\mathrm{x}_{\mathrm{k}, \mathrm{i}}}=\prod_{\mathrm{j}=1}^{\mathrm{k}} \mathrm{Q}_{\mathrm{j}}^{\mathrm{x}_{\mathrm{j}, \mathrm{i}}}$ for $\mathrm{i}=1, \ldots, \mathrm{p}$,

and it is necessarily linked with the condition of nondimensionality

$\operatorname{dim} \pi_{\mathrm{i}}=1 \quad$ for $\mathrm{i}=1, \ldots, \mathrm{p}$,

where $\mathrm{p}<\mathrm{k}$ is customarily valid.

Next, we will suppose that the $\pi_{\mathrm{i}}$-invariants can have interdependencies of arbitrary forms, and it may exist a corresponding relation

$\phi\left(\pi_{1}, \pi_{2}, \ldots, \pi_{\mathrm{p}}\right)=0$

which is to be understood as an alternative similarity hypothesis to Eq. (2.1). In this function the powers $\mathrm{x}_{\mathrm{j}, \mathrm{i}}$ from Eq. (2.2) are basically unknown numbers, and their determination is the proper problem of the Buckingham $\pi$-theorem. If there are more than one $\pi$-invariant, i.e., $p>1$, then we have with Eq. (2.4) the explicit representation

$\pi_{\mathrm{i}}=\varphi\left(\pi_{1}, \pi_{2}, \ldots, \pi_{\mathrm{p}}\right)$

in which $\varphi$ may be interpreted as a universal function within the framework of the similarity hypothesis, where, according to the implicit formulation (2.4), $\pi_{\mathrm{i}}$ (for any arbitrary $i \in\{1, \ldots, p\})$ is not an argument of that universal function. Note that in the special case of $p=1$, we will merely obtain one $\pi$-invariant, that is a non-dimensional universal constant. This special case is expressed by Eq. (2.5) in the singular form

$\pi=$ const

(or $\varphi=$ const.). In view to the determination of the powers $\mathrm{X}_{\mathrm{j}, \mathrm{i}}$, we will extend our treatment to the concise set of fundamental dimensions, $\mathrm{D}_{\mathrm{n}}$ for $\mathrm{n}=1, \ldots, \mathrm{r}$ such as length $\mathrm{L}$, time $T$, mass $M$, temperature $\Theta$, considering that any quantity's dimension can be analyzed in terms of the independent $D_{n}$ by homogeneous power factorization. Let that be expressed by

$\operatorname{dim} Q_{j}=D_{1}^{g_{1, j}} D_{2}^{g_{2, j}} \ldots . D_{r}^{g_{r, j}}=\prod_{n=1}^{r} D_{n}^{g_{n, j}}$ for $j=1, \ldots, k$ 
in which the powers $g_{n, j}$ for $n=1, \ldots, r$ and $j=1, \ldots, k$ are known from the relevant quantities $\mathrm{Q}_{j}$ according to the hypothesized similarity condition. Note that $\mathrm{r} \leq \mathrm{k}$ is valid, where $r$ is the highest number of fundamental dimensions that may occur. In other words: for $k$ quantities $Q_{j}$ including $r$ fundamental dimensions $D_{n}$ we obtain $p=k-r$ independent non-dimensional invariants, so-called $\pi$ numbers.

Now a straight-forward development of the analytical framework is attained by introducing Eq. (2.7) together with the factorization by powers from Eq. (2.2) into the condition of non-dimensionality (2.3). In doing so, we obtain this basic law as described in the following detailed representation

$\operatorname{dim} \pi_{i}=\prod_{j=1}^{k}\left(\prod_{n=1}^{r} D_{n}^{g_{n, j}}\right)^{x_{j, i}}=1 \quad$ for $i=1, \ldots, p$

Combining the two factorizations $\prod_{j}$ and $\prod_{n}$ in this equation enables to rewrite this set of conditions in the fully equivalent form

$\operatorname{dim} \pi_{i}=\prod_{n=1}^{r} D_{n} \sum_{j=1}^{k} g_{n, j} x_{j, i}=1 \quad$ for $i=1, \ldots, p$

For the following conclusion, the latter is more suitable than the former. Indeed, we may immediately infer from the factorizing analysis in dependence on the bases $D_{n}$ for $\mathrm{n}=1, \ldots, \mathrm{r}$ that the set of conditions

$\sum_{j=1}^{k} g_{n, j} x_{j, i}=0 \quad$ for $n=1, \ldots, r$ and $i=1, \ldots, p$

has to hold since each $D_{n}$-exponential factor must satisfy, owing to its mathematical independence, the condition of non-dimensionality (see Eqs. (2.3) and (2.9)), i.e., to be equal to unity. In matrix notation, Eq. (2.10) may be expressed by

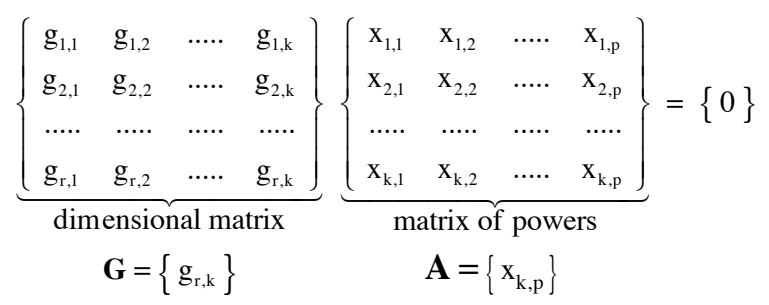

where the notation $\{0\}$ is an $r \times p$ matrix, and each column of the matrix of powers, $\mathbf{A}$, is forming so-called solution vectors $\mathbf{x}_{\mathrm{i}}$ for the invariants $\pi_{\mathrm{i}}$ for $\mathrm{i}=1, \ldots, p$. The set of equations (2.11) serves to determine the powers $\mathrm{x}_{\mathrm{j}, \mathrm{i}}$ for $j=1, \ldots, k$, and $i=1, \ldots, p$. So the homogeneous system of linear equations has, in accord with Eq. (2.11), for each of these $\pi$-invariants the alternative notation

$$
\mathbf{G} \cdot \mathbf{x}_{\mathrm{i}}=\mathbf{0} \quad \text { or } \quad\left\{\begin{array}{cccc}
\mathrm{g}_{1,1} & \mathrm{~g}_{1,2} & \ldots . . & \mathrm{g}_{1, \mathrm{k}} \\
\mathrm{g}_{2,1} & \mathrm{~g}_{2,2} & \ldots . & \mathrm{g}_{2, \mathrm{k}} \\
\ldots \ldots & \ldots . . & \ldots . . & \ldots . . \\
\mathrm{g}_{\mathrm{r}, 1} & \mathrm{~g}_{\mathrm{r}, 2} & \ldots . . & \mathrm{g}_{\mathrm{r}, \mathrm{k}}
\end{array}\right\}\left\{\begin{array}{c}
\mathrm{x}_{1, \mathrm{i}} \\
\mathrm{x}_{2, \mathrm{i}} \\
\ldots . \\
\mathrm{x}_{\mathrm{k}, \mathrm{i}}
\end{array}\right\}=\{0\}
$$

for $i=1, \ldots, p$

The rank of the dimensional matrix is equal to the number of fundamental dimensions, $r$. If the number of dimensional quantities, $\mathrm{k}$, is equal to $\mathrm{r}$, we will obtain: $\mathrm{p}=0$. In this case there is only a trivial solution. In the case of $p>0$, the homogeneous system of linear equation (2.12) is indeterminate, i.e., more unknowns than equations, a fact that is true in all instances presented here. Hence, for each of the $\mathrm{p}$ nondimensional $\pi$ numbers, it is necessary to make a reasonable choice for $\mathrm{p}$ of these unknowns, $\mathrm{x}_{\mathrm{k}, \mathrm{i}}$, to put this set of equations into a solvable state. After that we obtain for each $\pi$ number an inhomogeneous linear equation system that serves to determine the remaining $\mathrm{r}=\mathrm{k}-\mathrm{p}$ unknowns. Thus, the remaining $r \times r$ dimensional matrix $G_{0}=\left\{g_{r, r}\right\}$ has the rank $r$, too. It is the largest square sub-matrix for which the determinant is unequal to zero $\left(\left|g_{\mathrm{r}, \mathrm{r}}\right| \neq 0\right)$. Thus, we have

$$
\begin{gathered}
\mathbf{G}_{0} \cdot \mathbf{x}_{\mathrm{i}}=\mathbf{B}_{\mathrm{i}} \quad \text { or }\left\{\begin{array}{cccc}
\mathrm{g}_{1,1} & \mathrm{~g}_{1,2} & \ldots . & \mathrm{g}_{1, \mathrm{r}} \\
\mathrm{g}_{2,1} & \mathrm{~g}_{2,2} & \ldots . & \mathrm{g}_{2, \mathrm{r}} \\
\ldots . & \ldots \ldots & \ldots . . & \ldots . . \\
\mathrm{g}_{\mathrm{r}, 1} & \mathrm{~g}_{\mathrm{r}, 2} & \ldots \ldots & \mathrm{g}_{\mathrm{r}, \mathrm{r}}
\end{array}\right\}\left\{\begin{array}{c}
\mathrm{x}_{1, \mathrm{i}} \\
\mathrm{x}_{2, \mathrm{i}} \\
\ldots . \\
\mathrm{x}_{\mathrm{r}, \mathrm{i}}
\end{array}\right\}=\left\{\begin{array}{c}
\mathrm{B}_{1, \mathrm{i}} \\
\mathrm{B}_{2, \mathrm{i}} \\
\ldots . \\
\mathrm{B}_{\mathrm{r}, \mathrm{i}}
\end{array}\right\} \\
\text { for } \mathrm{i}=1, \ldots, \mathrm{p}
\end{gathered}
$$

This inhomogeneous system of linear equations can be solved for $\mathrm{x}_{\mathrm{m}, \mathrm{i}}$ for $\mathrm{m}=1, \ldots, \mathrm{r}$ by employing Cramer's rule.

\subsection{Example: The Logarithmic Wind Profile}

By following the general procedure explained before, a concrete analysis is now treated at which one is led to the logarithmic wind profile for thermally neutral stratification. At this example we will confine our attention to three basic quantities: $\mathrm{Q}_{1}$ is the height difference $\mathrm{z}-\mathrm{d}$ (in $\mathrm{m}$ ), where $\mathrm{z}$ and $\mathrm{d}$ are the height above ground and the zero-plane displacement, respectively, $\mathrm{Q}_{2}$ is the height-invariant friction velocity $\mathrm{u}_{*}\left(\right.$ in $\mathrm{m} \mathrm{s}^{-1}$ ), and $\mathrm{Q}_{3}$ is the shear of the mean horizontal wind speed $\partial \mathrm{U} / \partial \mathrm{z}$ (in s${ }^{-1}$ ) with $\mathrm{U}=\left|\hat{\mathbf{v}}_{\mathrm{H}}\right|$. In so doing, we may set up the similarity hypothesis $F\left(\mathrm{z}-\mathrm{d}, \mathrm{u}_{*}, \partial \mathrm{U} / \partial \mathrm{z}\right)=0$. Obviously, only $\mathrm{L}$ and $\mathrm{T}$ occur as fundamental independent dimensions.

Next, depending on $\mathrm{D}_{1}=\mathrm{L}$ and $\mathrm{D}_{2}=\mathrm{T}$, Eq. (2.9) yields

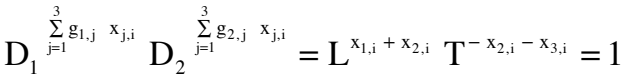

for $\mathrm{i}=1, \ldots, \mathrm{p}$ 
So, in agreement with formulae (2.10) to (2.12) one has the dimensional matrix $G=\left\{\begin{array}{ccc}1 & 1 & 0 \\ 0 & -1 & -1\end{array}\right\}$ and, hence, the (under-determined) homogeneous equations of solution

$\mathbf{G} \cdot \mathbf{x}_{\mathrm{i}}=0 \quad$ or $\quad\left(\begin{array}{ccc}1 & 1 & 0 \\ 0 & -1 & -1\end{array}\right)\left(\begin{array}{l}\mathrm{x}_{1, \mathrm{i}} \\ \mathrm{x}_{2, \mathrm{i}} \\ \mathrm{x}_{3, \mathrm{i}}\end{array}\right)=0$

for $\mathrm{i}=1, \ldots, \mathrm{p}$

with which $\mathrm{k}=3$ and $\mathrm{r}=2$ (rank of matrix $\mathbf{G}$ ) and, consequently, $\mathrm{p}=\mathrm{k}-\mathrm{r}=1$ are given. This designates a case of one non-dimensional invariant $\pi$ only. In a free choice we may arbitrarily define $x_{1,1}=1$ without loss of generality to obtain from Eq. (2.15) the two inhomogeneous equations of solution (in accord with Eq. (2.12))

$\left(\begin{array}{cc}1 & 0 \\ -1 & -1\end{array}\right)\left(\begin{array}{l}x_{2,1} \\ x_{3,1}\end{array}\right)=\left(\begin{array}{c}-1 \\ 0\end{array}\right)$

From this equation one easily calculate $\mathrm{x}_{2,1}=-1$ and $\mathrm{x}_{3,1}=1$. Thus, the full solution vector reads

$\mathbf{x}_{1}=\left(\begin{array}{l}x_{1,1} \\ x_{2,1} \\ x_{3,1}\end{array}\right)=\left(\begin{array}{c}1 \\ -1 \\ 1\end{array}\right)$

Finally, the elements of this solution vector are to be utilized owing to the general context of formulae (2.2) and (2.5) to find the desired universal relationship (i.e., the similarity law)

$\pi_{1}=(\mathrm{z}-\mathrm{d})^{1} \mathrm{u}_{*}^{-1}\left(\frac{\partial \mathrm{U}}{\partial \mathrm{z}}\right)^{1}=\frac{\mathrm{z}-\mathrm{d}}{\mathrm{u}_{*}} \frac{\partial \mathrm{U}}{\partial \mathrm{z}}=$ const

or in the re-arranged form

$\frac{\partial \mathrm{U}}{\partial \mathrm{z}}=\frac{\mathrm{u}_{*}}{\kappa(\mathrm{z}-\mathrm{d})}$

where $\kappa=\pi_{1}^{-1}$ is another non-dimensional universal constant [1,4], namely the von Kármán constant (see subsection 5.6).

We will append to Eq. (2.18) that since $\pi_{1}$ is yet arbitrary. If we choose, for instance, $x_{1,1}=a$, where $a \neq 0$ is an arbitrary real number, we will lead to another invariant $\pi_{1} *$. The relationship between this $\pi$ invariant and that, occurring in Eq. (2.18), is given by $\pi_{1}=\sqrt[a]{\pi_{1}^{*}}$. Therefore, for convenience, we may simply choose: $x_{1,1}=1$.

Integrating Eq. (2.19) over the height interval $\left[\mathrm{z}_{\mathrm{r}}, \mathrm{z}_{\mathrm{R}}\right]$, where $z_{r}$ and $z_{R}$ are the lower and upper boundaries of the fully turbulent part of the ASL, respectively, yields

$\mathrm{U}\left(\mathrm{z}_{\mathrm{R}}\right)-\mathrm{U}\left(\mathrm{z}_{\mathrm{r}}\right)=\frac{\mathrm{u}_{*}}{\kappa} \int_{\mathrm{z}_{\mathrm{r}}}^{\mathrm{z}_{\mathrm{R}}} \frac{\mathrm{dz}}{\mathrm{z}-\mathrm{d}} \mathrm{dz}=\frac{\mathrm{u}_{*}}{\kappa} \ln \frac{\mathrm{z}_{\mathrm{R}}-\mathrm{d}}{\mathrm{z}_{\mathrm{r}}-\mathrm{d}}$
If we assume that $U\left(z_{r}\right)$ extrapolates to zero when $z_{r}$ tends to $z_{r}=z_{0}+d$, where $z_{0}$ is the roughness length, we may write

$$
\mathrm{U}\left(\mathrm{z}_{\mathrm{R}}\right)=\frac{\mathrm{u}_{*}}{\kappa} \ln \frac{\mathrm{z}_{\mathrm{R}}-\mathrm{d}}{\mathrm{z}_{0}}
$$

This expression is called the logarithmic wind profile for (thermally) neutral stratification. Multiplying nominator and denominator of the logarithm in Eq. (2.21) by $u_{*} v$, where $v$ is the kinematic viscosity, and rearranging this equation yields

$\mathrm{u}_{\mathrm{R}}^{+}=\frac{\mathrm{U}\left(\mathrm{z}_{\mathrm{R}}\right)}{\mathrm{u}_{*}}=\frac{1}{\mathrm{\kappa}} \ln \frac{\mathrm{u}_{*}\left(\mathrm{z}_{\mathrm{R}}-\mathrm{d}\right)}{\mathrm{v}}-\frac{1}{\kappa} \ln \frac{\mathrm{u}_{*} \mathrm{z}_{0}}{\mathrm{v}}$

Over aerodynamically smooth surfaces we can ignore the zero-plane displacement, $d$. Thus, if we define the local (or roughness) Reynolds number by

$\eta=\frac{u_{*} \mathrm{z}}{\mathrm{v}}$

the global Reynolds number by

$\eta_{\mathrm{R}}=\frac{\mathrm{u}_{*} \mathrm{z}_{\mathrm{R}}}{\mathrm{v}}$

and

$\mathrm{D}=-\frac{1}{\kappa} \ln \frac{\mathrm{u}_{*} \mathrm{z}_{0}}{\mathrm{v}}$

we will obtain

$\mathrm{u}_{\mathrm{R}}^{+}=\frac{1}{\kappa} \ln \left(\eta_{\mathrm{R}}\right)+\mathrm{D}$

For aerodynamically smooth surfaces we have $\mathrm{D} \cong 5.5$ [22]. This equation for the normalized velocity, $\mathrm{u}_{\mathrm{R}}^{+}=\mathrm{U}\left(\mathrm{z}_{\mathrm{R}}\right) / \mathrm{u}_{*}$, describes the turbulent approximation of Prandtl and Taylor for sufficiently large Reynolds numbers (e.g., [23-26]).

\section{THE ATMOSPHERIC SURFACE LAYER}

\subsection{The Scope of the ASL Physics}

To outline the scope of the ASL physics, it is indispensable to consider the governing local balance equations for momentum (Newton's $2^{\text {nd }}$ axiom), water vapor, and total mass. For a turbulent system like the ASL these balance equations read [27-34]

$\bar{\rho} \frac{\mathrm{d} \hat{\mathbf{v}}}{\mathrm{dt}}+\nabla \cdot(\overline{\mathrm{p}} \mathbf{E}+\overline{\mathbf{J}}+\mathbf{F})=-\bar{\rho} \nabla \bar{\phi}-2 \bar{\rho} \boldsymbol{\Omega} \times \hat{\mathbf{v}}$

$\bar{\rho} \frac{\mathrm{d} \hat{\mathrm{q}}}{\mathrm{dt}}+\nabla \cdot\left(\overline{\mathbf{J}_{\mathrm{w}}}+\mathbf{W}\right)=\overline{\mathrm{I}_{\mathrm{w}}}$

and

$\frac{\partial \bar{\rho}}{\partial t}+\nabla \cdot(\bar{\rho} \hat{\mathbf{v}})=0$ 
respectively. Here, $\rho$ is the density of air, $\mathbf{v}$ is the wind vector, where $\mathrm{u}, \mathrm{v}$, and $\mathrm{w}$ are its components in east $(\mathrm{x})$, north $(y)$, and vertical $(z)$ direction of a Cartesian coordinate frame with the corresponding unit vectors $\mathbf{i}, \mathbf{j}$, and $\mathbf{k}, \mathrm{t}$ is time, $\mathrm{p}$ is the air pressure, $\phi$ is the geopotential, $\boldsymbol{\Omega}$ is the angular velocity of the Earth, and $q=\rho_{w} / \rho$ is the specific humidity, where $\rho_{w}$ is the partial density of water vapor. Furthermore, $\mathbf{E}$ is the identity tensor, $\overline{\mathbf{J}}=\bar{\rho} v\left(\nabla \hat{\mathbf{v}}+(\nabla \hat{\mathbf{v}})^{\mathrm{T}}\right)+\left(\mu_{\mathrm{d}}-\frac{2}{3} \bar{\rho} v\right)(\nabla \cdot \hat{\mathbf{v}}) \mathbf{E}$ is the mean Stokes stress tensor that corresponds to a symmetric secondrank tensor $\left((\nabla \hat{\mathbf{v}})^{\mathrm{T}}\right.$ means $\hat{\mathbf{v}} \nabla$, i.e., the Nabla operator acts on $\hat{\mathbf{v}}$, but the tensorial product is arranged as shown), $v$ is the kinematic viscosity, $\mu_{\mathrm{d}}$ is the second viscosity [35] also called the volume viscosity or the bulk viscosity, $\mathbf{F}=\overline{\rho \mathbf{v}^{n} \mathbf{v}^{\prime}}$ is the Reynolds stress tensor (also considered as symmetric), $\mathbf{J}_{w}$ is the macroscopic water vapor flux, $\mathbf{W}=\overline{\rho \mathbf{v} " q "}$ is the eddy flux of water vapor, and $I_{w}$ is the phase transition rate that represents a source or sink of water vapor. In the case of only humid air as customarily considered within the framework of the ASL physics $I_{w}$ may be ignored. Thus, eddy fluxes of water drops and ice particles are omitted. Note that Hesselberg's [36] density-weighted average, $\hat{\psi}=\overline{\rho \psi} / \bar{\rho}$, is applied denoted by a hat and for longer expressions by braces $(\langle\ldots\rangle)$, where $\psi$ represents a field quantity like $\mathbf{v}, \mathrm{h}$, and $\mathrm{q}$; the overbar (...) designates the Reynolds' mean, and the deviations from Reynolds' mean and Hesselberg's mean are denoted by a prime (') and a double prime ("), respectively. Moreover, the substantial derivative with respect to time of any field quantity, $\mathrm{d} / \mathrm{dt}$, is expressed by Euler's operator for the Hesselberg fluid [33] given by

$\frac{\mathrm{d}}{\mathrm{dt}}=\frac{\partial}{\partial \mathrm{t}}+\hat{\mathbf{v}} \cdot \nabla$

Note that Eq. (3.1) is also called the equation of motion, and Eq. (3.3) is usually called the equation of continuity.

In addition to these balance equations, we have to consider the prognostic equation for the potential temperature, $\Theta$. In the case of humid air this equation can be approximated by [33]

$$
\begin{aligned}
\mathrm{c}_{\mathrm{p}} \bar{\rho} \bar{\pi} \frac{\mathrm{d} \hat{\Theta}}{\mathrm{dt}} \cong & -\nabla \cdot\left(\overline{\mathbf{R}}+\overline{\mathbf{J}_{\mathrm{h}}}+\left\{1+\left(\frac{\mathrm{c}_{\mathrm{p}, \mathrm{v}}}{\mathrm{c}_{\mathrm{p}, \mathrm{d}}}-1\right) \hat{\mathrm{q}}\right\}\{\bar{\pi} \mathbf{H}\}\right) \\
& +\left\{\begin{array}{l}
\left\{1+\left(\frac{\mathrm{c}_{\mathrm{p}, \mathrm{v}}}{\mathrm{c}_{\mathrm{p}, \mathrm{d}}}-1\right) \hat{\mathrm{q}}\right\} \mathbf{H} \\
+\mathrm{c}_{\mathrm{p}, \mathrm{d}} \hat{\Theta}\left(\frac{\mathrm{c}_{\mathrm{p}, \mathrm{v}}}{\mathrm{c}_{\mathrm{p}, \mathrm{d}}}-1\right) \mathbf{W}
\end{array}\right\} \cdot \nabla \bar{\pi}+\overline{\varepsilon^{*}}-\overline{\mathbf{J}}: \nabla \hat{\mathbf{v}}
\end{aligned}
$$

Here, $c_{p}$ is the specific heat of humid air at constant pressure, $c_{p, d}$ is that of dry air, and $c_{p, v}$ is that of water vapor. Furthermore, $\pi=\mathrm{T} / \Theta$ is the Exner function, $\mathbf{R}$ represents the radiative flux, $\mathbf{H}=c_{p, 0} \overline{\rho \mathbf{v}^{\prime \prime} \Theta^{\prime \prime}}$ is the turbulent buoyancy heat flux, $\mathbf{J}_{\mathrm{h}}=-\mathrm{c}_{\mathrm{p}} \rho \alpha_{\mathrm{T}} \nabla \mathrm{T}$ is the molecular enthalpy flux (Fourier's law of heat conduction), and $\alpha_{\mathrm{T}}$ is the thermal diffusivity assumed to be isotropic. Moreover, the quantities $-\overline{\mathbf{J}}: \nabla \hat{\mathbf{v}}>0$ and $\overline{\varepsilon^{*}}=-\overline{\mathbf{J}: \nabla \mathbf{v} "}>0$ represent the direct dissipation and the turbulent dissipation of kinetic energy into internal energy, respectively, where the colon in these expressions denotes the double scalar product of the tensor algebra. Obviously, Eq. (3.5) has its origin in the first principle of thermodynamics (e.g., [29, 33]).

With respect to the Cartesian coordinate frame the mean Coriolis acceleration may be expressed by

$$
\begin{aligned}
-2 \boldsymbol{\Omega} \times \hat{\mathbf{v}}=- & (2 \Omega \cos \varphi \hat{\mathrm{w}}-2 \Omega \sin \varphi \hat{\mathrm{v}}) \mathbf{i} \\
& -2 \Omega \sin \varphi \hat{\mathrm{u}} \mathbf{j}+2 \Omega \cos \varphi \hat{\mathbf{u}} \mathbf{k}
\end{aligned}
$$

or, with the definitions of the Coriolis parameters $f=2 \Omega \sin \varphi$ and $f^{*}=2 \Omega \cos \varphi$, where $\varphi$ is the latitude,

$$
-2 \boldsymbol{\Omega} \times \hat{\mathbf{v}}=-(\mathrm{f} * \hat{\mathrm{w}}-\mathrm{f} \hat{\mathrm{v}}) \mathbf{i}-\mathrm{f} \hat{\mathbf{u}} \mathbf{j}+\mathrm{f} * \hat{\mathrm{u}} \mathbf{k}
$$

These equations are only valid for the northern hemisphere. For the southern hemisphere, we obtain them in an analogous manner. Since in most cases $|f * \hat{\mathrm{w}}|<<|f \hat{v}|$, the term $f * \hat{\mathrm{W}}$ may be ignored, especially under the prerequisites of the ASL physics. As the magnitude of $\mathrm{f} * \hat{\mathrm{u}}$ is much smaller than that of the acceleration of gravity, $g=\partial \phi / \partial z$, this Coriolis term may be ignored, too.

Following Monin and Obukhov [14], stationary and horizontally homogeneous conditions are prominent prerequisites of the ASL physics, i.e., any derivative with respect to time expressed by $\partial / \partial \mathrm{t}$ and with respect to the horizontal directions expressed by $\partial / \partial x$ and $\partial / \partial y$ may be neglected. Horizontal variations of the pressure field, however, should not be excluded. Under these premises we can infer from the equation of continuity (3.3) that $\partial(\bar{\rho} \hat{w}) / \partial z=0$ and, hence, $\bar{\rho} \hat{\mathrm{w}}=$ const. Since $\hat{\mathrm{w}}$ vanishes at any rigid surface like the earth's surface and $\bar{\rho}$ keeps finite (customarily considered as invariant with height within the framework of the ASL physics), the condition $\bar{\rho} \hat{\mathrm{w}}=$ const. can only be fulfilled if $\hat{\mathrm{W}}=0$. Thus, under stationary and horizontally homogeneous conditions the substantial derivative with respect to time as given by Eq. (3.4) equals zero. Therefore, the equation of motion (Eq. (3.1)) can be simplified to

$0=-\nabla_{H} \bar{p}-\bar{\rho} f \mathbf{k} \times \hat{\mathbf{v}}_{H}+\frac{\partial \tau}{\partial z}$

and 


$$
\frac{\partial}{\partial z}\left(\bar{\rho}\left\langle w^{\prime 2}\right\rangle\right)=-\frac{\partial \bar{p}}{\partial z}-\bar{\rho} g
$$

Here, the subscript $\mathrm{H}$ denotes the horizontal components of the wind vector and the gradient of the air pressure, and $\tau=\tau_{\mathrm{m}}+\tau_{\mathrm{t}}$ is the total friction stress vector, where $\tau_{\mathrm{m}}$ represents the molecular friction stress vector and $\tau_{\mathrm{t}}=-\overline{\rho \mathrm{u}^{\prime \prime} \mathrm{w}} \mathbf{i}-\overline{\rho \mathrm{v}^{\prime \prime} \mathrm{w}} \mathbf{j}$ the Reynolds stress vector. Using the definition of the geostrophic wind vector, $\mathbf{v}_{\mathrm{G}}=\mathbf{k} \times \nabla_{\mathrm{H}} \overline{\mathrm{p}} /(\bar{\rho} \mathrm{f})$, leads to

$$
\frac{\partial \tau}{\partial \mathrm{z}}=\bar{\rho} \mathrm{f} \mathbf{k} \times\left(\hat{\mathbf{v}}_{\mathrm{H}}-\mathbf{v}_{\mathrm{G}}\right)
$$

where $\delta \mathbf{v}_{\mathrm{G}}=\hat{\mathbf{v}}_{\mathrm{H}}-\mathbf{v}_{\mathrm{G}}$ is customarily called the ageostrophic wind vector. It describes the deviation of the horizontal wind vector from the geostrophic wind vector customarily expressed by $\hat{\mathbf{v}}_{\mathrm{H}}=\mathbf{v}_{\mathrm{G}}+\delta \mathbf{v}_{\mathrm{G}}$. Equation (3.10) represents the basis for the so-called Ekman physics; a special solution of them is the conventional Ekman spiral. Obviously, Eq. (3.9) becomes independent of the mean horizontal flow that obeys Eq. (3.8) (or (3.10)). Furthermore, it is usually assumed that for a mean representative state the condition $\left|\partial\left(\bar{\rho}\left\langle w^{\prime \prime 2}\right\rangle\right) / \partial z\right|<<|\partial \bar{p} / \partial z|$ is nearly fulfilled. Thus, Eq. (3.9) may further be simplified to

$$
\frac{\partial \bar{p}}{\partial z}=-\bar{\rho} g \text {. }
$$

This equation expresses the so-called hydrostatic equilibrium and is usually denoted as the hydrostatic equation.

We can see that the friction stress vector is only invariant with height if either $\mathrm{f}=0$ or $\hat{\mathbf{v}}_{\mathrm{H}}=\mathbf{v}_{\mathrm{G}}$. The former is fulfilled at the equator for which $\sin \varphi=0$, i.e., this is the trivial case. The latter is fulfilled at the top of the Ekman layer, $\mathrm{Z}_{\mathrm{E}}$, when the mean horizontal wind vector completely coincides with the geostrophic wind vector, i.e., $\hat{\mathbf{v}}_{\mathrm{H}}=\mathbf{v}_{\mathrm{G}}$. Below this height, the variation of the friction stress vector with height depends on the ageostrophic wind vector $\delta \mathbf{v}_{\mathrm{G}}$.

Integrating Eq. (3.10) over the height interval $\left[0, \mathrm{z}_{\mathrm{R}}\right]$, where $z_{R}$ is the upper boundary of the ASL, yields

$$
\tau\left(z_{R}\right)-\tau(0)=\int_{0}^{z_{R}} \bar{\rho} f \mathbf{k} \times\left(\hat{\mathbf{v}}_{H}-\mathbf{v}_{G}\right) d z
$$

From this equation we can infer that

$$
\begin{aligned}
& || \tau(0)|-| \tau\left(z_{R}\right)|| \leq\left|\tau(0)-\tau\left(z_{R}\right)\right| \\
& =\left|\int_{0}^{z_{R}} \bar{\rho} \mathrm{f} \mathbf{k} \times\left(\mathbf{v}_{\mathrm{G}}-\hat{\mathbf{v}}_{\mathrm{H}}\right) \mathrm{dz}\right| \leq \int_{0}^{z_{\mathrm{R}}} \bar{\rho}\left|\mathrm{f} \mathbf{k} \times\left(\mathbf{v}_{\mathrm{G}}-\hat{\mathbf{v}}_{\mathrm{H}}\right)\right| \mathrm{d} z
\end{aligned}
$$

As $\left|\mathrm{f} \mathbf{k} \times\left(\mathbf{v}_{\mathrm{G}}-\hat{\mathbf{v}}_{\mathrm{H}}\right)\right|=|\mathrm{f}|\left|\mathbf{v}_{\mathrm{G}}-\hat{\mathbf{v}}_{\mathrm{H}}\right|$, Eq. (3.13) may be written as ||$\tau(0)|-| \tau\left(\mathrm{z}_{\mathrm{R}}\right)|| \leq \int_{0}^{\mathrm{z}_{\mathrm{R}}} \bar{\rho}\left|\mathrm{f} \| \mathbf{v}_{\mathrm{G}}-\hat{\mathbf{v}}_{\mathrm{H}}\right| \mathrm{dz}$

Apparently, the variation of the magnitude of the friction stress vector with height depends on that of the ageostrophic wind vector. As the condition $|\tau(0)|>\left|\tau\left(z_{R}\right)\right|$ is usually fulfilled, we may write $|\tau(0)|-\left|\tau\left(\mathrm{z}_{\mathrm{R}}\right)\right|=|| \tau(0)|-| \tau\left(\mathrm{z}_{\mathrm{R}}\right)||$. If we assume that the magnitude of the Reynolds stress does not decrease more than 10 percent across that height interval $\left[0, z_{R}\right]$ we may define the height of the ASL in such a sense that we demand

$$
\frac{|\tau(0)|-\left|\tau\left(\mathrm{z}_{\mathrm{R}}\right)\right|}{|\tau(0)|} \leq \frac{1}{|\tau(0)|} \int_{0}^{\mathrm{z}_{\mathrm{R}}} \bar{\rho}|\mathrm{f}|\left|\mathbf{v}_{\mathrm{G}}-\hat{\mathbf{v}}_{\mathrm{H}}\right| \mathrm{dz} \leq 0.1
$$

This decrease corresponds to the relative accuracy with which the Reynolds stress vector can directly be determined.

In the case of the conventional Ekman spiral the magnitude of Reynolds stress vector varies with height according to

$|\tau(\mathrm{z})|=|\tau(0)| \exp (-\mathrm{a} \mathrm{z})$

with $\mathrm{a}=\sqrt{\mathrm{f} /\left(2 \mathrm{~K}_{\mathrm{m}}\right)}$, where $\mathrm{K}_{\mathrm{m}}$ is the eddy diffusivity assumed as height-invariant. The reciprocal of a may be called the Ekman length. Introducing formula (3.16) into Eq. (3.15) yields

$$
\frac{|\tau(0)|-|\tau(0)| \exp \left(-\mathrm{a} \mathrm{z}_{\mathrm{R}}\right)}{|\tau(0)|}=1-\exp \left(-\mathrm{a} \mathrm{z}_{\mathrm{R}}\right) \leq 0.1
$$

which is equivalent with $1 \geq \exp \left(-\mathrm{a} \mathrm{z}_{\mathrm{R}}\right) \geq 0.9$. Thus, we obtain for the height of the ASL

$\mathrm{z}_{\mathrm{R}} \leq-\frac{1}{\mathrm{a}} \ln (0.9)=-\frac{\mathrm{z}_{\mathrm{E}}}{\pi} \ln (0.9) \approx 3.35 \cdot 10^{-2} \mathrm{z}_{\mathrm{E}}$

where the relationship between the Ekman height and the Ekman length, $\mathrm{z}_{\mathrm{E}}=\pi / \mathrm{a}$, was used. For typical values of $\mathrm{K}_{\mathrm{m}}=5 \mathrm{~m}^{2} \mathrm{~s}^{-1} \quad$ and $\mathrm{f}=0.0001 \mathrm{~s}^{-1}, \quad$ we obtain $\mathrm{z}_{\mathrm{E}} \approx 993.5 \mathrm{~m}$, and, hence, $\mathrm{z}_{\mathrm{R}} \leq 33.3 \mathrm{~m}$.

Recognizing the premises of the ASL physics, the balance equation for water vapor (Eq. (3.2)) amounts to

$$
\frac{\partial}{\partial z}\left(\overline{J_{w, Z}}+W_{z}\right)=\overline{I_{w}}
$$

where the subscript $\mathrm{Z}$ denotes the vertical components. Since within the framework of the ASL physics only humid air is considered, phase transition processes are omitted. Thus, we have

$$
\frac{\partial}{\partial \mathrm{z}}\left(\overline{\mathrm{J}_{\mathrm{w}, \mathrm{Z}}}+\mathrm{W}_{\mathrm{Z}}\right)=0 \Rightarrow \overline{\mathrm{J}_{\mathrm{w}, \mathrm{Z}}}+\mathrm{W}_{\mathrm{z}}=\mathrm{const}
$$

Note that in the case of a fog event Eq. (3.19) should be used to prove whether the water vapor flux varies more than 10 percent of its near-surface amount. 
By ignoring the direct and turbulent dissipation of kinetic energy with respect to the first term of the right-hand side of Eq. (3.5) and, again, recognizing the premises of the ASL physics, Eq. (3.5) reduces to

$$
\begin{aligned}
& \frac{\partial}{\partial \mathrm{z}}\left(\overline{\mathrm{R}_{\mathrm{Z}}}+\overline{\mathrm{J}_{\mathrm{h}, \mathrm{Z}}}+\left\{1+\left(\frac{\mathrm{c}_{\mathrm{p}, \mathrm{v}}}{\mathrm{c}_{\mathrm{p}, \mathrm{d}}}-1\right) \hat{\mathrm{q}}\right\}\left\{\bar{\pi} \mathrm{H}_{\mathrm{z}}\right\}\right) \\
& =\left\{\left\{1+\left(\frac{\mathrm{c}_{\mathrm{p}, \mathrm{v}}}{\mathrm{c}_{\mathrm{p}, \mathrm{d}}}-1\right) \hat{\mathrm{q}}\right\} \mathrm{H}_{\mathrm{Z}}+\mathrm{c}_{\mathrm{p}, \mathrm{d}} \hat{\Theta}\left(\frac{\mathrm{c}_{\mathrm{p}, \mathrm{v}}}{\mathrm{c}_{\mathrm{p}, \mathrm{d}}}-1\right) \mathrm{W}_{\mathrm{z}}\right\} \frac{\partial \bar{\pi}}{\partial \mathrm{z}}
\end{aligned}
$$

In accord with the hydrostatic equation (3.11), the term $\partial \bar{\pi} / \partial z$ may be expressed by

$\frac{\partial \bar{\pi}}{\partial z}=-\frac{g}{c_{p} \hat{\Theta}}$

Obviously, this term is very small $\left(\approx 3.4 \cdot 10^{-5} \mathrm{~m}^{-1}\right)$. Since the radiative effect $\partial \overline{R_{z}} / \partial z$ is often ignored within the framework of the ASL physics and $\left(c_{p, v} / c_{p, d}-1\right) \hat{q} \ll<1$, we have

$$
\frac{\partial}{\partial z}\left(\overline{J_{h, z}}+\bar{\pi} H_{z}\right)=-\left\{H_{z}+c_{p, d} \hat{\Theta}\left(\frac{c_{p, v}}{c_{p, d}}-1\right) W_{z}\right\} \frac{g}{c_{p} \hat{\Theta}}
$$

Even for large amounts of $\mathrm{H}_{\mathrm{z}}$ and $\mathrm{W}_{\mathrm{z}}$ the right-hand side of this equation keeps relatively small so that we may consider the flux $\overline{\mathrm{J}_{\mathrm{h}, \mathrm{Z}}}+\bar{\pi} \mathrm{H}_{\mathrm{z}}$ is nearly height-invariant, too. Generally, we have to expect that the thickness of the constant flux layer for the transfer of sensible heat differs from that for the water vapor transfer and even differs from that for the transfer of momentum.

\subsection{The Constant Flux Approximation}

As we have outlined before, the most important prerequisite implies that the friction stress vector and the vertical components of the turbulent fluxes of heat and water vapor (here designated as micrometeorological fluxes) are considered as invariant with height. It can be expressed by $\partial \mathrm{F} / \partial \mathrm{z}=0 \Leftrightarrow \mathrm{F}=\operatorname{const}(\mathrm{z})$, where $\mathrm{F}$ stands for the micrometeorological fluxes of momentum (i.e., the magnitude of the friction stress vector),

$$
\tau=|\tau|=\left(\overline{\rho u^{\prime \prime} w^{\prime \prime}}+\overline{\rho v^{\prime \prime} w^{\prime \prime}}\right)^{\frac{1}{2}}=\bar{\rho} u_{*}^{2}=\text { const }
$$

sensible heat (from now on the subscript $\mathrm{Z}$ will be omitted),

$$
\mathrm{H}=\mathrm{c}_{\mathrm{p}, \mathrm{d}} \overline{\rho \mathrm{w}^{\prime \prime} \Theta^{\prime \prime}}=-\mathrm{c}_{\mathrm{p}, \mathrm{d}} \bar{\rho} \mathrm{u}_{*} \Theta_{*}=\text { const }
$$

and water vapor,

$$
\mathrm{W}=\overline{\rho \mathrm{w}^{\prime \prime} \mathrm{q}}=-\bar{\rho} \mathrm{u}_{*} \mathrm{q}_{*}=\text { const }
$$

respectively, where all molecular effects were neglected in comparison with the corresponding turbulent ones. This neglect is quite justified in the case of the fully turbulent ASL.
Here, $\mathbf{u}_{*}=+\sqrt{\tau / \rho}$ is the friction velocity, $\Theta_{*}$ is the heat flux temperature (also called the temperature scale), and $q_{*}$ is the water vapor flux concentration (also called the humidity scale). Note that in our contribution $\hat{v}$ is arbitrarily chosen as equal to zero. This choice can be justified by arranging the $\mathrm{x}$-axis (and, hence, the $\mathrm{y}$-axis) in such a manner that $\hat{v}$ vanishes.

This height-invariance of the micrometeorological fluxes may serve to define the thickness of the ASL. As outlined before, it generally demands that steady-state conditions and the condition of horizontally uniform fields of mean wind speed (i.e., $\hat{\mathrm{w}}=0$ ), mean temperature, and mean humidity are fulfilled. In addition, net source and sink effects owing to phase transition processes are excluded. Even though the condition of height invariance may customarily be fulfilled only in a micrometeorological sense (i.e., these micrometeorological fluxes may vary with height across the entire ASL, but not more than 10 percent of their values in the immediate vicinity of the surface), it serves as the basis for the so-called constant flux approximation on which micrometeorological scaling is based, namely (a) Monin-Obukhov scaling for forced-convective conditions [14], and (b) Prandt-ObukhovPriestley scaling for free-convective conditions [15-17], respectively.

\subsection{Flux-Gradient Relationships and Characteristic Numbers}

Analogous to Newton's law of friction in a viscous flow, Fourier's law of heat conduction, and Fick's law of diffusion, flux-gradient relationships for momentum (subscript $\mathrm{m}$ ), sensible heat (subscript h), and water vapor (subscript q) are often used in micrometeorology to parameterize the respective eddy fluxes, i.e.,

$$
\begin{aligned}
& \mathrm{u}_{*}^{2}=\frac{|\tau|}{\bar{\rho}}=\mathrm{K}_{\mathrm{m}}\left|\frac{\partial \hat{\mathbf{v}}_{\mathrm{H}}}{\partial \mathrm{z}}\right| \\
& \mathrm{H}=-\mathrm{c}_{\mathrm{p}, \mathrm{d}} \bar{\rho} \mathrm{K}_{\mathrm{h}} \frac{\partial \hat{\Theta}}{\partial \mathrm{z}}
\end{aligned}
$$

and

$$
\mathrm{W}=-\bar{\rho} \mathrm{K}_{\mathrm{q}} \frac{\partial \hat{\mathrm{q}}}{\partial \mathrm{z}}
$$

Here, $\mathrm{K}_{\mathrm{m}}, \mathrm{K}_{\mathrm{h}}$, and $\mathrm{K}_{\mathrm{q}}$ are the corresponding eddy diffusivities with respect to the vertical direction. These eddy diffusivities can be related to each other by the turbulent Prandtl number

$$
\operatorname{Pr}_{\mathrm{t}}=\frac{\mathrm{K}_{\mathrm{m}}}{\mathrm{K}_{\mathrm{h}}}
$$

the turbulent Schmidt number for water vapor,

$$
\mathrm{Sc}_{\mathrm{t}, \mathrm{q}}=\frac{\mathrm{K}_{\mathrm{m}}}{\mathrm{K}_{\mathrm{q}}}
$$

and the turbulent Lewis-Semenov number for water vapor, 
$\mathrm{LS}_{\mathrm{t}, \mathrm{q}}=\frac{\mathrm{K}_{\mathrm{h}}}{\mathrm{K}_{\mathrm{q}}}$

These non-dimensional characteristic numbers are frequently assumed to be equal to unity. We will scrutinize this assumption in subsection 5.5.

Since these micrometeorological fluxes are considered to be proportional to the vertical gradients of the mean field quantities, i.e., $\mathrm{F} \propto \partial \hat{\psi} / \partial \mathrm{z}$, where $\psi=\mathbf{v}_{\mathrm{H}}$ for $\mathrm{F}=\tau$, $\psi=\Theta$ for $\mathrm{F}=\mathrm{H}$, and $\psi=\mathrm{q}$ for $\mathrm{F}=\mathrm{W}$, the constant-flux approximation serves to mediate simple connections of vertical profiles of the mean quantity, $\hat{\psi}$, to the turbulent flux, $F$, even under non-neutral stratification of the ASL.

\subsection{The Local Balance Equation of Turbulent Kinetic Energy}

The local balance equation of turbulent kinetic energy (TKE) serves to derive the eddy diffusivities for momentum and - via the turbulent Prandtl number and the speciesdependent turbulent Schmidt numbers - the eddy diffusivities for sensible heat, water vapor, and trace species. It is customarily denoted as one-and-a-half-order closure. For horizontally homogeneous conditions it reads (e.g., [33, 37])

$$
\begin{aligned}
& \bar{\rho} \frac{\partial}{\partial t}\left(\frac{1}{2}\left\langle\mathbf{v}^{\prime 2}\right\rangle\right)+\frac{\partial}{\partial z}\left\{\frac{1}{2} \overline{\rho w^{\prime \prime} \mathbf{v}^{\prime 2}}+\frac{1}{\bar{\rho}} \overline{\rho w^{\prime \prime} p^{\prime}}\right\} \\
& =-\overline{\varepsilon^{*}}-\tau \cdot \frac{\partial \hat{\mathbf{v}}_{\mathrm{H}}}{\partial \mathrm{z}}\left(1-\mathrm{Ri}_{\mathrm{f}}\right)
\end{aligned}
$$

Here, $1 / 2 \mathbf{v}^{\prime 2}$ is the specific TKE of the eddying motion, $E=1 / 2 \overline{\rho w^{\prime \prime} v^{\prime 2}}$ is the eddy flux of TKE, $P \cong \overline{\rho w^{\prime \prime} p^{\prime}} / \bar{\rho}$ is the eddy flux of pressure, $p, \tau=-\overline{\rho u " w n} \mathbf{i}-\overline{\rho v^{\prime \prime} w "} \mathbf{j}$ is the Reynolds' stress vector, and $\hat{\mathbf{v}}_{\mathrm{H}}=\hat{\mathrm{u}} \mathbf{i}+\hat{\mathrm{v}} \mathbf{j}$ is the mean horizontal wind vector. Furthermore, $\mathrm{Ri}_{\mathrm{f}}$ is the so-called flux-Richardson number. It represents the ratio of the thermal gain (or loss) of TKE to the mechanically generated TKE. In the case of humid air, the flux-Richardson number for horizontally homogeneous conditions amounts to [33]

$$
\mathrm{Ri}_{\mathrm{f}}=-\frac{\mathrm{g}}{\mathrm{c}_{\mathrm{p}} \hat{\Theta}} \frac{\left\{1+\left(\frac{\mathrm{c}_{\mathrm{p}, \mathrm{v}}}{\mathrm{c}_{\mathrm{p}, \mathrm{d}}}-1\right) \hat{\mathrm{q}}\right\} \mathrm{H}+\mathrm{c}_{\mathrm{p}, \mathrm{d}} \hat{\Theta}\left(\frac{\mathrm{c}_{\mathrm{p}, \mathrm{v}}}{\mathrm{c}_{\mathrm{p}, \mathrm{d}}}-1\right) \mathrm{W}}{\tau \cdot \frac{\partial \hat{\mathbf{v}}_{\mathrm{H}}}{\partial \mathrm{z}}}
$$

The flux-Richardson number serves to characterize the thermal stratification of air. For unstable stratification we have

$$
\mathrm{Ri}_{\mathrm{f}}<0 \text { if }\left\{1+\left(\frac{\mathrm{c}_{\mathrm{p}, \mathrm{v}}}{\mathrm{c}_{\mathrm{p}, \mathrm{d}}}-1\right) \hat{\mathrm{q}}\right\} \mathrm{H}+\mathrm{c}_{\mathrm{p}, \mathrm{d}} \hat{\Theta}\left(\frac{\mathrm{c}_{\mathrm{p}, \mathrm{v}}}{\mathrm{c}_{\mathrm{p}, \mathrm{d}}}-1\right) \mathrm{W}>0
$$

Stable stratification is characterized by

$\mathrm{Ri}_{\mathrm{f}}>0$ if $\left\{1+\left(\frac{\mathrm{c}_{\mathrm{p}, \mathrm{v}}}{\mathrm{c}_{\mathrm{p}, \mathrm{d}}}-1\right) \hat{\mathrm{q}}\right\} \mathrm{H}+\mathrm{c}_{\mathrm{p}, \mathrm{d}} \hat{\Theta}\left(\frac{\mathrm{c}_{\mathrm{p}, \mathrm{v}}}{\mathrm{c}_{\mathrm{p}, \mathrm{d}}}-1\right) \mathrm{W}<0$

Neutral stratification means that $\mathrm{Ri}_{\mathrm{f}}=0$.
In the case of stable stratification, there exists a critical value of the flux-Richardson number given by $\mathrm{Ri}_{\mathrm{f}}=1$. It is characterized by the fact that TKE mechanical gain is equal to TKE thermal loss, so that the turbulent flow becomes increasingly viscous (laminar) owing to the concurrently acting direct and turbulent dissipation of TKE. It is to be expected that the true critical value is smaller than $\mathrm{Ri}_{\mathrm{f}}=1$. Currently, a critical value of $\mathrm{Ri}_{\mathrm{f}, \mathrm{cr}}=0.25$ is accepted (e.g., $[21,24,33,38])$.

Introducing the flux-gradient relationships leads to

$\mathrm{Ri}=\operatorname{Pr}_{\mathrm{t}} \mathrm{Ri}_{\mathrm{f}}$

where $\mathrm{Ri}$ is the so-called gradient-Richardson number given by

$R i=\frac{g}{\hat{\Theta}} \frac{\left\{1+\left(\frac{c_{p, v}}{c_{p, d}}-1\right) \hat{q}\right\} \frac{\partial \hat{\Theta}}{\partial z}+\left(\frac{c_{p, v}}{c_{p, d}}-1\right) \hat{\Theta} \frac{\partial \hat{q}}{\partial z}}{\left\{\frac{\partial \hat{\mathbf{v}}_{H}}{\partial z}\right\}^{2}}$

Like the flux-Richardson number, the gradient-Richardson number serves to characterize the thermal stratification of the ASL. It is positive for stable stratification $(\mathrm{Ri}>0)$ and negative for unstable stratification $(\mathrm{Ri}<0)$. The case of neutral stratification is characterized by $\mathrm{Ri}=0$. If the turbulent Prandtl number is equal to unity as frequently assumed, the gradient-Richardson number and the flux-Richardson number would be identical. Note that the various $\mathrm{Ri}$ numbers may be simplified by using $\left(\mathrm{c}_{\mathrm{p}, \mathrm{v}} / \mathrm{c}_{\mathrm{p}, \mathrm{d}}-1\right) \hat{\mathrm{q}} \ll<1$.

\subsection{The Local Balance Equations of Temperature Variance}

Local balance equations for the temperature variance, $\left\langle\Theta^{\prime \prime 2}\right\rangle$, can be deduced like the local balance equation of TKE (3.33). For horizontally homogeneous conditions one obtains (e.g., $[33,37])$

$$
\begin{aligned}
& \bar{\rho} \frac{\partial}{\partial t}\left(\frac{1}{2}\left\langle\Theta^{\prime \prime 2}\right\rangle\right)+\frac{\partial}{\partial z}\left(\frac{1}{2} \overline{\rho w^{\prime \prime} \Theta^{\prime \prime 2}}\right) \\
& =-\overline{\rho w^{\prime \prime} \Theta^{\prime \prime}} \frac{\partial \hat{\Theta}}{\partial z}-\frac{1}{c_{p}} \overline{\Theta " \frac{\partial J_{h, z}}{\partial z}}
\end{aligned}
$$

where the second term of the right-hand side of this equation can be approximated by

$$
\begin{aligned}
& \frac{1}{c_{p}} \overline{\Theta "} \overline{\frac{\partial J_{h, z}}{\partial z}} \cong-\frac{\alpha_{T}}{2} \frac{\partial}{\partial z} \overline{\left(\rho \frac{\partial\left(\Theta^{\prime \prime 2}\right)}{\partial z}\right)}+\alpha_{T} \rho \overline{\left(\frac{\partial \Theta^{\prime \prime}}{\partial z}\right)^{2}} \\
& =-\frac{\alpha_{\mathrm{T}}}{2} \frac{\partial}{\partial \mathrm{z}}\left(\bar{\rho}\left\langle\frac{\partial\left(\Theta^{\prime \prime 2}\right)}{\partial \mathrm{z}}\right\rangle\right)+\alpha_{\mathrm{T}} \bar{\rho}\left\langle\left(\frac{\partial \Theta^{\prime \prime}}{\partial \mathrm{z}}\right)^{2}\right\rangle
\end{aligned}
$$

using $\Theta " \cong T "$. Thus, we have 


$$
\begin{aligned}
& \bar{\rho} \frac{\partial}{\partial t}\left(\frac{1}{2}\left\langle\Theta^{\prime \prime 2}\right\rangle\right)+\frac{\partial}{\partial z}\left(\frac{1}{2} \overline{\rho w^{\prime \prime} \Theta^{\prime 2}}\right) \\
& =-\overline{\rho w^{\prime \prime} \Theta "} \frac{\partial \hat{\Theta}}{\partial z}+\frac{\alpha_{T}}{2} \frac{\partial}{\partial z}\left(\bar{\rho}\left\langle\frac{\partial\left(\Theta^{\prime \prime 2}\right)}{\partial z}\right\rangle\right)-\bar{\rho} \hat{N}
\end{aligned}
$$

where the so-called dissipation of temperature variance, $\hat{\mathrm{N}}$, is defined by

$$
\hat{\mathrm{N}}=\alpha_{\mathrm{T}}\left\langle\left(\frac{\partial \Theta^{\prime \prime}}{\partial \mathrm{z}}\right)^{2}\right\rangle
$$

Similar equations can be derived for the variances of specific humidity and the mass fractions of trace species, if phase transition processes and chemical reactions may be ignored. Otherwise, additional terms occur [33].

\section{COMPLETE SIMILARITY VERSUS INCOMPLETE SIMILARITY}

Before we derive the similarity hypotheses for the ASL, it seems to be indispensable to discuss what complete similarity and incomplete similarity does mean. Let us consider the transfer of momentum, sensible heat, and water vapor across the ASL. The standardized procedure of dimensional analysis described in section 2 provides for Monin-Obukhov scaling [1]

$$
\begin{aligned}
& \frac{\mathrm{z}-\mathrm{d}}{\mathrm{u}_{*}} \frac{\partial \mathrm{U}}{\partial \mathrm{z}}=\varphi_{\mathrm{m}}\left(\zeta, \eta, \eta_{\mathrm{R}}, \operatorname{Pr}, \mathrm{Sc}_{\mathrm{q}}\right) \\
& \frac{\mathrm{z}-\mathrm{d}}{\Theta_{*}} \frac{\partial \hat{\Theta}}{\partial \mathrm{z}}=\varphi_{\mathrm{h}}\left(\zeta, \eta, \eta_{\mathrm{R}}, \operatorname{Pr}, \mathrm{Sc}_{\mathrm{q}}\right)
\end{aligned}
$$

and

$$
\frac{\mathrm{z}-\mathrm{d}}{\mathrm{q}_{*}} \frac{\partial \hat{\mathrm{q}}}{\partial \mathrm{z}}=\varphi_{\mathrm{q}}\left(\zeta, \eta, \eta_{\mathrm{R}}, \operatorname{Pr}, \mathrm{Sc}_{\mathrm{q}}\right)
$$

Here, $\varphi_{\mathrm{m}}\left(\zeta, \eta, \eta_{\mathrm{R}}, \operatorname{Pr}, \mathrm{Sc}_{\mathrm{q}}\right), \quad \varphi_{\mathrm{h}}\left(\zeta, \eta, \eta_{\mathrm{R}}, \operatorname{Pr}, \mathrm{Sc}_{\mathrm{q}}\right), \quad$ and $\varphi_{\mathrm{q}}\left(\zeta, \eta, \eta_{\mathrm{R}}, \operatorname{Pr}, \mathrm{Sc}_{\mathrm{q}}\right)$ are the local stability functions (or similarity functions) for momentum, sensible heat, and water vapor, respectively. Furthermore, $\zeta=(\mathrm{z}-\mathrm{d}) / \mathrm{L}$ is the Obukhov number, and $\mathrm{L}$ is the Obukhov stability length given by $[14,16,39]$

$$
\begin{aligned}
L & =-\frac{c_{p, d} \bar{\rho} u_{*}{ }^{3}}{\kappa \frac{g}{\hat{\Theta}}\left(H+0.61 c_{p, d} \hat{\Theta} W\right)} \\
& =\frac{u_{*}{ }^{2}}{\kappa \frac{g}{\hat{\Theta}}\left(\Theta_{*}+0.61 \hat{\Theta} q_{*}\right)}
\end{aligned}
$$

$\mathrm{g}$ is the acceleration of gravity, and $\hat{\Theta}$ is the mean potential temperature customarily chosen as a representative value for the ASL. Furthermore, $\operatorname{Pr}=v / \alpha_{\mathrm{T}}$ is the Prandtl number, $\mathrm{Sc}_{\mathrm{q}}=v / \mathrm{D}_{\mathrm{q}}$ is the Schmidt number for water vapor, and $\mathrm{D}_{\mathrm{q}}$ is the corresponding molecular diffusivity. As pointed out by Barenblatt [1], this kind of scaling is based on the assumption of complete similarity of the flow in both Reynolds numbers, i.e. the local one, $\eta$, and the global one, $\eta_{R}$. The plausibility of such an assumption and, consequently, of neglecting the dependence on $\eta$ and $\eta_{R}$ is usually argued on the basis of the very large values of both Reynolds numbers above the thin sublayer, a layer of a few millimeters thickness adjacent to the earth's surface usually called the viscous sublayer. The assumption of the existence of finite limits of the local stability functions $\varphi_{\mathrm{m}}(\zeta), \varphi_{\mathrm{h}}(\zeta)$, and $\varphi_{\mathrm{q}}(\zeta)$ as both Reynolds numbers tend to infinity is accepted implicitly. If $\varphi_{\mathrm{m}}(\zeta), \varphi_{\mathrm{h}}(\zeta)$, and $\varphi_{\mathrm{q}}(\zeta)$ tend to finite limits as $\eta \rightarrow \infty$ and $\eta_{R} \rightarrow \infty$ in accordance with the assumption of complete similarity, then for sufficiently large $\eta$ and $\eta_{R}$ a universal similarity law, independent of both Reynolds numbers, must hold [1]; and the local similarity functions for momentum, sensible heat and water vapor,

$$
\begin{aligned}
& \frac{\mathrm{z}-\mathrm{d}}{\mathrm{u}_{*}} \frac{\partial \mathrm{U}}{\partial \mathrm{z}}=\varphi_{\mathrm{m}}\left(\zeta, \operatorname{Pr}, \mathrm{Sc}_{\mathrm{q}}\right) \\
& \frac{\mathrm{z}-\mathrm{d}}{\Theta_{*}} \frac{\partial \hat{\Theta}}{\partial \mathrm{z}}=\varphi_{\mathrm{h}}\left(\zeta, \operatorname{Pr}, \mathrm{Sc}_{\mathrm{q}}\right)
\end{aligned}
$$

and

$$
\frac{\mathrm{z}-\mathrm{d}}{\mathrm{q}_{*}} \frac{\partial \hat{\mathrm{q}}}{\partial \mathrm{z}}=\varphi_{\mathrm{q}}\left(\zeta, \operatorname{Pr}, \mathrm{Sc}_{\mathrm{q}}\right)
$$

may be considered as universal functions. These are customarily called the Monin-Obukhov similarity laws [1]. Note that in the case of the fully turbulent ASL the dependence of these universal functions on both the Prandt number and the Schmidt number for water vapor plays no role.

It is known that already in the case of neutral stratification one can detect a weak dependence of these universal functions on both Reynolds numbers. The weak dependence serves to introduce the assumption of incomplete similarity of the flow in the local Reynolds number, which is apparently not contradicted by experimental data on flows in smooth pipes, etc. [1]. Thus, Barenblatt and Monin [40, 41] made a similar assumption for thermally stratified flows in the ASL.

\section{MONIN-OBUKHOV SCALING}

\subsection{Similarity Hypothesis for Momentum}

Considering the first similarity hypothesis of Monin and Obukhov [14] that states that the vertical transfer of momentum across the ASL is only determined by $\mathrm{Q}_{1}=\mathrm{z}-\mathrm{d}$, the Obukhov stability length, $\mathrm{Q}_{2}=\mathrm{L}$, the friction velocity, $\mathrm{Q}_{3}=\mathrm{u}_{*}$, and $\mathrm{Q}_{4}=\partial \mathrm{U} / \partial \mathrm{z}$, the similarity hypothesis can mathematically be expressed by $F\left(\mathrm{Q}_{1}, \mathrm{Q}_{2}, \mathrm{Q}_{3}, \mathrm{Q}_{4}\right)=F\left(\mathrm{z}-\mathrm{d}, \mathrm{L}, \mathrm{u}_{*}, \partial \mathrm{U} / \partial \mathrm{z}\right)=0$. Obviously, the number of dimensional quantities is $\mathrm{k}=4$. The rank of the dimensional matrix is $r=2$, and we have 
$\mathrm{p}=\mathrm{k}-\mathrm{r}=2$ independent $\pi$ numbers, and, hence, a universal function is established. These facts are true in all instances of flux-gradient relationships presented here. The dimensional $\pi$-invariants analysis provides then

$$
\pi_{1}=\frac{\mathrm{z}-\mathrm{d}}{\mathrm{u}_{*}} \frac{\partial \mathrm{U}}{\partial \mathrm{z}}=\varphi_{\mathrm{m}}\left(\pi_{2}\right)=\varphi_{\mathrm{m}}(\zeta)
$$

with $\pi_{2}=(\mathrm{z}-\mathrm{d}) / \mathrm{L}=\zeta$. Apparently, this formula does not contain $\kappa$. This is quite reasonable because the von Kármán constant is a non-dimensional quantity. In the case of neutral stratification $\kappa$ is related to a $\pi$ number by $\pi_{1}=\varphi_{\mathrm{m}}(0)=\kappa^{-1}$ (see Eq. (2.19)). In the case of non-neutral stratification, however, it cannot directly be addressed by a formalized procedure of non-dimensionalization. Following Monin and Obukhov [14], we may put this constant into Eq. (5.1), but mainly for historical reasons and convenience. Thus, the non-dimensional wind shear is given by

$\frac{\kappa(\mathrm{z}-\mathrm{d})}{\mathrm{u}_{*}} \frac{\partial \mathrm{U}}{\partial \mathrm{z}}=\Phi_{\mathrm{m}}(\zeta)$

where $\Phi_{\mathrm{m}}(\zeta)=\kappa \varphi_{\mathrm{m}}(\zeta)$ is the conventional local similarity function (or conventional universal function) for momentum $[14,42]$. Note that the quantity $\Lambda_{\mathrm{p}}=\kappa(\mathrm{z}-\mathrm{d})$ in Eq. (5.2) is customarily designated as Prandtl's mixing length of the universal wall law for thermally neutral stratification $\left(\Phi_{\mathrm{m}}(0)=1\right)$. This kind of stratification may prevail either (a) during the transition from stable to unstable stratification and vice versa when steady-state conditions, as required by the constant flux approximation, are not to be expected (e.g., $[43,44])$, or (b) under the condition of strong wind shear when thermal effects become of minor importance.

Combining Eqs. (3.27) and (5.2) provides [42]

$\mathrm{K}_{\mathrm{m}}=\frac{\mathrm{u}_{*} \kappa(\mathrm{z}-\mathrm{d})}{\Phi_{\mathrm{m}}(\zeta)}$

As mentioned before, for neutral stratification, i.e., $\zeta=0$, we obtain $\Phi_{\mathrm{m}}(0)=1$. Thus, Eq. (5.3) amounts to $\mathrm{K}_{\mathrm{m}}=\mathrm{u}_{*} \kappa(\mathrm{z}-\mathrm{d})=\mathrm{u}_{*} \Lambda_{\mathrm{p}}$, and Eq. (3.27) becomes $\partial \mathrm{U} / \partial \mathrm{z}=\mathrm{u}_{*} / \Lambda_{\mathrm{P}}$ which is identical with Eq. (2.19).

In all instances with more than one $\pi$ number, a universal function cannot be quantified by the dimensional $\pi$ invariants analysis. However, as mentioned before, the local similarity function for momentum must be equal to unity if $\zeta=0$. But for non-neutral conditions as originally investigated by Monin and Obukhov [14], it has to be determined empirically or/and theoretically.

\subsection{Similarity Hypothesis for Sensible Heat}

The second similarity hypothesis of Monin and Obukhov [14] states that the vertical transfer of sensible heat across the ASL is only determined by $z-d, L, \Theta_{*}$, and $\partial \hat{\Theta} / \partial z$, expressed by $F\left(\mathrm{z}-\mathrm{d}, \mathrm{L}, \Theta_{*}, \partial \hat{\Theta} / \partial \mathrm{z}\right)=0$. The dimensional $\pi$-invariants analysis provides then

$\pi_{1}=\frac{\mathrm{z}-\mathrm{d}}{\Theta_{*}} \frac{\partial \hat{\Theta}}{\partial \mathrm{z}}=\varphi_{\mathrm{h}}\left(\pi_{2}\right)=\varphi_{\mathrm{h}}(\zeta)$

As before, the von Kármán constant may be put into Eq. (5.4) for historical reasons and convenience. In doing so, the non-dimensional vertical component of the temperature gradient reads

$\frac{\kappa(\mathrm{z}-\mathrm{d})}{\Theta_{*}} \frac{\partial \hat{\Theta}}{\partial \mathrm{z}}=\Phi_{\mathrm{h}}(\zeta)$

where $\Phi_{\mathrm{h}}(\zeta)=\kappa \varphi_{\mathrm{h}}(\zeta)$ is the conventional local similarity function (or conventional universal function) for sensible heat [14]. Sometimes, an additional factor $\alpha_{\mathrm{h}}$ is introduced into Eq. (5.5),

$\frac{\alpha_{\mathrm{h}} \kappa(\mathrm{z}-\mathrm{d})}{\Theta_{*}} \frac{\partial \hat{\Theta}}{\partial \mathrm{z}}=\alpha_{\mathrm{h}} \Phi_{\mathrm{h}}(\zeta)=\Phi_{\mathrm{h}}{ }^{*}(\zeta)$

with $\Phi_{\mathrm{h}}{ }^{*}(\zeta)=\alpha_{\mathrm{h}} \Phi_{\mathrm{h}}(\zeta)$, to address that the turbulent Prandtl number, $\operatorname{Pr}_{t}$, differ from unity in the case of neutral stratification [45]. Such an additional factor might be used for convenience. But it cannot be justified on the basis of dimensional analysis. Under neutral condition with respect to dry air, as considered, for instance, by Businger et al. [46], the similarity hypothesis mentioned before is not fulfilled because the vertical component of the temperature gradient, $\partial \hat{\Theta} / \partial z$, is equal to zero, and, hence, formulae (5.4) to (5.6) become unpredictable. Consequently, the similarity function (5.6) is not further considered here.

Combining Eqs. (3.28) and (5.5) leads to the eddy diffusivity for sensible heat

$\mathrm{K}_{\mathrm{h}}=\frac{\mathrm{u}_{*} \kappa(\mathrm{z}-\mathrm{d})}{\Phi_{\mathrm{h}}(\zeta)}$

Thus, we obtain for the turbulent Prandtl number given by Eq. (3.30)

$\operatorname{Pr}_{\mathrm{t}}=\frac{\Phi_{\mathrm{h}}(\zeta)}{\Phi_{\mathrm{m}}(\zeta)}$

\subsection{Similarity Hypothesis for Water Vapor}

Monin and Obukhov [14] did not consider the vertical transfer of water vapor across the ASL. But this transfer of matter can be dealt with in a similar manner, i.e., the water vapor transfer is only determined by $\mathrm{z}-\mathrm{d}, \mathrm{L}$, the density scale of water vapor, $\rho_{\mathrm{w}, *}\left(\rho_{\mathrm{w}, *}=\bar{\rho} \mathrm{q}_{*}\right)$ and the vertical gradient, $\partial \overline{\rho_{\mathrm{w}}} / \partial \mathrm{z}$, of the mean partial density of water vapor, $\overline{\rho_{\mathrm{w}}}=\bar{\rho} \hat{\mathrm{q}}$, expressed by $F\left(\mathrm{z}-\mathrm{d}, \mathrm{L}, \rho_{\mathrm{w}, *}, \partial \overline{\rho_{\mathrm{w}}} / \partial \mathrm{z}\right)=0$. The use of the partial density of water vapor is required because the specific humidity is a mass fraction, and, hence, a 
non-dimensional quantity. The dimensional $\pi$-invariants analysis provides then

$\pi_{1}=\frac{\mathrm{z}-\mathrm{d}}{\rho_{\mathrm{w}, *}} \frac{\partial \overline{\rho_{\mathrm{w}}}}{\partial \mathrm{z}}=\varphi_{\mathrm{q}}\left(\pi_{2}\right)=\varphi_{\mathrm{q}}(\zeta)$

If we assume that the mean air density is height-invariant in the ASL and define $\Phi_{\mathrm{q}}(\zeta)=\kappa \varphi_{\mathrm{q}}(\zeta)$, where $\Phi_{\mathrm{q}}(\zeta)$ is called the conventional local similarity function (or conventional universal function) for water vapor, we will obtain for the non-dimensional vertical component of the humidity gradient

$\frac{\kappa(\mathrm{z}-\mathrm{d})}{\mathrm{q}_{*}} \frac{\partial \hat{\mathrm{q}}}{\partial \mathrm{z}}=\Phi_{\mathrm{q}}(\zeta)$

If we combine Eqs. (3.29) and (5.10), we will obtain for the eddy diffusivity for water vapor:

$\mathrm{K}_{\mathrm{q}}=\frac{\mathrm{u}_{*} \kappa(\mathrm{z}-\mathrm{d})}{\Phi_{\mathrm{q}}(\zeta)}$

Thus, for water vapor, the turbulent Schmidt number, Eq. (3.31), and the turbulent Lewis-Semenov number, Eq. (3.32), read

$\mathrm{Sc}_{\mathrm{t}, \mathrm{q}}=\frac{\Phi_{\mathrm{q}}(\zeta)}{\Phi_{\mathrm{m}}(\zeta)}$

and

$\mathrm{LS}_{\mathrm{t}, \mathrm{q}}=\frac{\mathrm{K}_{\mathrm{q}}}{\mathrm{K}_{\mathrm{h}}}=\frac{\Phi_{\mathrm{h}}(\zeta)}{\Phi_{\mathrm{q}}(\zeta)}$

respectively.

\subsection{Empirical $\Phi$-Functions for the Transfer of Momen- tum, Sensible Heat, and Water Vapor}

Since the similarity hypotheses of Monin and Obukhov [14] can only serve to show that universal functions may exist, such conventional $\Phi$-functions for the transfer of momentum, sensible heat, and water vapor have to be determined empirically and/or theoretically. Unfortunately, the results of these $\Phi$-functions obtained from sophisticated field campaigns show a considerable scatter (see Figs. 1, 2).

The empirical results of Zilitinkevič and Čalikov [47] for stable stratification and Dyer and Hicks [48] for unstable stratification, for instance, may be gathered by

$$
\Phi_{\mathrm{m}}(\zeta)=\left\{\begin{array}{lll}
\left(1-\gamma_{2} \zeta\right)^{-1 / 4} & \text { for } \zeta<0 & \text { (unstable) } \\
1 & \text { for } \zeta=0 & \text { (neutral) } \\
1+\gamma_{1} \zeta & \text { for } \zeta>0 & \text { (stable) }
\end{array}\right.
$$

and

$$
\Phi_{\mathrm{q}}(\zeta)=\Phi_{\mathrm{h}}(\zeta)= \begin{cases}\Phi_{\mathrm{m}}{ }^{2}(\zeta) & \text { for } \zeta<0 \\ 1 & \text { for } \zeta=0 \\ \Phi_{\mathrm{m}}(\zeta) & \text { for } \zeta>0\end{cases}
$$
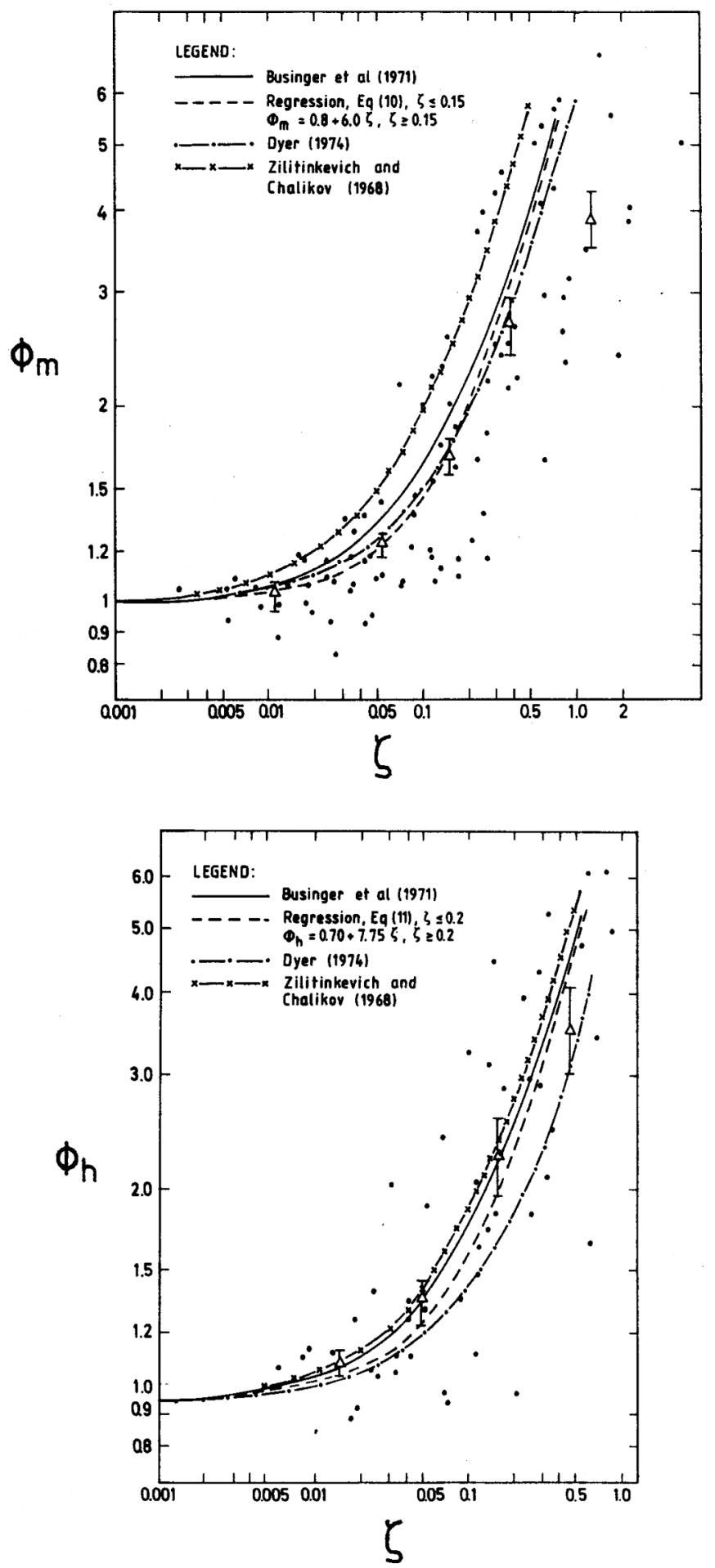

Fig. (1). The local similarity functions $\Phi_{\mathrm{m}}(\zeta)$ and $\Phi_{\mathrm{h}}(\zeta)$ as a function of $\zeta$ for stable stratification (adopted from [53]). For the references in this figure see [46, 47, 117].

with $\gamma_{1} \cong 5$ and $\gamma_{2} \cong 16$. The relationship $\Phi_{\mathrm{m}}(\zeta)=\left(1-\gamma_{2} \zeta\right)^{-1 / 4}$ in Eq. (5.14) is called the BusingerDyer-Pandolfo relationship (Dyer, unpublished, [49-51]), later experimentally proved by Dyer and Hicks [48], 

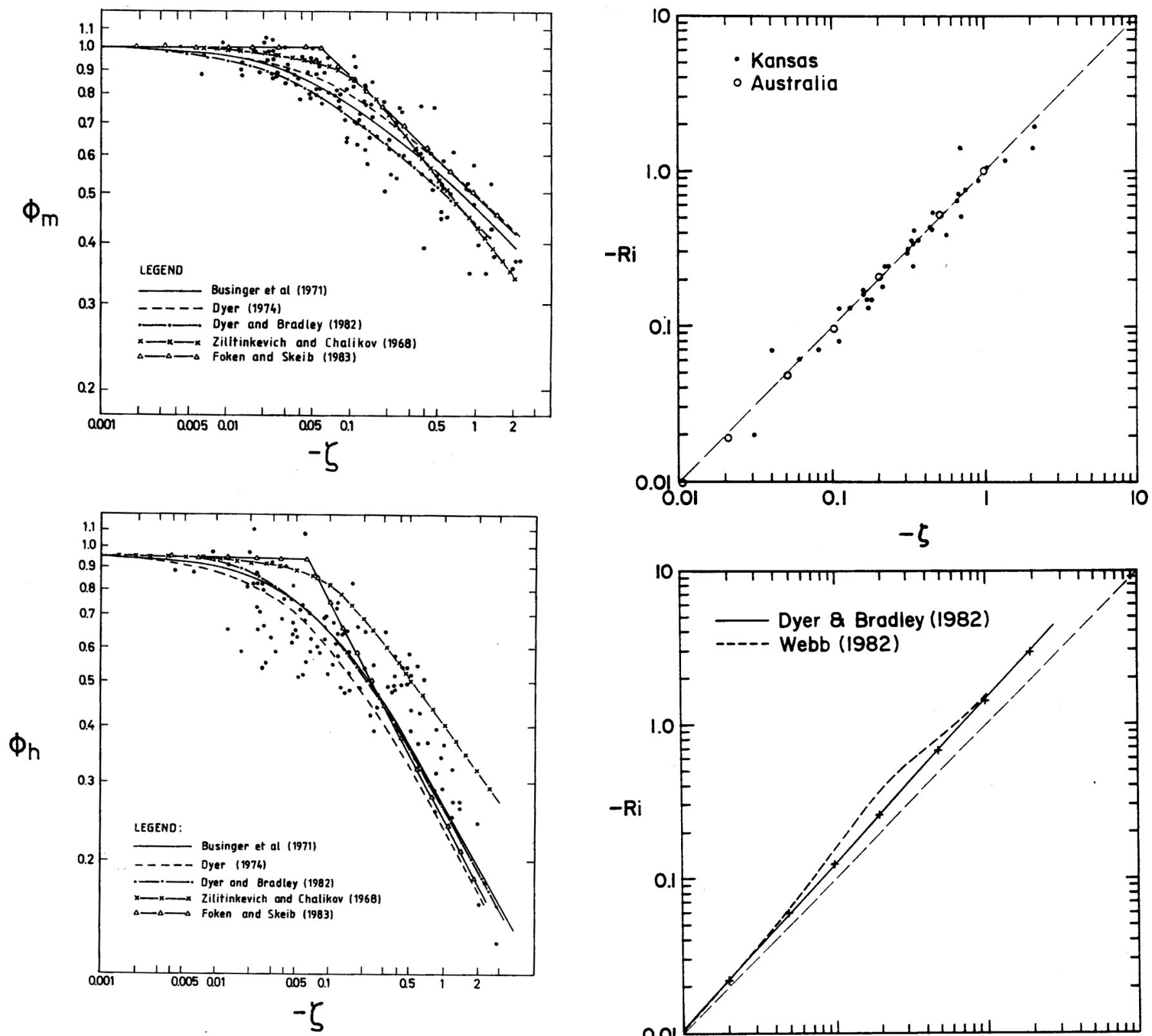

Fig. (2). As in Fig. (1), but for unstable stratification. For the references in this figure see $[46,47,57,117,126]$.

Businger et al. [46] and others, where their results mainly cover the stability range $-2 \leq \zeta<0$ (see also $[21,52,53]$, as well as Fig. (2)). The linear formula $\Phi_{\mathrm{m}}(\zeta)=1+\gamma_{1} \zeta$ in Eq. (5.14) was first recommended by Monin and Obukhov [14] for stable stratification (and weakly unstable stratification) and later experimentally proved by Čalikov [54], Zilitinkevič and Čalikov [47], Businger et al. [46] and others mainly for the stability range $0 \leq \zeta<1$, but there is a large scatter in the case of momentum with some values of $\Phi_{\mathrm{m}}(\zeta)$ for $\zeta>1$ (see Fig. 1). The relationship for unstable stratification, $\Phi_{\mathrm{h}}(\zeta)=\Phi_{\mathrm{m}}{ }^{2}(\zeta)$ in Eq. (5.15), as already suggested by Businger [49] and Pandolfo [50] was eventually proved by Dyer and Hicks [48] for the stability range

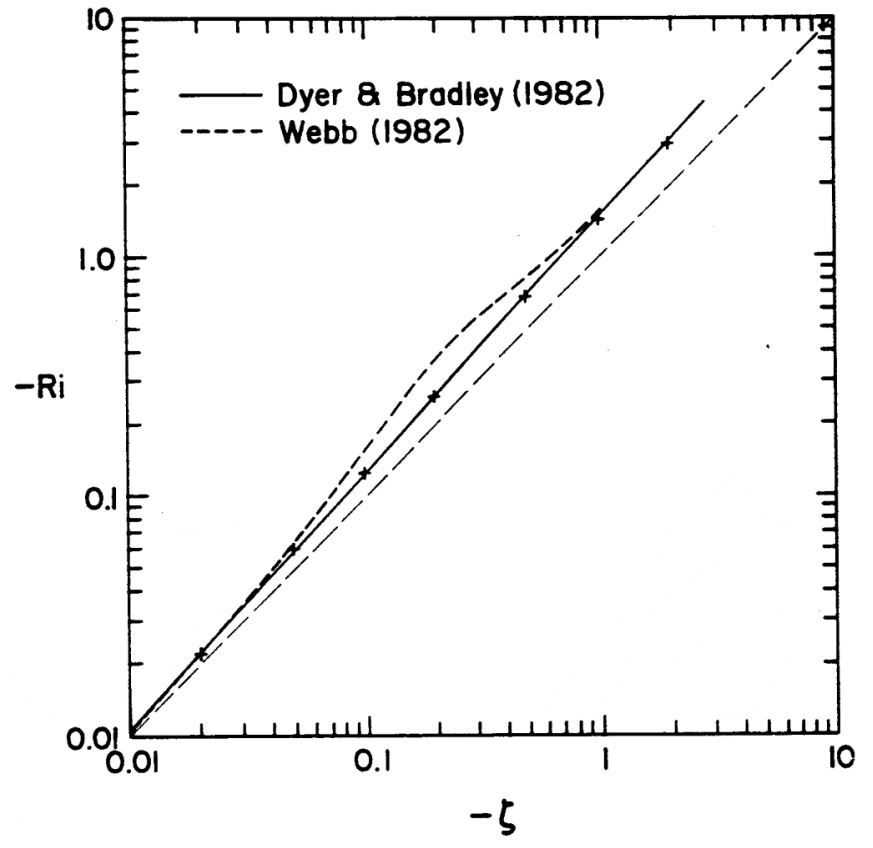

Fig. (3). Gradient Richardson number, Ri, versus Obukhov number, $\zeta$, for various field experiments (adopted from [51]). For the references in this figure see $[57,58]$.

$-1 \leq \zeta<0$. As recommended by Webb [55], the relationship $\Phi_{\mathrm{q}}(\zeta)=\Phi_{\mathrm{h}}(\zeta)=\Phi_{\mathrm{m}}(\zeta)$ may be acceptable for stable stratification.

Expressing the gradient-Richardson number (3.36) by the nondimensional gradients and assuming that $\Phi_{\mathrm{q}}(\zeta)=\Phi_{\mathrm{h}}(\zeta)$ (see formula (5.15)) yield then [56]

$\mathrm{Ri}=\frac{\Phi_{\mathrm{h}}(\zeta)}{\left(\Phi_{\mathrm{m}}(\zeta)\right)^{2}} \zeta$ 
Obviously, the Businger-Pandolfo relationship $\Phi_{\mathrm{h}}(\zeta)=\Phi_{\mathrm{m}}{ }^{2}(\zeta)$ for unstable stratification leads to

$\mathrm{Ri}=\zeta$ for $\zeta<0$

Dyer and Bradley [57] and Webb [58], however, pointed out that small deviations from this identity might occur (see Fig. 3).

If we accept Webb's [55] recommendation $\Phi_{\mathrm{q}}(\zeta)=\Phi_{\mathrm{h}}(\zeta)=\Phi_{\mathrm{m}}(\zeta)$ for stable stratification we will obtain

$\mathrm{Ri}=\frac{\zeta}{1+\gamma_{1} \zeta}$ for $\zeta>0$

Obviously, under such conditions $\operatorname{Pr}_{t}$ is equal (or close) to unity for stable stratification, i.e., $\mathrm{Ri}$ and $\mathrm{Ri}_{\mathrm{f}}$ are (nearly) identical. We can infer from Eq. (5.18) that for stable stratification $\gamma_{1}$ is not a constant because it depends on both the gradient Richardson number and the Obukhov number expressed by

$\gamma_{1}=\frac{1}{\zeta\left(\frac{1}{\mathrm{Ri}}-1\right)} \geq 0$

Such a dependency of $\gamma_{1}$ on the Obukhov number was found by $\mathrm{Kramm}$ et al. [59]. If $\mathrm{Ri} \cong \mathrm{Ri}_{\mathrm{f}, \mathrm{cr}}=0.25$ the quantity $\gamma_{1}$ will equal $\gamma_{1}=1 /(3 \zeta)$. As illustrated in Fig. (1), Obukhov numbers greater than two do not frequently occur. Therefore for strongly stable stratification a value of $\gamma_{1} \approx 1 / 6$ has to be expected.

Beside the formulae (5.14) and (5.15), Businger et al. [46] found

$$
\Phi_{\mathrm{m}}(\zeta)= \begin{cases}\left(1-\gamma_{4} \zeta\right)^{-1 / 4} & \text { for } \zeta<0 \\ 1 & \text { for } \zeta=0 \\ 1+\gamma_{3} \zeta & \text { for } \zeta>0\end{cases}
$$

and

$$
\Phi_{\mathrm{h}}(\zeta)= \begin{cases}0.74\left(1-\gamma_{5} \zeta\right)^{-1 / 2} & \text { for } \zeta<0 \\ 0.74 & \text { for } \zeta=0 \\ 0.74+\gamma_{3} \zeta & \text { for } \zeta>0\end{cases}
$$

with $\gamma_{3} \cong 4.7, \gamma_{4} \cong 15$, and $\gamma_{5} \cong 9$. Introducing these local similarity functions into formula (5.16) provides

$$
\operatorname{Ri}=\left\{\begin{array}{cc}
0.74\left(\frac{1-\gamma_{4} \zeta}{1-\gamma_{5} \zeta}\right)^{\frac{1}{2}} \zeta & \text { for } \zeta<0 \\
\frac{\zeta}{1+\gamma_{3} \zeta}\left(1-\frac{0.26}{1+\gamma_{3} \zeta}\right) & \text { for } \zeta>0
\end{array}\right.
$$

Obviously, for unstable stratification we have $|\mathrm{Ri}|<|\zeta|$. In the case of stable stratification the influence of the term $0.26 /\left(1+\gamma_{3} \zeta\right)$ becomes weaker and weaker when the Obukhov number increases, i.e., the results inferred from formulae (5.18) and (5.22) only differ slightly for strongly stable conditions.

Recently, Cheng and Brutsaert [60] suggested for stable stratification

$\Phi_{\mathrm{m}}(\zeta)=1+\gamma_{6}\left(\frac{\zeta+\zeta^{\gamma_{7}}\left(1+\zeta^{\gamma_{7}}\right)^{\frac{1-\gamma_{7}}{\gamma_{7}}}}{\zeta+\left(1+\zeta^{\gamma_{7}}\right)^{\frac{1}{\gamma_{7}}}}\right)$

and

$\Phi_{\mathrm{h}}(\zeta)=1+\gamma_{8}\left(\frac{\zeta+\zeta^{\gamma_{9}}\left(1+\zeta^{\gamma_{9}}\right)^{\frac{1-\gamma_{9}}{\gamma_{9}}}}{\zeta+\left(1+\zeta^{\gamma_{9}}\right)^{\frac{1}{\gamma_{9}}}}\right)$

with $\gamma_{6}=6.1, \gamma_{7}=2.5, \gamma_{8}=5.3$, and $\gamma_{9}=1.1$. These formulae should cover the entire range of stable stratification. For neutral conditions, i.e., $\zeta=0$, one obtains $\Phi_{\mathrm{h}}(0)=\Phi_{\mathrm{m}}(0)=1$. For moderate stable stratification both formulae can be approximated by linear expressions, $\Phi_{\mathrm{m}}(\zeta) \cong 1+\gamma_{6} \zeta$ and $\Phi_{\mathrm{h}}(\zeta) \cong 1+\gamma_{8} \zeta$. For increasing stability formulae (5.23) and (5.24) tend to $\Phi_{\mathrm{m}}(\zeta)=1+\gamma_{6}$ and $\Phi_{\mathrm{h}}(\zeta)=1+\gamma_{8}$. Obviously, for the entire range of stable stratification $\Phi_{\mathrm{m}}(\zeta)$ and $\Phi_{\mathrm{h}}(\zeta)$ slightly differ from each other.

The results for strongly stable stratification should generally be considered with care. As reported by Cheng and Brutsaert [60], the calculated $\Phi_{\mathrm{h}}(\zeta)-1$ data points for $\zeta>2$ were excluded from the analysis because the larger scatter suggested either unacceptable error in the measurements or perhaps other unexplained physical effects. As these authors pointed out, one possible reason could be that these data points are already outside the stable surface layer so that Monin-Obukhov similarity, as expressed, for instance, by Eqs. (4.6) and (5.5), may not be valid.

It is obvious that formulae (5.23) and (5.24) lead to logarithmic profiles for neutral and strongly stable conditions. The latter, already found by Webb [55], seems to be awkward because if the magnitude of turbulent fluctuations decreases towards the small values of the quiet regime with increasing stability (e.g., [61, 62]), the near-surface flow should become mainly laminar. In the case of a pure laminar flow viscous effects are dominant leading to $\partial \mathrm{U} / \partial \eta=\mathrm{u}_{*}$, $\partial \hat{\Theta} / \partial \eta=\operatorname{Pr} \Theta_{*}$, and $\partial \hat{\mathrm{q}} / \partial \eta=\mathrm{Sc}_{\mathrm{q}} \mathbf{u}_{*}$. Thus, linear profiles have to be expected. The same is true when the respective eddy diffusivities become invariant with height. Such height invariance might be possible when the quiet regime prevails 
and the magnitude of the turbulent fluctuations is small across the entire ASL. Thus, we have to assume that MoninObukhov similarity is incomplete (see section 4) under strongly stable conditions. If under such conditions the constant flux approximation is no longer valid as debated, for instance, by Webb [55] and Poulos and Burns [63], MoninObukhov similarity must not be expected. $\hat{\varepsilon}=\bar{\varepsilon} * / \bar{\rho}$ (see Eq. (5.47)). Relating the latter to the Heisenberg-von Weizsäcker law, $\hat{\varepsilon}=\mathrm{K}_{\mathrm{m}}{ }^{3} \Lambda^{-4}[69,70]$, and postulating a mixing length for non-neutral conditions by $\Lambda=\Lambda_{\mathrm{P}} \Phi_{\Lambda}(\zeta)$, with which Fortak [71] and Herbert and Panhans $[72,73]$ introduced the further similarity function $\Phi_{\Lambda}(\zeta)$ for improving the treatment of this length scale in

Table 1. Various Formulae for the Similarity Function $\Phi_{\Lambda}(\zeta)[72,73]$

\begin{tabular}{|c|c|}
\hline Model Number & Formulae \\
\hline \hline 1 & $\Phi_{\Lambda}(\zeta)=\Phi_{\mathrm{m}}{ }^{-1}(\zeta)$ \\
\hline 2 & $\Phi_{\Lambda}(\zeta)=1-\frac{1}{2}\left\{\zeta \Phi_{\mathrm{m}}(\zeta)\right\}^{-\frac{1}{2}} \int_{0}^{\zeta}\left\{\zeta^{\prime} \Phi_{\mathrm{m}}\left(\zeta^{\prime}\right)\right\}^{\frac{1}{2}}\left\{\frac{\mathrm{d}}{\mathrm{d} \zeta} \ln \Phi_{\mathrm{m}}\left(\zeta^{\prime}\right)\right\} \mathrm{d} \zeta^{\prime}$ \\
\hline 3 & $\Phi_{\Lambda}(\zeta)=-0.11 \zeta+\left\{1+(0.11 \zeta)^{2}\right\}^{\frac{1}{2}}$ \\
\hline 4 & $\Phi_{\Lambda}(\zeta)=\Phi_{\mathrm{m}}{ }^{-1}(\zeta)\left\{1-\zeta \frac{\Phi_{\mathrm{h}}(\zeta)}{\Phi_{\mathrm{m}}{ }^{2}(\zeta)}\right\}^{-\frac{1}{4}}$ \\
\hline
\end{tabular}

Instead of the Businger-Dyer-Pandolfo relationship for momentum under unstable stratification, the O'KEYPS formula $^{1}$,

$\Phi_{\mathrm{m}}{ }^{4}(\zeta)-\gamma_{10} \zeta \Phi_{\mathrm{m}}{ }^{3}(\zeta)=1 \quad$ for $\zeta \leq 0$,

may alternatively be applied. It indicates a $\Phi_{\mathrm{m}}(\zeta) \cong\left(-\gamma_{10} \zeta\right)^{-1 / 3}$ behavior for large negative Obukhov numbers, for which $\Phi_{\mathrm{m}}(\zeta)<-\gamma_{10} \zeta$ becomes valid. The O'KEYPS formula with $\gamma_{10}=9$ is experimentally proved for the range $-2 \leq \zeta<0$ [46]; Panofsky and Dutton [52], however, recommended: $\gamma_{10}=15$. From a physical point of view the O'KEYPS formula seems to be more preferable than the Businger-Dyer-Pandolfo relationship because the former can be related to the local balance equation of the TKE (see subsection 3.4). For horizontally homogeneous and steady-state conditions the non-dimensional form of this TKE equation reads

$0=-\Phi_{\mathrm{d}}(\zeta)+\Phi_{\mathrm{m}}(\zeta)-\zeta-\Phi_{\varepsilon}(\zeta)$

where $\Phi_{\mathrm{d}}(\zeta)=\Phi_{\mathrm{E}}(\zeta)+\Phi_{\mathrm{P}}(\zeta) \quad$ represent the nondimensional divergence of both the eddy flux of TKE, $\mathrm{E}=1 / 2 \overline{\rho w^{\prime \prime} \mathrm{v}^{\prime 2}}$, denoted by $\Phi_{\mathrm{E}}(\zeta)$ and the eddy flux $\mathrm{P} \cong \overline{\rho \mathrm{w}^{\prime \prime} \mathrm{p}^{\prime}} / \bar{\rho}$ resulting from pressure and vertical wind speed fluctuations and expressed by $\Phi_{\mathrm{P}}(\zeta)$. Furthermore, $\Phi_{\varepsilon}(\zeta)$ is the similarity function of the energy dissipation

${ }^{1}$ O'KEYPS stands for the initials of various authors who proposed this formula (Obukhov [16], Kazansky and Monin [64], Ellison [65], Yamamoto [66], Panofsky [67], Sellers [68]). dependence on non-neutral conditions (see also Eq. (5.34)), lead to

$\Phi_{\mathrm{m}}{ }^{4}(\zeta)-\left(\frac{\Phi_{\mathrm{d}}(\zeta)}{\zeta}-1\right) \zeta \Phi_{\mathrm{m}}{ }^{3}(\zeta)=\Phi_{\Lambda}^{-4}(\zeta)$

Herbert and Panhans [72, 73] also examined different expressions for $\Phi_{\Lambda}(\zeta)$ (see Table 1 and Fig. (4)). As illustrated in Figs. $(\mathbf{5}, \mathbf{6})$, they found that its definition at the cost of an analytical hypothesis for the TKE-transport term leads to the most satisfactory agreement with the observational data in [74].

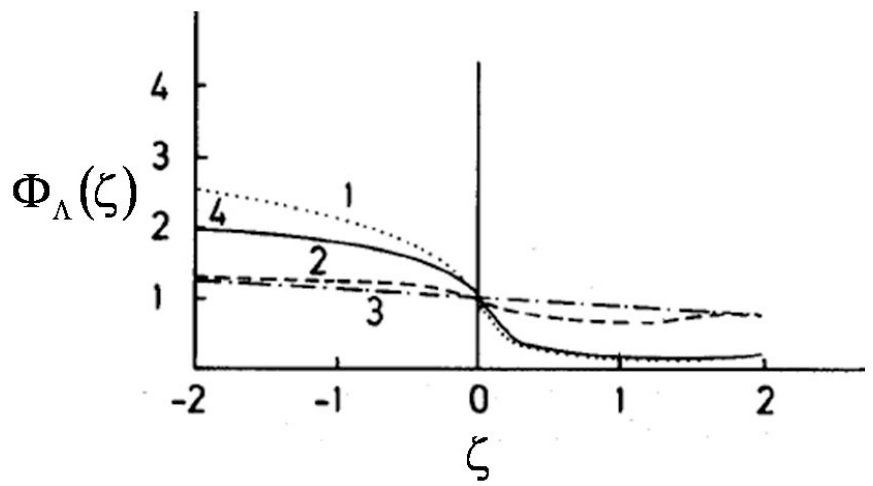

Fig. (4). Similarity function $\Phi_{\Lambda}(\zeta)$ as a function of $\zeta$ (adopted from $[72,73])$. The numbers are related to the models listed in Table $\mathbf{1}$.

The simplest possible case of interest, however, is a Prandtl-type mixing length for neutral stratification so that $\Lambda=\Lambda_{\mathrm{P}}$. The omission of non-neutral effects in $\Phi_{\Lambda}(\zeta)$ supposes the argument that buoyancy and mean wind shear may generate turbulence in which the deviation of $\Phi_{\Lambda}(\zeta)$ from 
unity is too small to contribute significantly to the energy dissipation. This concept is usually employed in one-and-ahalf-order closure schemes (e.g., $[38,75])$. With this simplification, Eq. (5.27) becomes an extended version of the O'KEYPS formula given by [59]

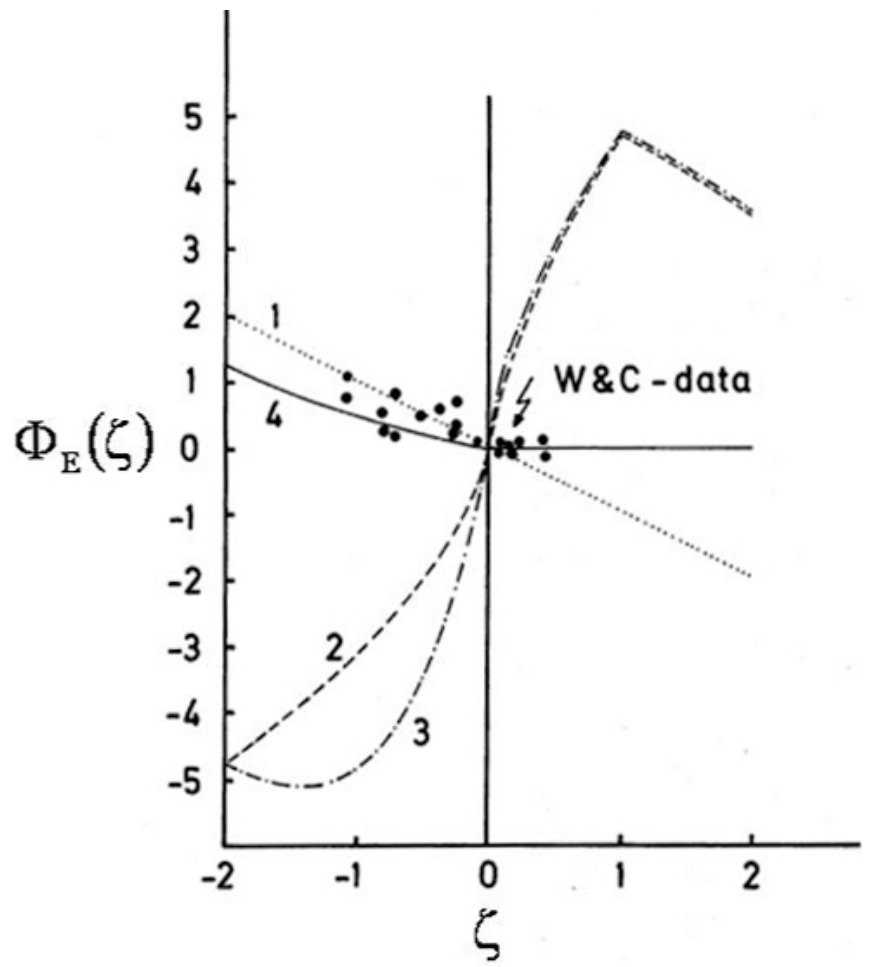

Fig. (5). Non-dimensional rate of TKE, $\Phi_{\mathrm{E}}(\zeta)$, as a function of $\zeta$ (adopted from [72, 73]). The numbers are related to the models listed in Table 1, and the $\mathrm{W} \& \mathrm{C}$ points represent observed values of Wyngaard and Coté [74].

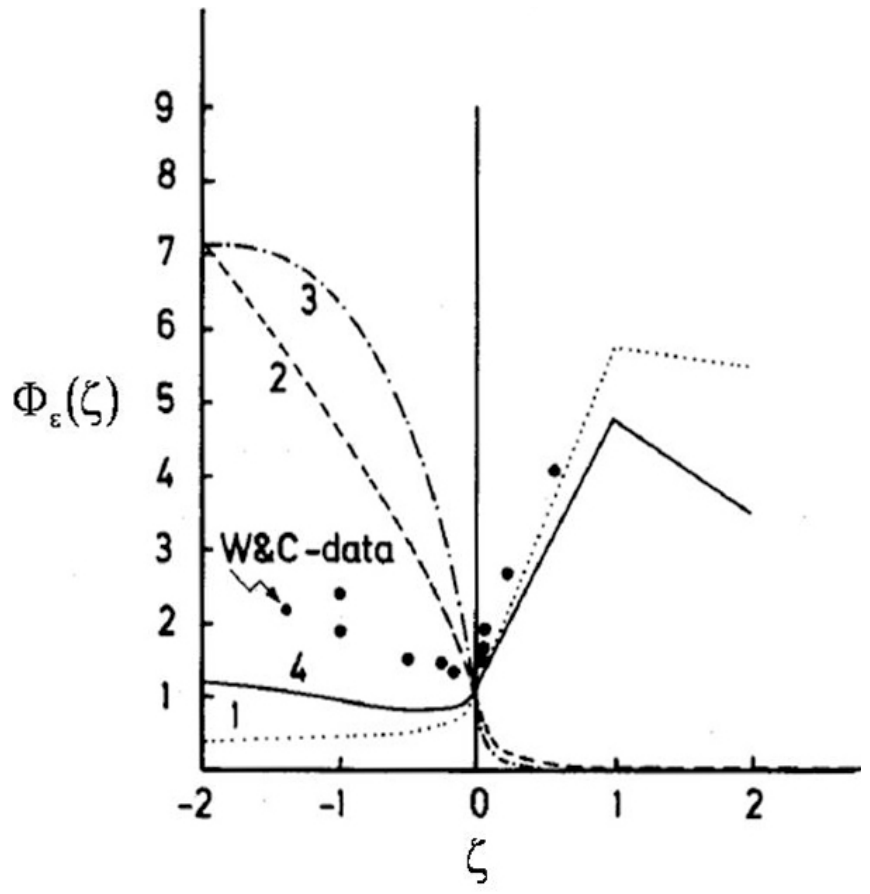

Fig. (6). As in Fig. (5), but for the similarity function, $\Phi_{\varepsilon}(\zeta)$, of the energy dissipation.
$\Phi_{\mathrm{m}}{ }^{4}(\zeta)-\left(\frac{\Phi_{\mathrm{d}}(\zeta)}{\zeta}-1\right) \zeta \Phi_{\mathrm{m}}{ }^{3}(\zeta)=1$

Comparing this equation with formula (5.25) yields then

$\gamma_{10}=\frac{\Phi_{\mathrm{d}}(\zeta)}{\zeta}-1$

i.e., it is unlikely that the quantity $\gamma_{10}$ is a constant, as already pointed out by Fortak [71], Herbert and Panhans [72, 73], and Kramm et al. [59]. In contrast to the conventional O'KEYPS formula, the extended version (5.28) is not restricted to unstable stratification. The same is true in the case of formula (5.27).

Local similarity functions of the form

$\Phi_{\mathrm{m}}(\zeta)=\left(1-\gamma_{11} \zeta\right)^{-1 / 3}$

as found, for instance, by Carl et al. [76] as well as Gavrilov and Petrov [77] for unstable stratification in the range of $-10 \leq \zeta<0$, reflect the same asymptotic behavior like the conventional O'KEYPS formula, but they disagree with that of the Businger-Dyer-Pandolfo relationship. Here, $\gamma_{11}=15$ is assumed.

Recently, McNaughton [78] disputed the MoninObukhov similarity in an unstable ASL beneath a convective outer layer. He stated that "Monin-Obukhov similarity theory is flawed because it fails to account for the variations in the forcing of the whole surface layer imposed by the large eddies of the outer layer". As several of McNaughton's [78] model assumptions are rather arbitrary (leading to some inconsistent formulations) and are not always covered by the scope of the ASL physics, we do not further assess his findings.

\subsection{The Turbulent Numbers of Schmidt, Prandtl and Lewis-Semenov}

Often, the turbulent Schmidt and Prandtl numbers are related to each other by $\mathrm{Sc}_{\mathrm{t}, \mathrm{q}} \cong \mathrm{Pr}_{\mathrm{t}}$. Thus, the turbulent Lewis-Semenov number amounts to $\mathrm{LS}_{\mathrm{t}, \mathrm{q}} \cong 1 \Rightarrow \Phi_{\mathrm{q}}(\zeta) \cong \Phi_{\mathrm{h}}(\zeta)$, i.e., the values of $\mathrm{Pr}_{\mathrm{t}}, \mathrm{Sc}_{\mathrm{t}, \mathrm{q}}$, and $\mathrm{LS}_{\mathrm{t}, \mathrm{q}}$ only depend on the ratio of the local stability functions for heat and momentum. The use of a common eddy diffusivity and, hence, of a common local stability function for all scalar quantities is based on some empirical results that the turbulent transfer of sensible heat and water vapor is similar (e.g., $[48,79,80]$ ), which is adopted to the other scalars as well (e.g., [52, 81, 82]). This is in agreement with some empirical results derived from concurrent measurements of ozone fluxes and ozone profiles [83].

Obviously, Webb's [55] recommendation for stable stratification suggests that the turbulent Prandtl number approaches to $\mathrm{Pr}_{\mathrm{t}}=1$ for stable (and nearly neutral) stratification. Whereas the expressions of Businger et al. [46] lead to $\mathrm{Pr}_{\mathrm{t}}=0.74$ for (nearly) neutral conditions. The latter one substantially agrees with an average of $\mathrm{Pr}_{t}=0.78$ suggested 
by Reichardt [84]. Laboratory results like that of Reichardt, however, are equally inconsistent with each other, suggesting only that the turbulent Prandtl number is not to far from unity [42]. Empirical findings (e.g., [85-88]) and theoretical results (e.g., [89-91]) of different authors, for instance, suggest that $\operatorname{Pr}_{\mathrm{t}}$ depends on the local (or roughness) Reynolds number, $\eta$, and may vary between 0.5 and 1 . On the other hand, Deissler's [92] results indicate that $\operatorname{Pr}_{t}$ approaches to unity at high velocity gradients regardless of the (molecular) Prandtl number. It might be pertinent to remark that most existing theories of heat transfer either assume $\operatorname{Pr}_{t}=1$ or an average, but constant value of $\mathrm{Pr}_{\mathrm{t}}=0.78$ (e.g., [23, 84, 93]). Note that Ludwieg's [86] investigation mentioned above bears an aura of credibility and provides a link to Taylor's vorticity transport theory [93]. Ludwieg [86] measured the variation with the normalized radius $r / R$ ( $r$ is the radial distance from the centre of the pipe, $\mathrm{R}$ is the pipe radius) of the turbulent Prandtl number for air flowing in a pipe. As illustrated in Fig. (7), his results indicate that $\mathrm{Pr}_{\mathrm{t}}$ varies smoothly and continuously from a value nearly 0.94 close to the pipe wall to a value of about 0.67 at the centre of the pipe, where a possible dependence on the Mach number, Ma, cannot be not detected. Obviously, $\operatorname{Pr}_{\mathrm{t}}=0.67$ also corresponds to that of Businger et al. [46] for nearly neutral conditions. According to Kestin and Richardson [93] as well as Schlichting [23], Ludwieg's [78] results are closest to being correct. It may be represented by [94] (see Fig. 7)

$$
\operatorname{Pr}_{t}=\frac{0.649-0.952}{1+\exp \left(\frac{\frac{\mathrm{r}}{\mathrm{R}}-0.438}{0.162}\right)}+0.952
$$

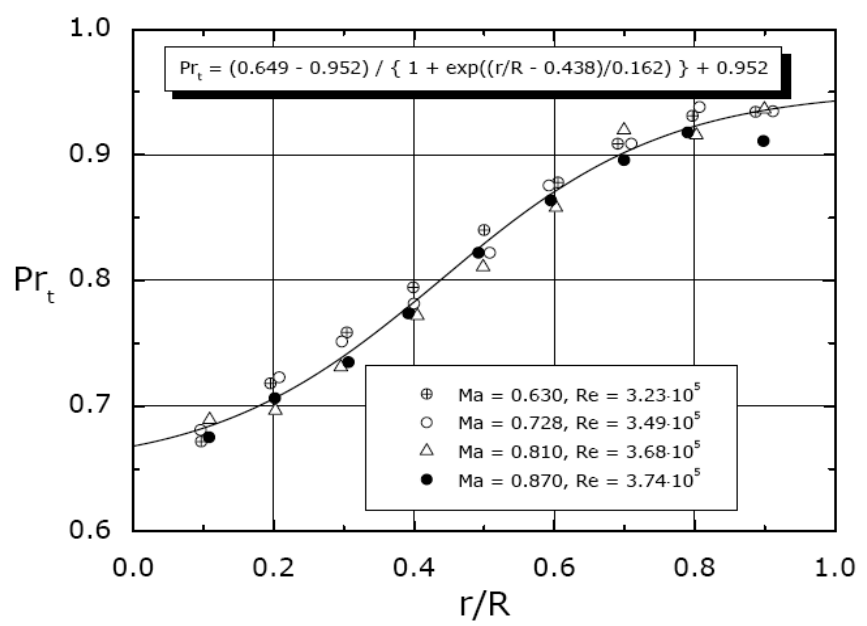

Fig. (7). Variation of the turbulent Prandtl number, $\mathrm{Pr}_{\mathrm{t}}$, with the normalized radius $r / R$ ( $r$ is the radial distance from the center of the pipe, $\mathrm{R}$ is the pipe radius) for air flowing in a pipe, where $\mathrm{Ma}$ is the Mach number (adopted from [86]).

Nevertheless, we have to notice that already the $\mathrm{Pr}_{t}$ values empirically derived for the (nearly) neutral atmospheric surface layer from the aforementioned relationships can notably differ from each other. These controversial results, of course, may be associated with the value of the von Kármán constant $\kappa=0.35$ obtained by Businger et al. [46], which appreciably differs from $\kappa=0.4$ used by Reichardt [84] as well as from $\kappa=0.41$ suggested by Dyer and Hicks [48]. Lumley and Panofsky [42] already pointed out that the question of the relative size of $\mathrm{K}_{\mathrm{h}}$ and $\mathrm{K}_{\mathrm{m}}$ has still not been answered satisfactorily. Nearly forty years later, Kramm et al. [94] stated: "We have to recognize that their statement is further valid." Hitherto, values of turbulent Schmidt numbers determined for the ASL are scarce, and the value of Dyer and Hicks [48] for water vapor seems to be one of the most reliable results.

Following, for instance, Panofsky and Dutton [52], Pal Arya [20], as well as Kraus and Businger [95] the expressions (5.14) and (5.15) should be used for practical purposes, where a von Kármán constant of $\kappa=0.4$ has to be preferred. This recommendation will be scrutinized in section 7 .

\subsection{The Von Kármán Constant}

In the previous subsection we stated that the controversial results regarding the turbulent Prandtl number may be associated with the value of the von Kármán constant. This constant is related to the mixing length $\Lambda$ by $[23,96]$

$\Lambda=\kappa\left|\frac{\frac{\partial \mathrm{U}}{\partial \mathrm{z}}}{\frac{\partial^{2} \mathrm{U}}{\partial \mathrm{z}^{2}}}\right|$

For thermally neutral stratification for which the logarithmic wind profile may be valid (see, e.g., Eq. (2.21)) we obtain $\Lambda=\Lambda_{\mathrm{P}}=\kappa(\mathrm{z}-\mathrm{d})$, i.e., Prandtl's mixing length. In the case of non-neutral stratification Eq. (5.32) results in

$$
\Lambda=\kappa\left|\frac{\mathrm{z}-\mathrm{d}}{\frac{(\mathrm{z}-\mathrm{d})}{\Phi_{\mathrm{m}}(\zeta)} \frac{\partial}{\partial \mathrm{z}} \Phi_{\mathrm{m}}(\zeta)-1}\right|=\Lambda_{\mathrm{P}} \Phi_{\Lambda}(\zeta)
$$

with

$$
\Phi_{\Lambda}(\zeta)=\left|\frac{1}{\frac{(\mathrm{z}-\mathrm{d})}{\Phi_{\mathrm{m}}(\zeta)} \frac{\partial}{\partial \mathrm{z}} \Phi_{\mathrm{m}}(\zeta)-1}\right|
$$

The similarity function $\Phi_{\Lambda}(\zeta)$ introduced by Fortak [71] and Herbert and Panhans $[72,73]$ for improving the treatment of this length scale in dependence on non-neutral conditions is quite justified by this equation. With this similarity function one obtains Eq. (5.27). If $\left|\frac{(\mathrm{z}-\mathrm{d})}{\Phi_{\mathrm{m}}(\zeta)} \frac{\partial}{\partial \mathrm{z}} \Phi_{\mathrm{m}}(\zeta)\right|<<1$ this similarity function may be approximated by $\Phi_{\Lambda}(\zeta) \cong 1$, and, hence, Eq. (5.27) results in formula (5.28). 
Usually, a value of $\kappa=0.40$ is preferred. However, based on 553 independent determinations of $\kappa$ (the largest, most comprehensive atmospheric data set ever used to evaluate the von Kármán constant) Andreas et al. [26] derived a value of $\kappa=0.387 \pm 0.003$, constant for $2 \leq \eta \leq 100$. These independent determinations were performed on the basis of the friction stress, $\tau$, and the vertical profiles of wind speed, $\mathrm{U}(\mathrm{z})$, collected during the comprehensive study of the Surface Heat Budget of the Arctic Ocean (SHEBA), and an $800 \mathrm{~h}$ of observation period over the Antarctic sea ice on Ice Station Weddell (ISW). All of these profiles reflect near-neutral stratification, and each exhibits a logarithmic layer that extends over all sampling heights. A value of $\kappa=0.387 \pm 0.010$ was also found by

Frenzen and Vogel [97] but their result is based on 29 data pairs only. Frenzen and Vogel $[97,98]$ also suggest that $\kappa$ decreases weakly with increasing roughness Reynolds number. Obviously, their findings disagree with those of Andreas et al. [26]. Nevertheless, for consistent modeling purposes we recommend to use the value of the von Kármán constant simultaneously derived with the local similarity functions of momentum, sensible heat, and matter.

\subsection{Variance Relationships}

In the subsections 5.1 to 5.3 , we have derived fluxgradient relationships on the basis of the dimensional $\pi$ invariants analysis. In studies on ASL turbulence, however, we have not only to consider covariance terms that represent the eddy fluxes, but also variance terms. Therefore, there is a strong interest to apply the procedure of nondimensionalization for determining the various variance terms like $\left\langle\mathrm{u}^{\prime 2}\right\rangle,\left\langle\mathrm{v}^{\prime^{2}}\right\rangle,\left\langle\mathrm{w}^{\prime^{2}}\right\rangle,\left\langle\Theta^{\prime^{2}}\right\rangle$, and $\left\langle\mathrm{q}^{\prime 2}\right\rangle$. To make this goal, we have to replace the vertical gradients in the various similarity hypotheses by the respective variance terms. Thus, in all instances of variance relationships, the number of dimensional quantities is $\mathrm{k}=4$, too. The rank of the various dimensional matrices is $r=2$, and, again, we have $\mathrm{p}=\mathrm{k}-\mathrm{r}=2$ independent $\pi$ numbers, i.e., also in the cases of variance relationships universal functions are established.

In the case of momentum, we consider the variance of the vertical velocity component, $\left\langle w^{m^{2}}\right\rangle$. Therefore, the similarity hypothesis reads $F\left(\mathrm{z}-\mathrm{d}, \mathrm{L}, \mathrm{u}_{*},\left\langle\mathrm{w}^{\mathrm{N}^{2}}\right\rangle\right)=0$. The dimensional $\pi$-invariants analysis provides then

$\pi_{1}=\frac{\sigma_{\mathrm{w}}}{\mathrm{u}_{*}}=\varphi_{\mathrm{w}}\left(\pi_{2}\right)=\varphi_{\mathrm{w}}(\zeta)$

where $\sigma_{\mathrm{w}}=\left\langle\mathrm{w}^{\prime 2}\right\rangle^{1 / 2}$ is the standard deviation of the vertical velocity component, $\sigma_{\mathrm{w}} / \mathrm{u}_{*}$ is called the normalized standard deviation, and $\varphi_{\mathrm{w}}(\zeta)$ is the respective local similarity function (or universal function). Since it cannot be quantified by the dimensional $\pi$-invariants analysis because there exist, again, two $\pi$ numbers, it has to be determined empirically or/and theoretically. Lumley and Panofsky [42], for instance, recommended for both stable and unstable stratification

$\frac{\sigma_{\mathrm{w}}}{\mathrm{u}_{*}}=\varphi_{\mathrm{w}}(\zeta)=\mathrm{A}_{\mathrm{w}}\left(\Phi_{\mathrm{m}}(\zeta)-2.5 \zeta\right)^{\frac{1}{3}}$

that leads to $\sigma_{w} / u_{*}=A_{w}=1.3$ for neutral stratification (recently disputed by Wilson [99]). This formula fits the observation well, but in the case of stable stratification there is a large scatter [52]. Panofsky et al. [100] eventually recommended for unstable stratification

$$
\frac{\sigma_{\mathrm{w}}}{\mathrm{u}_{*}}=\varphi_{\mathrm{w}}(\zeta)=\mathrm{A}_{\mathrm{w}}(1-3 \zeta)^{\frac{1}{3}}
$$

that fits observation at smooth sites very well [52]. Since $\zeta$ varies with height and $u_{*}$ is height-invariant, the normalized standard deviation is a function of height, too. Its variation with height can simply be determined by using the condition: $\sigma_{\mathrm{w}} / \varphi_{\mathrm{w}}(\zeta)=$ const.

Local similarity functions for the normalized standard deviations $\quad \sigma_{\mathrm{u}} / \mathrm{u}_{*}=\left\langle\mathrm{u}^{\prime \prime 2}\right\rangle^{1 / 2} / \mathrm{u}_{*}=\varphi_{\mathrm{u}}(\zeta) \quad$ and $\sigma_{\mathrm{v}} / \mathrm{u}_{*}=\left\langle\mathrm{v}^{\prime \prime}\right\rangle^{1 / 2} / \mathrm{u}_{*}=\varphi_{\mathrm{v}}(\zeta)$ of the horizontal velocity components $\mathrm{u}$ and $\mathrm{v}$ can be deduced in a similar manner. However, $\varphi_{\mathrm{u}}(\zeta)$ and $\varphi_{\mathrm{v}}(\zeta)$ considerably differ from $\varphi_{\mathrm{w}}(\zeta)$. Following Panofsky et al. [100], the normalized standard deviation of the horizontal wind component, $\sigma_{U} / \mathrm{u}_{*}$, may be written as

$$
\frac{\sigma_{\mathrm{U}}}{\mathrm{u}_{*}}=\left(\mathrm{A}_{\mathrm{U}}-\mathrm{B}_{\mathrm{U}} \zeta_{\mathrm{i}}\right)^{\frac{1}{3}}
$$

with $\mathrm{A}_{\mathrm{U}}=12$ and $\mathrm{B}_{\mathrm{U}}=0.5$, where $\zeta_{\mathrm{i}}$ corresponds to the height of the lowest inversion, $z_{i}$, considered as the top of the boundary layer. In contrast to this, the results of Johansson et al. [101] suggest $\mathrm{A}_{\mathrm{U}}=10$ and $\mathrm{B}_{\mathrm{U}}=0.88$. Customarily, the Deardorff velocity $\mathrm{w}_{*}=\left(\mathrm{g} \mathrm{H} \mathrm{z}_{\mathrm{i}} /\left(\Theta_{\mathrm{m}} \mathrm{c}_{\mathrm{p}} \bar{\rho}\right)\right)^{\frac{1}{3}}$ is considered as an appropriate velocity scale in convective-mixedlayer similarity, but not the friction velocity. However, in accord with the definition of the Obukhov stability length (4.4) this velocity can be related to the friction velocity by $\mathrm{w}_{*}=\mathrm{u}_{*} \kappa^{-1 / 3}\left(-\zeta_{\mathrm{i}}\right)^{1 / 3}[100]$. As a fixed height $\mathrm{z}_{\mathrm{i}}$ is used in this formula, the quantity $\sigma_{U} / u_{*}$ does not vary with height, in complete contrast to $\sigma_{w} / u_{*}$. This instance of the normalized standard deviation of the horizontal wind component reflects a weakness of the dimensional $\pi$-invariants analysis. It might be that the similarity hypothesis provides an apparently reasonable result, even though it disagrees with the physical behavior because a generalized homogeneity or symmetry does not exist. Thus, in their comments on the paper of Johansson et al. [101] Andreas and Hicks [102] argued that, perhaps, it is time to acknowledge that the similarity hypothesis on which the derivation of $\sigma_{U} / u_{*}$ is based, 
violates too many of the assumptions on which MoninObukhov scaling relies and to stop trying to force $\sigma_{U} / \mathrm{u}_{*}$ into artificial similarity relations (see also subsection 5.10).

In the instance of the temperature variance, $\left\langle\Theta^{12}\right\rangle$, the similarity hypothesis is given by $F\left(\mathrm{z}-\mathrm{d}, \mathrm{L}, \Theta_{*},\left\langle\Theta^{\prime 2}\right\rangle\right)=0$. The dimensional $\pi$ invariants analysis provides

$\pi_{1}=\frac{\sigma_{\Theta}}{\Theta_{*}}=\varphi_{\Theta}\left(\pi_{2}\right)=\varphi_{\Theta}(\zeta)$

where $\sigma_{\Theta}=\left\langle\Theta^{\prime \prime 2}\right\rangle^{1 / 2}$ is the standard deviation of the potential temperature, $\sigma_{\Theta} / \Theta_{*}$ is the normalized standard deviation for temperature, and $\varphi_{\Theta}(\zeta)$ is the respective local similarity (or universal) function. Since $\Theta_{*}$ is height-invariant, the standard deviation is a function of height, according to $\sigma_{\Theta} / \varphi_{\Theta}(\zeta)=$ const. The local similarity function may be expressed by [21]

$$
\varphi_{\Theta}(\zeta)= \begin{cases}\mathrm{A}_{\Theta}\left(\mathrm{B}_{\Theta}-\mathrm{C}_{\Theta} \zeta\right)^{-\frac{1}{3}} & \text { for } \zeta<0 \\ \text { const. } & \text { for } \zeta \geq 0\end{cases}
$$

Here, $\mathrm{A}_{\Theta}, \mathrm{B}_{\Theta}$, and $\mathrm{C}_{\Theta}$ are constants. Wyngaard et al. [103], for instance, found for unstable stratification in the range of $-0.7 \leq \zeta<0: A_{\Theta}=-0.95, B_{\Theta}=0$, and $C_{\Theta}=1$ which closely agree with those of Monji [104] deduced for the range of $-10 \leq \zeta \leq-0.1$. Tillman's [105] results also derived for the range of $-10 \leq \zeta \leq-0.1$ differ notably. He found: $A_{\Theta}=0.95, B_{\Theta}=0.05$, and $C_{\Theta}=1$. For stable stratification in the range of $0 \leq \zeta \leq 1$, Wyngaard et al. [103] obtained $\varphi_{\Theta}(\zeta)=1.8$. This result was confirmed by Tillman [105], but only for the range of $0 \leq \zeta \leq 0.5$.

In the case of water vapor, we have to consider the fluctuation of the partial density of water vapor, $\overline{\rho_{w}{ }^{2}}$ because, as mentioned before, the specific humidity is a nondimensional quantity. The similarity hypothesis reads: $F\left(\mathrm{z}-\mathrm{d}, \mathrm{L}, \rho_{\mathrm{w}, *}, \overline{\rho_{\mathrm{w}}{ }^{2}}\right)=0$. The dimensional $\pi$-invariants analysis gives then

$$
\frac{\tilde{\sigma}_{\mathrm{q}}}{\rho_{\mathrm{w}, *}} \cong \frac{\bar{\rho}\left\langle\mathrm{q}^{\prime \prime 2}\right\rangle^{\frac{1}{2}}}{\bar{\rho} \mathrm{q}_{*}}=\frac{\left\langle\mathrm{q}^{\mathrm{\prime}^{2}}\right\rangle^{\frac{1}{2}}}{\mathrm{q}_{*}}=\frac{\sigma_{\mathrm{q}}}{\mathrm{q}_{*}}=\varphi_{\mathrm{q}}(\zeta)
$$

where $\tilde{\sigma}_{q}=\left(\overline{\rho_{w}^{12}}\right)^{1 / 2}$ is the standard deviation of the partial density of water vapor. It may be approximated by $\tilde{\sigma}_{q}=\left(\overline{\rho_{w}{ }^{\prime 2}}\right)^{1 / 2} \cong\left(\bar{\rho}^{2}\left\langle q^{\prime \prime 2}\right\rangle\right)^{1 / 2}=\bar{\rho}\left\langle q^{\prime \prime 2}\right\rangle^{1 / 2}$ with $\sigma_{q}=\left\langle q^{\prime 2}\right\rangle^{1 / 2}$, the standard deviation of the specific humidity. The local similarity function, $\varphi_{\mathrm{q}}(\zeta)$, may be considered as a universal function, too. Again, we have: $\sigma_{\mathrm{q}} / \varphi_{\mathrm{q}}(\zeta)=$ const. The local similarity function $\varphi_{\mathrm{q}}(\zeta)$ may be expressed in a similar manner like $\varphi_{\Theta}(\zeta)$ (see Eq. (5.40)). Högström and Smedman-Högström [106], for instance, postulated for unstable stratification:

$\varphi_{\mathrm{q}}(\zeta)=1.03 \zeta^{-\frac{1}{3}}$

As pointed out by Panofsky and Dutton [52], it does not significantly differ from the normalized standard deviation recommended by Wyngaard et al. [103] for the potential temperature.

Equations (5.37), (5.40), and (5.42) can be applied to derive the so-called structure parameters (also called the structure constant $), \mathrm{C}_{\chi}{ }^{2}(\chi$ stands for $\mathrm{w}, \Theta$, and $\mathrm{q}$ ), that are closely identified with the structure parameter $\mathrm{C}_{\mathrm{n}}{ }^{2}$ of the refractive index for acoustic and electromagnetic waves propagating to the atmosphere (e.g., $[8,52,107])$. Rearranging, for instance, Eq. (5.40) provides

$\left\langle\Theta^{\prime \prime 2}\right\rangle=\Theta_{*}^{2} \varphi_{\Theta}^{2}(\zeta)$

Dividing this equation by $(\mathrm{z}-\mathrm{d})^{2 / 3}$ yields then

$$
\mathrm{C}_{\Theta}{ }^{2}=\frac{\left\langle\Theta^{\prime \prime}\right\rangle}{(\mathrm{z}-\mathrm{d})^{\frac{2}{3}}}=\frac{\Theta_{*}^{2} \varphi_{\Theta}{ }^{2}(\zeta)}{(\mathrm{z}-\mathrm{d})^{\frac{2}{3}}}
$$

The quantity $\mathrm{C}_{\Theta}{ }^{2}$ is the structure parameter for forcedconvective conditions, where $\mathrm{z}-\mathrm{d}$ serves as a characteristic length scale. Combining formulae (5.40) and (5.44) provides for unstable stratification:

$$
\frac{\mathrm{C}_{\Theta}{ }^{2}(\mathrm{z}-\mathrm{d})^{\frac{2}{3}}}{\Theta_{*}{ }^{2}}=0.90 \zeta^{-\frac{2}{3}}
$$

Such a $\zeta^{-2 / 3}$ - behavior was also suggested by Kaimal and Finnigan [107]. These authors related the left side of this equation - via the terms in the one-dimensional spectral forms for velocity and temperature - to the energy dissipation. Their values are nearly 50 per cent higher than those provided by formula (5.45).

\subsection{Dissipation of Kinetic Energy}

In deriving the local similarity function (or universal function) for the averaged dissipation of kinetic energy $\hat{\varepsilon}$, we have to replace the vertical gradient of the mean horizontal wind speed, $\mathrm{Q}_{4}=\partial \mathrm{U} / \partial \mathrm{z}$, in the similarity hypothesis of subsection 5.1 by $\hat{\varepsilon}$. Thus, the similarity hypothesis reads: $F\left(\mathrm{z}-\mathrm{d}, \mathrm{L}, \mathrm{u}_{*}, \hat{\varepsilon}\right)=0$. The dimensional $\pi$-invariants analysis provides then

$$
\pi_{1}=\frac{\mathrm{z}-\mathrm{d}}{\mathrm{u}_{*}{ }^{3}} \hat{\varepsilon}=\varphi_{\varepsilon}\left(\pi_{2}\right)=\varphi_{\varepsilon}(\zeta)
$$

Introducing, again, the von Kármán constant $\kappa$ yields [56] 
$\frac{\kappa(\mathrm{z}-\mathrm{d})}{\mathrm{u}_{*}{ }^{3}} \hat{\varepsilon}=\Phi_{\varepsilon}(\zeta)$

This local similarity function $\Phi_{\varepsilon}(\zeta)=\kappa \varphi_{\varepsilon}(\zeta)$ may also be considered as a universal function. Note that in the case of neutral stratification for which the similarity hypothesis, $F\left(\mathrm{z}-\mathrm{d}, \mathrm{u}_{*}, \hat{\varepsilon}\right)=0$, seems to be acceptable, $\kappa$ is related to the $\pi$ number by $\pi_{1}=\varphi_{\varepsilon}(0)=\kappa^{-1}$. It follows that $\Phi_{\varepsilon}(0)$ is equal to unity. For thermal stratification, Wyngaard and Coté [74] as well as Kaimal et al. [108], for instance, recommended

$$
\Phi_{\varepsilon}(\zeta)= \begin{cases}\left(1+0.5|\zeta|^{2 / 3}\right)^{3 / 2} & \text { for }-2 \leq \zeta \leq 0 \\ \left(1+2.5|\zeta|^{3 / 5}\right)^{3 / 2} & \text { for } 0 \leq \zeta \leq 2\end{cases}
$$

\subsection{Dissipation of Temperature Variance}

The dissipation of the temperature variance may be considered as an example for the dissipation of variance of a passive scalar. The similarity hypothesis for describing this dissipation reads $F\left(\mathrm{z}-\mathrm{d}, \mathrm{L}, \mathrm{u}_{*}, \Theta_{*}, \hat{\mathrm{N}}\right)=0$, where $\hat{\mathrm{N}}$ is, again, the mean dissipation rate of temperature variance (see Eq. (3.40)). Obviously, the number of the dimensional quantities is $\mathrm{k}=5$, and the rank of the dimensional matrix is $\mathrm{r}=3$. Again, we have $\mathrm{p}=\mathrm{k}-\mathrm{r}=2$ independent $\pi$ numbers. Based on the dimensional $\pi$-invariants analysis we can deduce

$\pi_{1}=\frac{\mathrm{z}-\mathrm{d}}{\mathrm{u}_{*} \Theta_{*}^{2}} \hat{\mathrm{N}}=\varphi_{\mathrm{N}}\left(\pi_{2}\right)=\varphi_{\mathrm{N}}(\zeta)$

or by introducing, again, the von Kármán constant $\kappa$

$\frac{\kappa(\mathrm{z}-\mathrm{d})}{\mathrm{u}_{*} \Theta_{*}{ }^{2}} \hat{\mathrm{N}}=\Phi_{\mathrm{N}}(\zeta)$

where $\Phi_{\mathrm{N}}(\zeta)=\kappa \varphi_{\mathrm{N}}(\zeta)$ may also be considered as the universal function of the dissipation of temperature variance. If the quantity $\Omega=\hat{N} / \hat{\varepsilon}$ relates the dissipation of temperature variance to the dissipation of kinetic energy [8], we will obtain

$\Omega=\frac{\hat{N}}{\hat{\varepsilon}}=\frac{\Theta_{*}{ }^{2} \Phi_{\mathrm{N}}(\zeta)}{u_{*}{ }^{2} \Phi_{\varepsilon}(\zeta)}$

Since the scaling quantities $\mathrm{u}_{*}$ and $\Theta_{*}$ are considered as height-invariant with within the framework of MoninObukhov scaling, the variation of $\Omega$ with height is governed by the similarity functions $\Phi_{\mathrm{N}}(\zeta)$ and $\Phi_{\varepsilon}(\zeta)$.

\subsection{Numerical Predictions of Various $\Phi$-Functions}

Predictions of Monin-Obukhov similarity functions were performed, for instance, by Prenosil [109], Claussen [110], and Khanna and Brasseur [111] using different theoretical principles.

Prenosil [109] used a second-order closure model, a notably improved version of the ASL model of Lewellen and Teske [112]. As he reported, $\Phi_{\mathrm{m}}(\zeta)$ and $\Phi_{\mathrm{h}}(\zeta)$ could be verified favorably; where difficulties arose in the case of all variance terms, especially within the range of unstable stratification.

Claussen's [110] results are based on a spectral model, where measured one-dimensional spectra of velocity and temperature variance were considered. The similarity functions $\Phi_{\mathrm{m}}(\zeta)$ and $\Phi_{\mathrm{h}}(\zeta)$ were calculated for the range $-2 \leq \zeta \leq 2$. His results showed a good agreement with observations with the exception of the range $-1 \leq \zeta \leq 0$ in which $\Phi_{\mathrm{m}}(\zeta)$ was overestimated. It seems that this overestimation was caused by neglecting the spectral divergence of the vertical transport of TKE.

Monin-Obukhov similarity may be indirectly influenced by the boundary layer depth, $\mathrm{z}_{\mathrm{i}}$. In such a case complete similarity must not be expected. The global Reynolds number (see Eq. (2.24)), now slightly modified by $\eta_{i}=u_{*} z_{i} / v$, has to be considered in the local similarity functions, as expressed by Eqs. (4.1) to (4.3). Based on their detailed analysis of the Monin-Obukhov similarity from high-resolution large-eddy simulation (LES) data, Khanna and Brasseur [111] argued that such an indirect influence is possible. The results of these authors can be summarized as follows: The simulated temperature field is found to satisfy the MoninObukhov similarity hypothesis and agree well with observations. The simulated velocity field, on the other hand, shows significant departures. Except for the horizontal variance (see subsection 5.7), Monin-Obukhov scales are the appropriate normalizing scales for the near-ground-layer statistics. However, the LES suggest that $z_{i}\left(\right.$ or $\left.\eta_{i}=u_{*} z_{i} / v\right)$ has an 'indirect' influence on all near-ground-layer variables except temperature, and the LES-predicted Monin-Obukhov-scaled variables exhibit a functional dependence on both $\zeta=\mathrm{z} / \mathrm{L}$ and $\eta / \eta_{i}=z / z_{i}$. The simulated two-dimensional spectra of velocity and temperature fluctuations, however, suggest that while large scales deviate from Monin-Obukhov similarity, inertial range scales are Monin-Obukhov-similar. Discrepancies with field observations raise important questions of the non-dimensional quantity $\eta / \eta_{i}$ over which Monin-Obukhov similarity holds for a particular variable. However, in their conclusions Khanna and Brasseur [111] conceded that, although LES provides complete time-dependent threedimensional information of the large-scale fields, MoninObukhov similarity is a near-ground phenomenon and there are numerical difficulties in simulating this region that hinder a detailed analysis.

Obviously, there is an urgent need to improve higherorder closure models and LES techniques for better predicting Monin-Obukhov similarity laws. 


\section{PRANDTL-OBUKHOV-PRIESTLEY SCALING}

\subsection{Similarity Hypothesis for Sensible Heat}

Under free-convective conditions the Obukhov stability length is not longer relevant for the vertical profiles of mean values of wind speed, potential temperature, and specific humidity (and long-lived trace species) because the vertical transfer of momentum, sensible heat, and matter is rather independent of the friction velocity $\mathrm{u} *[42]$.

According to Prandtl [15], Obukhov [16], and Priestley [17], the similarity hypothesis for the free-convective range is given by $F\left(\mathrm{Q}_{1}, \mathrm{Q}_{2}, \mathrm{Q}_{3}, \mathrm{Q}_{4}\right)=F\left(\mathrm{z}-\mathrm{d}, \mathrm{H} /\left(\mathrm{c}_{\mathrm{p}, 0} \bar{\rho}\right), \mathrm{g} / \Theta_{\mathrm{m}}, \partial \hat{\Theta} / \partial \mathrm{z}\right)=0$, where $\mathrm{Q}_{2}=\mathrm{H} /\left(\mathrm{c}_{\mathrm{p}, 0} \rho\right)$ and $\mathrm{Q}_{3}=\mathrm{g} / \Theta_{\mathrm{m}}$. In this instance, the number of the dimensional quantities is $\mathrm{k}=4$, too. Now, the rank of the dimensional matrix is $r=3$, and we obtain $\mathrm{p}=\mathrm{k}-\mathrm{r}=1$ independent $\pi$ number. The dimensional $\pi$ invariants analysis provides then

$\pi_{1}=(\mathrm{z}-\mathrm{d})^{\frac{4}{3}}\left(\frac{\mathrm{H}}{\mathrm{c}_{\mathrm{p}, 0} \bar{\rho}}\right)^{-\frac{2}{3}}\left(\frac{\mathrm{g}}{\Theta_{\mathrm{m}}}\right)^{\frac{1}{3}}\left(\frac{\partial \hat{\Theta}}{\partial \mathrm{z}}\right)$

Rearranging provides finally

$$
\frac{\partial \hat{\Theta}}{\partial z}=\pi_{1}\left(\frac{\mathrm{H}}{\mathrm{c}_{\mathrm{p}, 0} \bar{\rho}}\right)^{\frac{2}{3}}\left(\frac{\mathrm{g}}{\Theta_{\mathrm{m}}}\right)^{-\frac{1}{3}}(\mathrm{z}-\mathrm{d})^{-\frac{4}{3}}
$$

The $\pi$ number is equal to Priestley's constant, C, i.e., $\pi_{1}=\mathrm{C} \cong-1.07$. Equation (6.2) is customarily called the $-4 / 3$ power law [75]. Rearranging this equation in the sense of Monin-Obukhov scaling, where only dry air is considered (i.e., the influence of water vapor is ignored), leads to $[75]$

$\frac{\kappa(\mathrm{z}-\mathrm{d})}{\Theta_{*}} \frac{\partial \hat{\Theta}}{\partial \mathrm{z}}=-\pi \kappa^{4 / 3}(-\zeta)^{-1 / 3}=0.32(-\zeta)^{-1 / 3}=(-30.5 \zeta)^{-1 / 3}$

It is obvious that formula (5.12) with $\Phi_{\mathrm{h}}(\zeta)=\Phi_{\mathrm{m}}{ }^{2}(\zeta)=(1-\gamma \zeta)^{-1 / 2}$ does not converge to the asymptotic solution (6.3) when $\zeta \ll 0$. Furthermore, the local similarity function (5.30) and the O'KEYPS formula (5.25) on the one hand and formula (6.3) on the other hand suggest that under free-convective conditions the $1 / 3$ power law, and, hence, formula (5.30) should be valid for both momentum and sensible heat.

\subsection{Variance Relationship}

To derive the variance relationship for free-convective conditions, we have to replace the vertical gradient of the potential temperature in the similarity hypotheses of subsection 6.1 by the variance term $\left\langle\Theta^{\prime^{2}}\right\rangle$. In doing so, we obtain: $F\left(\mathrm{z}-\mathrm{d}, \mathrm{H} /\left(\mathrm{c}_{\mathrm{p}, \mathrm{O}} \bar{\rho}\right), \mathrm{g} / \Theta_{\mathrm{m}},\left\langle\Theta^{\prime 2}\right\rangle\right)=0$. The dimensional $\pi$ invariants analysis gives then

$$
\pi_{1}=(\mathrm{z}-\mathrm{d})^{\frac{1}{3}}\left(\frac{\mathrm{H}}{\mathrm{c}_{\mathrm{p}, 0} \bar{\rho}}\right)^{-\frac{2}{3}}\left(\frac{\mathrm{g}}{\Theta_{\mathrm{m}}}\right)^{\frac{1}{3}}\left\langle\Theta^{\prime 2}\right\rangle^{\frac{1}{2}}
$$

or

$$
\left\langle\Theta^{\prime \prime 2}\right\rangle^{\frac{1}{2}}=\pi_{1}\left(\frac{\mathrm{H}}{\mathrm{c}_{\mathrm{p}, 0} \bar{\rho}}\right)^{\frac{2}{3}}\left(\frac{\mathrm{g}}{\Theta_{\mathrm{m}}}\right)^{-\frac{1}{3}}(\mathrm{z}-\mathrm{d})^{-\frac{1}{3}}
$$

Rearranging this equation in the sense of the MoninObukhov similarity hypothesis, where, as before, only dry air is considered (see subsection 6.1), leads to the asymptotic solution for free-convective conditions

$$
\frac{\sigma_{\Theta}}{\Theta_{*}}=\frac{\left\langle\Theta^{\prime \prime 2}\right\rangle^{1 / 2}}{\Theta_{*}}=\pi_{1} \kappa^{1 / 3} \zeta^{-1 / 3}
$$

Apparently, any empirical approach like formula (5.30) should be in agreement with the $\zeta^{-1 / 3}$ behavior under freeconvective conditions. In accord with the empirical results of Wyngaard et al. [103], Monji [104], and Tillman [105], the normalized standard deviation $\sigma_{\Theta} / \Theta_{*}$ shows a $\zeta^{-1 / 3}$ behavior for the entire unstable range.

According to formula (6.5), we obtain for the temperature variance

$$
\left\langle\Theta^{\prime \prime 2}\right\rangle=\pi_{1}^{2}\left(\frac{\mathrm{H}}{\mathrm{c}_{\mathrm{p}, 0} \bar{\rho}}\right)^{\frac{4}{3}}\left(\frac{\mathrm{g}}{\Theta_{\mathrm{m}}}\right)^{-\frac{2}{3}}(\mathrm{z}-\mathrm{d})^{-\frac{2}{3}}
$$

Dividing this equation by $(\mathrm{z}-\mathrm{d})^{2 / 3}$ yields then

$$
\mathrm{C}_{\Theta}{ }^{2}=\frac{\left\langle\Theta^{\prime \prime 2}\right\rangle}{(\mathrm{z}-\mathrm{d})^{\frac{2}{3}}}=\pi_{1}^{2}\left(\frac{\mathrm{H}}{\mathrm{c}_{\mathrm{p}, 0} \bar{\rho}}\right)^{\frac{4}{3}}\left(\frac{\mathrm{g}}{\Theta_{\mathrm{m}}}\right)^{-\frac{2}{3}}(\mathrm{z}-\mathrm{d})^{-\frac{4}{3}}
$$

where $\mathrm{C}_{\Theta}{ }^{2}$ is the structure parameter for free-convective conditions. Panofsky and Dutton [52] recommended $\pi_{1}^{2} \cong 2.5$ so that the $\pi$ number amounts to $\pi_{1} \cong 1.58$. Thus, the product $\pi_{1} \kappa^{1 / 3}$ that occurs in Eq. (6.6) amounts to $\pi_{1} \kappa^{1 / 3} \cong 1.16$, when $\kappa=0.4$ is adopted. This value is more than 20 per cent higher than that recommended by Wyngaard et al. [103].

\section{ASSESSING THE INTEGRAL SIMILARITY FUNCTIONS}

It is well known that gradients of horizontal wind speed, temperature and humidity cannot be measured because of the limited spatial resolution of available sensors. This means that the true flux-gradient relationships and, hence, the local similarity functions, which can also be considered as nondimensional gradients, are unsuitable for estimating the eddy fluxes of momentum, sensible heat and water vapor. Consequently, it is indispensable to relate these eddy fluxes, at least, to finite differences of horizontal wind speed, temperature, and humidity. This can be performed by integrating the 
non-dimensional gradients over the layer under study, where the constant flux assumptions (or approximations), as discussed in section 3 , are considered. This was already carried out in the case of the logarithmic wind profile for neutral stratification (see formula (2.20)). The results of such integrations are customarily denoted as (vertical) profile functions.

Results from direct measurements of eddy fluxes and corresponding vertical profiles of the mean values of wind speed, temperature, and humidity obtained from concurrent measurements can be used to derive local similarity functions. Note that for the purpose of evaluation of such local similarity functions, quite independent data sets of directly measured eddy fluxes and mean vertical profiles even obtained concurrently are required. Data sets from field campaigns not considered for deriving such local similarity functions clearly satisfy this requirement.

\subsection{Profile Relations and Integral Similarity Functions}

Integrating expression (5.2) for the non-dimensional wind shear, $\Phi_{\mathrm{m}}(\zeta)$, over the height interval $\left[\mathrm{z}_{\mathrm{r}}, \mathrm{z}_{\mathrm{R}}\right]$, where $z_{r}$ and $z_{R}$ are the lower and upper boundaries of the fully turbulent part of the ASL, respectively, yields

$$
\begin{aligned}
\mathrm{U}\left(\mathrm{z}_{\mathrm{R}}\right)-\mathrm{U}\left(\mathrm{z}_{\mathrm{r}}\right) & =\frac{\mathrm{u}_{*}}{\kappa} \int_{\mathrm{z}_{\mathrm{r}}}^{\mathrm{z}_{\mathrm{R}}} \frac{\Phi_{\mathrm{m}}((\mathrm{z}-\mathrm{d}) / \mathrm{L})}{\mathrm{z}-\mathrm{d}} \mathrm{dz} \\
& =\frac{\mathrm{u}_{*}}{\kappa} \int_{\mathrm{z}_{\mathrm{r}}}^{z_{\mathrm{R}}} \frac{1-1+\Phi_{\mathrm{m}}((\mathrm{z}-\mathrm{d}) / \mathrm{L})}{\mathrm{z}-\mathrm{d}} \mathrm{dz} \\
& =\frac{\mathrm{u}_{*}}{\kappa}\left(\int_{\mathrm{z}_{\mathrm{r}}}^{\mathrm{z}_{\mathrm{R}}} \frac{1}{\mathrm{z}-\mathrm{d}} \mathrm{dz}-\int_{\mathrm{z}_{\mathrm{r}}}^{\mathrm{z}_{\mathrm{R}}} \frac{1-\Phi_{\mathrm{m}}((\mathrm{z}-\mathrm{d}) / \mathrm{L})}{\mathrm{z}-\mathrm{d}} \mathrm{dz}\right) \\
& =\frac{\mathrm{u}_{*}}{\kappa}\left(\ln \frac{\mathrm{z}_{\mathrm{R}}-\mathrm{d}}{\mathrm{Z}_{\mathrm{r}}-\mathrm{d}}-\Psi_{\mathrm{m}}\left(\zeta_{\mathrm{R}}, \zeta_{\mathrm{r}}\right)\right)
\end{aligned}
$$

with

$\Psi_{\mathrm{m}}\left(\zeta_{\mathrm{R}}, \zeta_{\mathrm{r}}\right)=\int_{\mathrm{z}_{\mathrm{r}}}^{\mathrm{z}_{\mathrm{R}}} \frac{1-\Phi_{\mathrm{m}}((\mathrm{z}-\mathrm{d}) / \mathrm{L})}{\mathrm{z}-\mathrm{d}} \mathrm{dz}=\int_{\zeta_{\mathrm{r}}}^{\zeta_{\mathrm{R}}} \frac{1-\Phi_{\mathrm{m}}(\zeta)}{\zeta} \mathrm{d} \zeta$

that is called the integral similarity function for momentum.

Equation (7.1) was derived first by Panofsky [113] to obtain the so-called logarithmic wind profile if for neutral stratification $\Phi_{\mathrm{m}}(\zeta)$ approaches to unity leading to $\Psi_{\mathrm{m}}\left(\zeta_{\mathrm{R}}, \zeta_{\mathrm{r}}\right)=0$. The integral similarity function is clearly defined by Eq. (7.2), i.e., this definition is independent of the shape of $\Phi_{\mathrm{m}}(\zeta)$ as illustrated, for instance, by formulae (5.14) (5.20), and (5.25). 114]

Introducing formulae (5.14) into Eq. (7.2) yields [44,

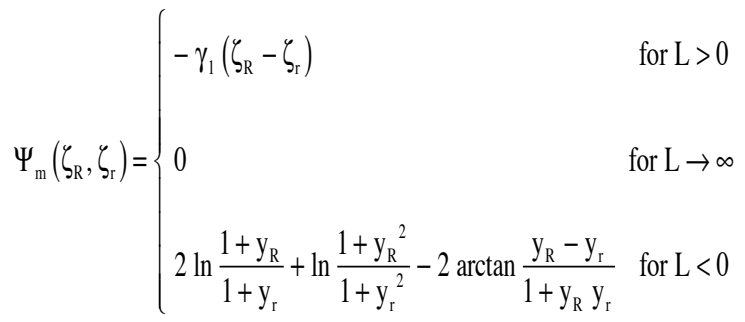

with $\mathrm{y}_{\mathrm{r}, \mathrm{R}}=\Phi_{\mathrm{m}}^{-1}\left(\zeta_{\mathrm{r}, \mathrm{R}}\right)=\left(1-\gamma_{2} \zeta_{\mathrm{r}, \mathrm{R}}\right)^{1 / 4}$, the reciprocal expressions of the local similarity functions in the unstable case at the two heights $z_{r}$ and $z_{R}$. Paulson's [115] solutions substantially agree with our solutions when $y_{r}$ approaches to unity while $\zeta_{\mathrm{r}} \rightarrow 0$. Introducing the conventional O'KEYPS formula (5.25) into Eq. (7.2) provides

$$
\left.\begin{array}{rl}
\Psi_{\mathrm{m}}\left(\zeta_{\mathrm{R}}, \zeta_{\mathrm{r}}\right)= & \Phi_{\mathrm{m}}\left(\zeta_{\mathrm{r}}\right)-\Phi_{\mathrm{m}}\left(\zeta_{\mathrm{R}}\right) \\
+2 \ln \frac{1+\Phi_{\mathrm{m}}\left(\zeta_{\mathrm{R}}\right)}{1+\Phi_{\mathrm{m}}\left(\zeta_{\mathrm{r}}\right)}+\ln \frac{1+\Phi_{\mathrm{m}}{ }^{2}\left(\zeta_{\mathrm{R}}\right)}{1+\Phi_{\mathrm{m}}{ }^{2}\left(\zeta_{\mathrm{r}}\right)} \\
+2 \arctan \frac{\Phi_{\mathrm{m}}\left(\zeta_{\mathrm{R}}\right)-\Phi_{\mathrm{m}}\left(\zeta_{\mathrm{r}}\right)}{1+\Phi_{\mathrm{m}}\left(\zeta_{\mathrm{R}}\right) \Phi_{\mathrm{m}}\left(\zeta_{\mathrm{r}}\right)} \\
-3 \ln \frac{\Phi_{\mathrm{m}}\left(\zeta_{\mathrm{R}}\right)}{\Phi_{\mathrm{m}}\left(\zeta_{\mathrm{r}}\right)}
\end{array}\right\} \text { for } \mathrm{L} \leq 0
$$

with $\Phi_{\mathrm{m}}\left(\zeta_{\mathrm{r}, \mathrm{R}}\right)$ provided by the O'KEYPS formula. Obviously, the O'KEYPS solution (7.4) is more bulky than that obtained with the Businger-Dyer-Pandolfo relationship. This might be the reason why the latter is more widely used, even though the former has a stronger physical background. For $\zeta_{\mathrm{r}} \rightarrow 0$, we have $\Phi_{\mathrm{m}}\left(\zeta_{\mathrm{r}}\right) \rightarrow 1$, and, hence, formula (7.4) approaches to Paulson's [115] O'KEYPS-solution.

Introducing formula (5.30) into Eq. (7.2) provides

$\Psi_{\mathrm{m}}\left(\zeta_{\mathrm{R}}, \zeta_{\mathrm{r}}\right)=\frac{3}{2} \ln \frac{\mathrm{y}_{\mathrm{R}}^{2}+\mathrm{y}_{\mathrm{R}}+1}{\mathrm{y}_{\mathrm{r}}^{2}+\mathrm{y}_{\mathrm{r}}+1}-\sqrt{3} \arctan \frac{\mathrm{x}_{\mathrm{R}}-\mathrm{x}_{\mathrm{r}}}{1+\mathrm{x}_{\mathrm{R}} \mathrm{x}_{\mathrm{r}}}$

for $\mathrm{L} \leq 0$

with $\mathrm{y}_{\mathrm{r}, \mathrm{R}}=\Phi_{\mathrm{m}}^{-1}\left(\zeta_{\mathrm{r}, \mathrm{R}}\right)=\left(1-\gamma_{11} \zeta_{\mathrm{r}, \mathrm{R}}\right)^{1 / 3}$, the reciprocal expressions of the local similarity functions in the unstable case at the two heights $z_{r}$ and $z_{R}$, and $\mathrm{x}_{\mathrm{r}, \mathrm{R}}=\left(2 \mathrm{y}_{\mathrm{r}, \mathrm{R}}+1\right) / \sqrt{3}$. It approaches to Lettau's [116] solution when $\zeta_{\mathrm{r}}$ tends to zero. Equations (7.3) to (7.5) are illustrated in Fig. (8). As expected, formulae (7.4) and (7.5) only differ hardly when $\zeta$ tends to Obukhov numbers much smaller than zero which represent free-convective conditions. Simultaneously, the difference between Eq. (7.3) and the other two formulae grows continuously. 


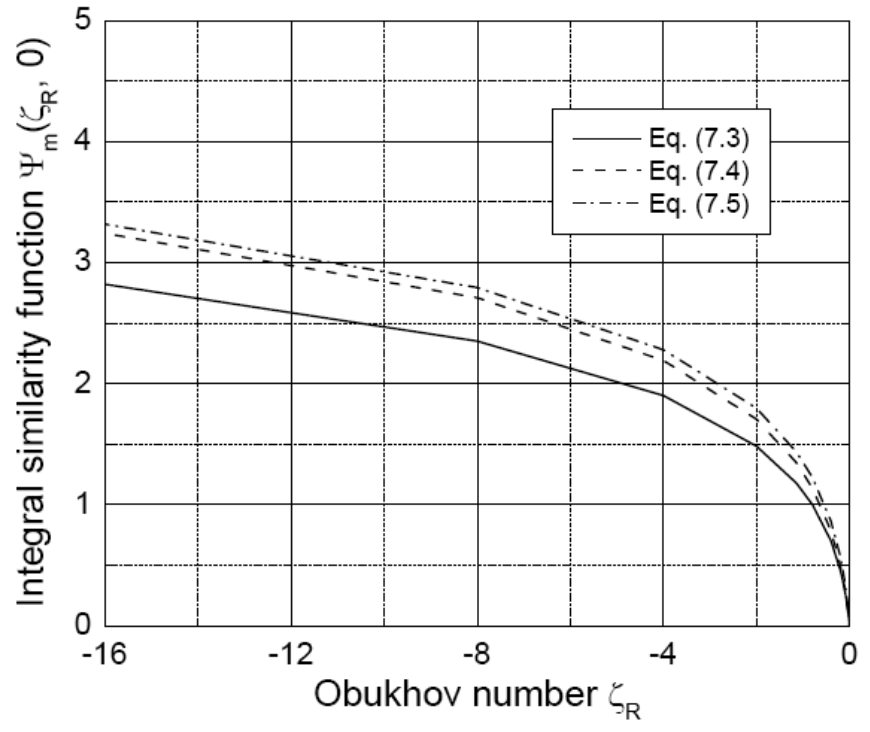

Fig. (8). The integral similarity function $\Psi_{m}\left(\zeta_{R}, 0\right)$ for momentum obtained from formulae (7.3) to (7.5) and plotted against the Obukhov number $\zeta_{\mathrm{R}}=\mathrm{z}_{\mathrm{R}} / \mathrm{L}$.

Equation (5.5) for the non-dimensional temperature gradient, $\Phi_{\mathrm{h}}(\zeta)$, can be integrated over the height interval $\left[\mathrm{z}_{\mathrm{r}}, \mathrm{z}_{\mathrm{R}}\right]$ in a similar manner like in the case of momentum (see formulae (7.1) and (7.2)). One obtains

$\hat{\Theta}\left(z_{\mathrm{R}}\right)-\hat{\Theta}\left(z_{\mathrm{r}}\right)=\frac{\Theta_{*}}{\kappa}\left(\ln \frac{\mathrm{z}_{\mathrm{R}}-\mathrm{d}}{\mathrm{z}_{\mathrm{r}}-\mathrm{d}}-\Psi_{\mathrm{h}}\left(\zeta_{\mathrm{R}}, \zeta_{\mathrm{r}}\right)\right)$

with

$\Psi_{\mathrm{h}}\left(\zeta_{\mathrm{R}}, \zeta_{\mathrm{r}}\right)=\int_{\zeta_{\mathrm{r}}}^{\zeta_{\mathrm{R}}} \frac{1-\Phi_{\mathrm{h}}(\zeta)}{\zeta} \mathrm{d} \zeta$

that is called the integral similarity function for sensible heat. As in the case of momentum, this definition is independent of the shape of the respective local similarity function.

Introducing formulae (5.15) into the definition (7.7) yields [44, 114]

$\Psi_{h}\left(\zeta_{R}, \zeta_{r}\right)= \begin{cases}\Psi_{m}\left(\zeta_{R}, \zeta_{r}\right) & \text { for } L>0 \\ 0 & \text { for } L \rightarrow \infty \\ 2 \ln \frac{1+y_{R}^{2}}{1+y_{r}^{2}} & \text { for } L<0\end{cases}$

Paulson's [115] solutions substantially agree with those of Eq. (7.8) when $\mathrm{y}_{\mathrm{r}} \rightarrow 1$ while $\zeta_{\mathrm{r}} \rightarrow 0$.

If we assume that $\Phi_{\mathrm{h}}(\zeta)=\Phi_{\mathrm{m}}{ }^{2}(\zeta) \Leftrightarrow \mathrm{Ri}=\zeta$ holds for the entire range of unstable stratification and that the local similarity function for momentum is given by Eq. (5.30), we will obtain
$\Psi_{\mathrm{h}}\left(\zeta_{\mathrm{R}}, \zeta_{\mathrm{r}}\right)=\frac{3}{2} \ln \frac{\mathrm{y}_{\mathrm{R}}{ }^{2}+\mathrm{y}_{\mathrm{R}}+1}{\mathrm{y}_{\mathrm{r}}{ }^{2}+\mathrm{y}_{\mathrm{r}}+1}+\sqrt{3} \arctan \frac{\mathrm{x}_{\mathrm{R}}-\mathrm{x}_{\mathrm{r}}}{1+\mathrm{x}_{\mathrm{R}} \mathrm{x}_{\mathrm{r}}}$

for $\mathrm{L} \leq 0$

Formulae (7.8) and (7.9) are illustrated in Fig. (9). As shown, Eq. (7.9) provides appreciably larger values of $\Psi_{\mathrm{h}}\left(\zeta_{\mathrm{R}}, 0\right)$ than formula (7.8).

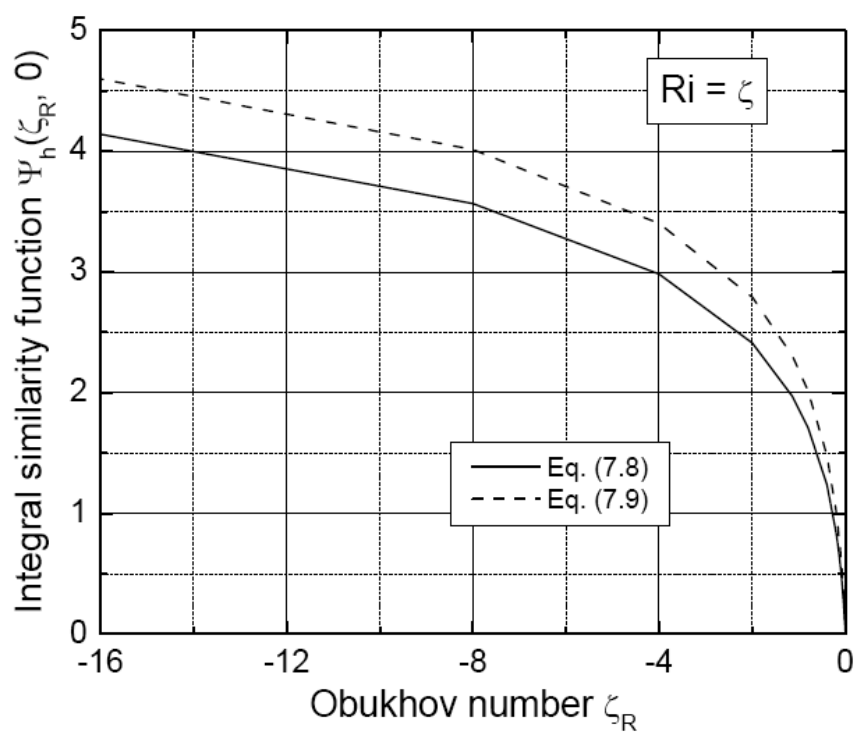

Fig. (9). The integral similarity function $\Psi_{h}\left(\zeta_{R}, 0\right)$ for sensible heat obtained from Eqs. (7.8) and (7.9) and plotted against the Obukhov number $\zeta_{\mathrm{R}}=\mathrm{z}_{\mathrm{R}} / \mathrm{L}$.

Equation (5.10) for the non-dimensional humidity gradient, $\Phi_{\mathrm{q}}(\zeta)$, can be integrated over the height interval $\left[\mathrm{z}_{\mathrm{r}}, \mathrm{z}_{\mathrm{R}}\right]$ in a similar manner like in the case of momentum. One obtains

$\hat{\mathrm{q}}\left(\mathrm{z}_{\mathrm{R}}\right)-\hat{\mathrm{q}}\left(\mathrm{z}_{\mathrm{r}}\right)=\frac{\mathrm{q}_{*}}{\kappa}\left(\ln \frac{\mathrm{z}_{\mathrm{R}}-\mathrm{d}}{\mathrm{z}_{\mathrm{r}}-\mathrm{d}}-\Psi_{\mathrm{q}}\left(\zeta_{\mathrm{R}}, \zeta_{\mathrm{r}}\right)\right)$

with

$\Psi_{\mathrm{q}}\left(\zeta_{\mathrm{R}}, \zeta_{\mathrm{r}}\right)=\int_{\zeta_{\mathrm{r}}}^{\zeta_{\mathrm{R}}} \frac{1-\Phi_{\mathrm{q}}(\zeta)}{\zeta} \mathrm{d} \zeta$

that is called the integral similarity function for water vapor. Assuming $\Phi_{\mathrm{q}}(\zeta)=\Phi_{\mathrm{h}}(\zeta)$, as recommended by Webb [55] and Dyer [117] for stable stratification as well as Dyer and Hicks [48] as well as Dyer and Bradley [57] for unstable stratification, one obtains the same expression like in the case of the sensible heat transfer. Note that long-lived trace species can be dealt with in a similar manner.

Obviously, the local similarity functions, $\Phi_{\mathrm{m}}(\zeta)$, $\Phi_{\mathrm{h}}(\zeta)$, and $\Phi_{\mathrm{q}}(\zeta)$, impose as universal laws for describing the surface (constant flux) layer turbulence [59, 118]. Reviews of empirical findings can be found in $[21,75,117$, 119]. The equation sets (7.1) to (7.3), (7.6) to (7.8), (7.10), and (7.11) may be used to determine the scaling quantities 
$\mathrm{u}_{*}, \Theta_{*}$, and $\mathrm{q}_{*}$, and, hence the corresponding fluxes $\tau, \mathrm{H}$, and $\mathrm{W}$, as well as the roughness length, $\mathrm{z}_{0}$ (for $\mathrm{z}_{\mathrm{r}}=\mathrm{z}_{0}+\mathrm{d}$ ), and the zero-plane displacement, $\mathrm{d}$, from vertical profile measurements of wind speed, temperature and humidity (e.g., [43, 44, 59, 114, 120-122]).

Integrating Eq. (6.2) over the interval $\left[\mathrm{z}_{\mathrm{r}}, \mathrm{z}_{\mathrm{R}}\right]$ leads to the Priestley-Estoque relation [123]

$$
\left\{\begin{array}{l}
\mathrm{H} \\
\mathrm{Q}
\end{array}\right\}=-\bar{\rho} \Gamma_{\mathrm{h}}\left\{\begin{array}{cc}
\mathrm{c}_{\mathrm{p}, 0} & \left(\hat{\Theta}_{\mathrm{R}}-\hat{\Theta}_{\mathrm{r}}\right) \\
\hat{\mathrm{q}}_{\mathrm{R}}-\hat{\mathrm{q}}_{\mathrm{r}}
\end{array}\right\}
$$

with

$$
\begin{aligned}
& \Gamma_{\mathrm{h}}=\frac{\mathrm{C}_{1}}{3\left\{\left(\mathrm{z}_{\mathrm{r}}-\mathrm{d}\right)^{-\frac{1}{3}}-\left(\mathrm{z}_{\mathrm{R}}-\mathrm{d}\right)^{-\frac{1}{3}}\right\}} \\
& \left(-\frac{\frac{g}{\Theta_{m}}\left(\hat{\Theta}_{R}-\hat{\Theta}_{r}\right)}{3\left\{\left(z_{r}-d\right)^{-\frac{1}{3}}-\left(z_{R}-d\right)^{-\frac{1}{3}}\right\}}\right)^{\frac{1}{2}}
\end{aligned}
$$

where, as in the case of forced-convective conditions, $\mathrm{Sc}_{\mathrm{t}, \mathrm{i}} \cong \mathrm{Pr}_{\mathrm{t}}$ is assumed to determine the vertical transfer of water vapor also. The constant $\mathrm{C}_{1} \cong 0.90$ can be derived from Priestley's constant. Note that this expression is strongly sensitive to the choice of $z_{r}$.

As under free-convective conditions Monin-Obukhov scaling fails, Estoque [123] proposed to calculate the friction velocity in the same manner like the vertical eddy fluxes of sensible heat and water vapor. Thus, one obtains

$\mathrm{u}_{*}^{2}=\Gamma_{\mathrm{u}}\left(\hat{\mathrm{u}}_{\mathrm{R}}-\hat{\mathrm{u}}_{\mathrm{r}}\right)$

with $\Gamma_{\mathrm{u}}=\Gamma_{\mathrm{h}}$. Unfortunately, Estoque's [123] postulate is not scrutinized, and other relations might be more adequate. By assuming that $\Phi_{\mathrm{h}}(\zeta)=\Phi_{\mathrm{m}}{ }^{2}(\zeta)$ holds for the entire range of unstable stratification, Herbert and Kramm [124], for instance, derived:

$$
\begin{aligned}
& \Gamma_{\mathrm{u}}=\frac{\mathrm{C}_{2}}{6\left\{\left(\mathrm{z}_{\mathrm{r}}-\mathrm{d}\right)^{-\frac{1}{6}}-\left(\mathrm{z}_{\mathrm{R}}-\mathrm{d}\right)^{-\frac{1}{6}}\right\}} \\
& \left(\frac{\hat{\mathrm{u}}_{\mathrm{R}}-\hat{\mathrm{u}}_{\mathrm{r}}}{6\left\{\left(\mathrm{z}_{\mathrm{r}}-\mathrm{d}\right)^{-\frac{1}{6}}-\left(\mathrm{z}_{\mathrm{R}}-\mathrm{d}\right)^{-\frac{1}{6}}\right\}} \frac{\frac{\mathrm{g}}{\Theta_{\mathrm{m}}}\left(\hat{\Theta}_{\mathrm{r}}-\hat{\Theta}_{\mathrm{R}}\right)}{3\left\{\left(\mathrm{z}_{\mathrm{r}}-\mathrm{d}\right)^{-\frac{1}{3}}-\left(\mathrm{z}_{\mathrm{R}}-\mathrm{d}\right)^{-\frac{1}{3}}\right\}}\right)^{\frac{1}{3}}
\end{aligned}
$$

It is strongly sensitive to the choice of $\mathrm{z}_{\mathrm{r}}$, too.

\subsection{Computed Eddy Fluxes Versus Measured Eddy Fluxes}

As mentioned before, the equation sets (7.1) to (7.3), (7.6) to (7.8), (7.10), and (7.11) may be used to determine the scaling quantities $\mathrm{u}_{*}, \Theta_{*}$, and $\mathrm{q}_{*}$, and, hence the corresponding fluxes $\tau, H$, and $W$, as well as the roughness length, $z_{0}$ (for $z_{r}=z_{0}+d$ ), and the zero-plane displacement, $d$, from vertical profile measurements of wind speed, temperature and humidity.

Results derived with the method developed by Kramm and Herbert [44, 114] are illustrated in Figs. (10-24). This method is described in the Appendix. Figs. $(\mathbf{1 0}, \mathbf{1 1})$ show examples of vertical profile of wind speed, potential temperature and specific humidity obtained from observed data collected during the GREIV I 1974 experiment. This experiment took place over a flat site covered with winter barley (about $0.25 \mathrm{~m}$ high) and rape (0.50 to $0.75 \mathrm{~m}$ high), near Meppen/Emsland in northern Germany in April 1974. Data sets of wind speed, dry- and wet-bulb temperatures (simultaneously measured 30-min averages) were obtained by groups from the Universities of Kiel (April 20 - 24, 1974) and Munich (April 24 - 27, 1974). The observations of the Kiel group were performed at heights of $0.5,1.26,3.18$ and $8 \mathrm{~m}$ and those of the Munich group at heights of $0.5,1,2,4,8$ and $16 \mathrm{~m}$ above ground. Both groups used Lambrecht cup anemometers and Frankenberger-type psychrometers. In addition, the 30-min run data of friction velocity and the vertical eddy fluxes of sensible and latent heat directly determined by the University of Mainz group using ultrasonic anemometer-thermometer (Kaijo-Denki 3D) and Lyman alpha hygrometer (self-developed) measurements were used for comparison. These fast-response measurements of the Mainz group were carried out in the vicinity of the instrumented mast of the Kiel group at a height of $2 \mathrm{~m}$ above ground. Note that the GREIV I 1974 data, fully documented in [18], has not been used in deriving the universal functions on which the integral similarity functions presented here are based.

If $\mathrm{z}_{0}+\mathrm{d}>\mathrm{z}_{1}$ or more than 40 iteration steps had been required to determine $z_{0}$ and $d$, the profile data sets were generally rejected by the computer program. As mentioned before, such criteria occurred for profile data collected under very stable conditions with low wind speeds and temperature inversions or in the transition phase between lapse and inversion conditions, if stationary states required by the constant flux concept must not be expected [43, 44].

Of 109 profile data sets of the Kiel group, 77 data sets were suitable for computation. From the 110 data sets of the Munich group, 73 an 69 data sets, respectively, were appropriate for computation, based on vertical profiles which included 5 and 6 levels (with and without the $16 \mathrm{~m}$ level of observation). 
GREIV I, Meppen, April 21, 1974, 12:45 LT
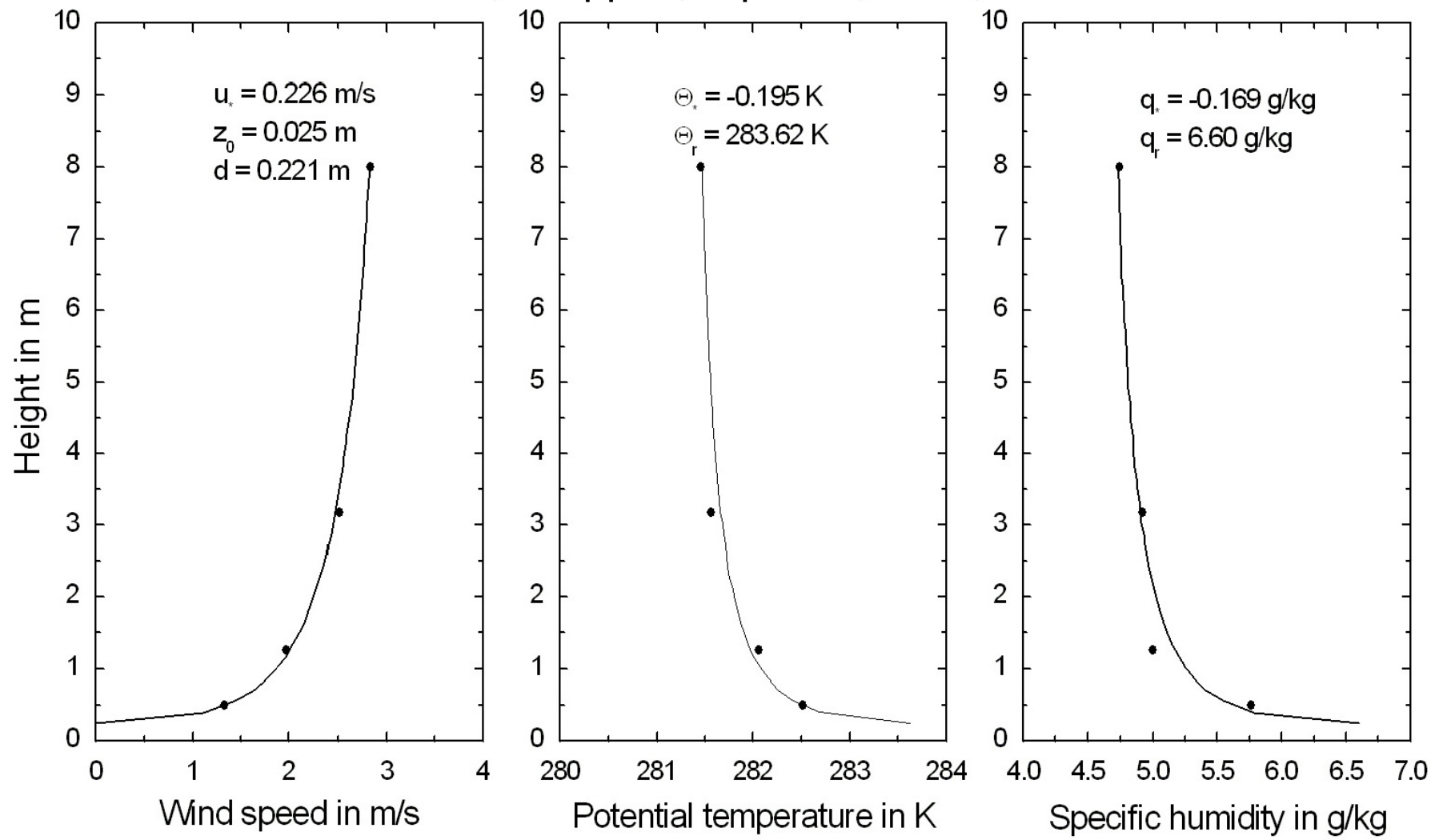

Fig. (10). Typical vertical profile of wind speed, potential temperature and specific humidity calculated for unstable stratification. The dots represent the observed values and the solid lines the calculated profiles.

GREIV I, Meppen, April 23, 1974, 17:45 LT
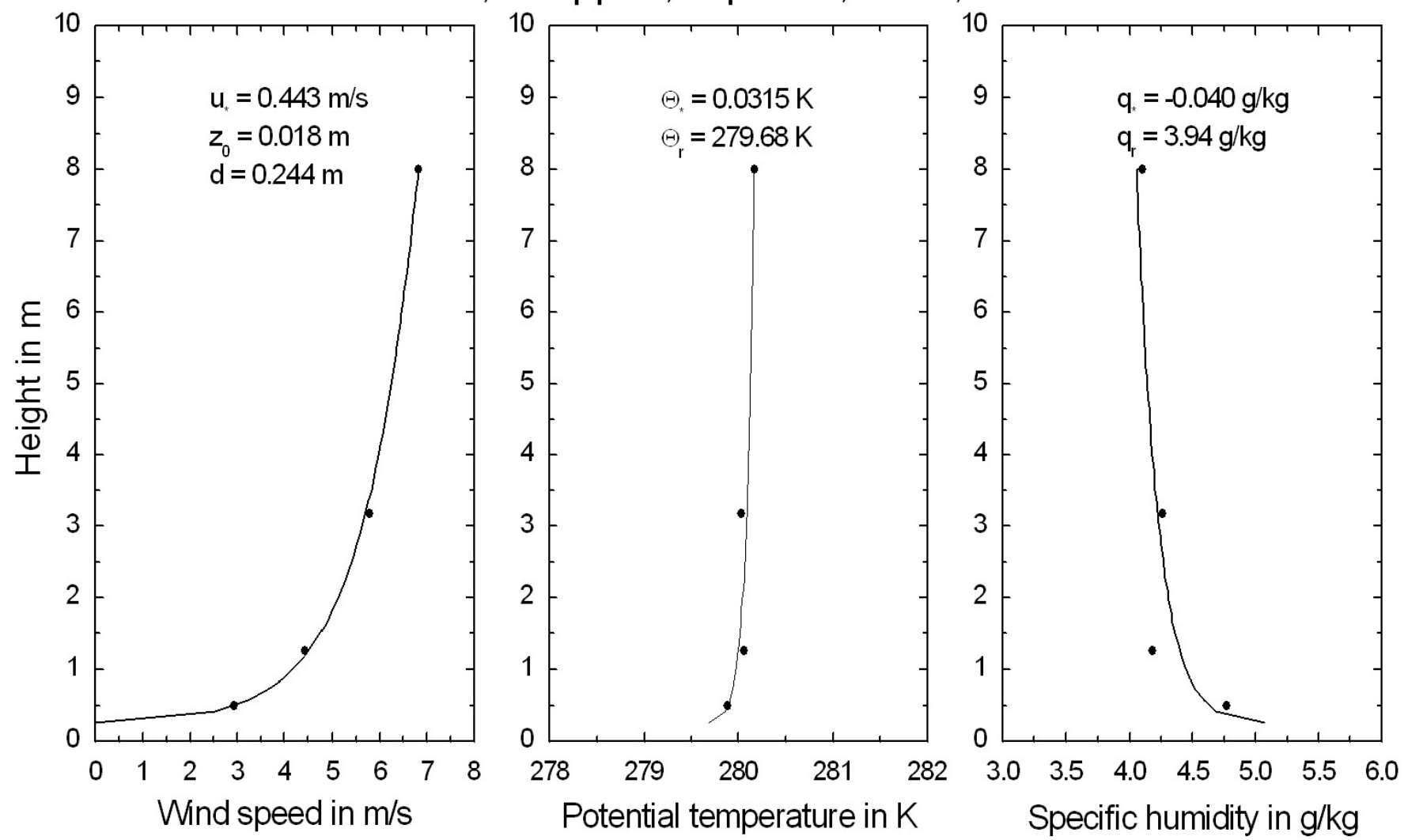

Fig. (11). As in Fig. (10), but for stable stratification. 


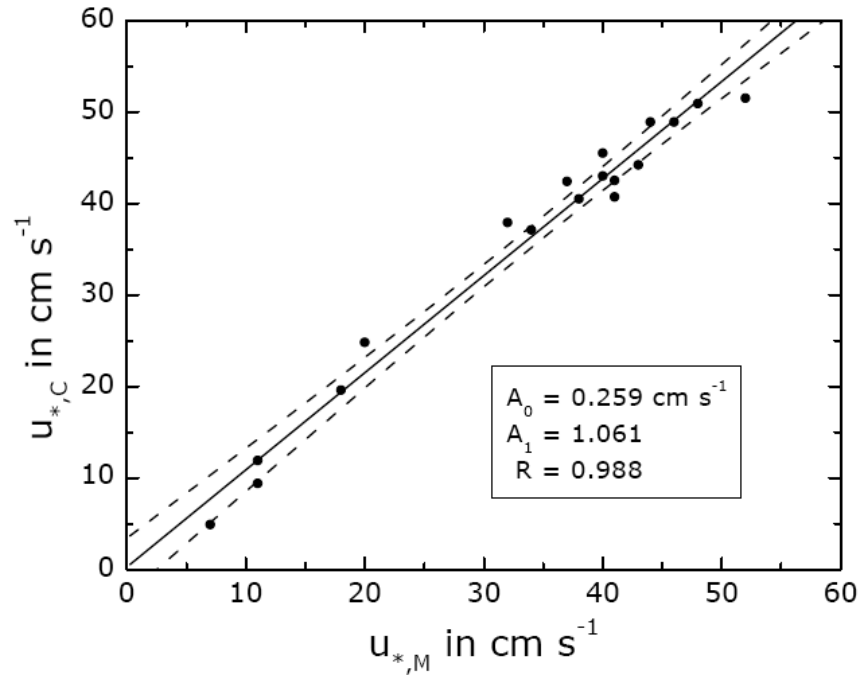

Fig. (12). Calculated friction velocity (index C) versus directly determined friction velocity (index $M$ ). $A_{0}$ and $A_{1}$ are the coefficients of the least-squares fit (solid line), and $\mathrm{R}$ is the correlation coefficient. The dashed lines represent the $95 \%$ confidence band (with reference to [44]).

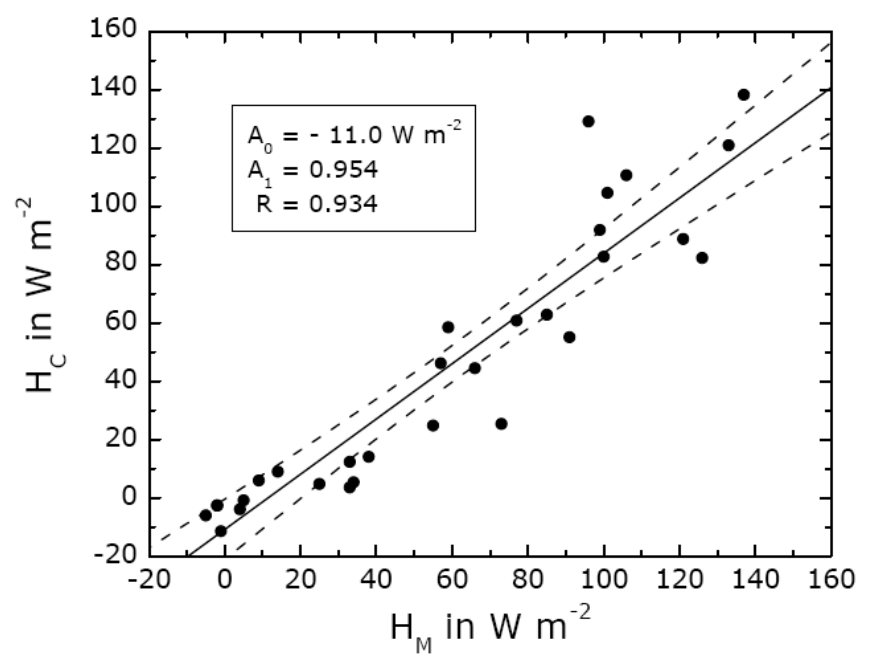

Fig. (13). As in Fig. (12), but for the vertical component of the sensible heat flux.

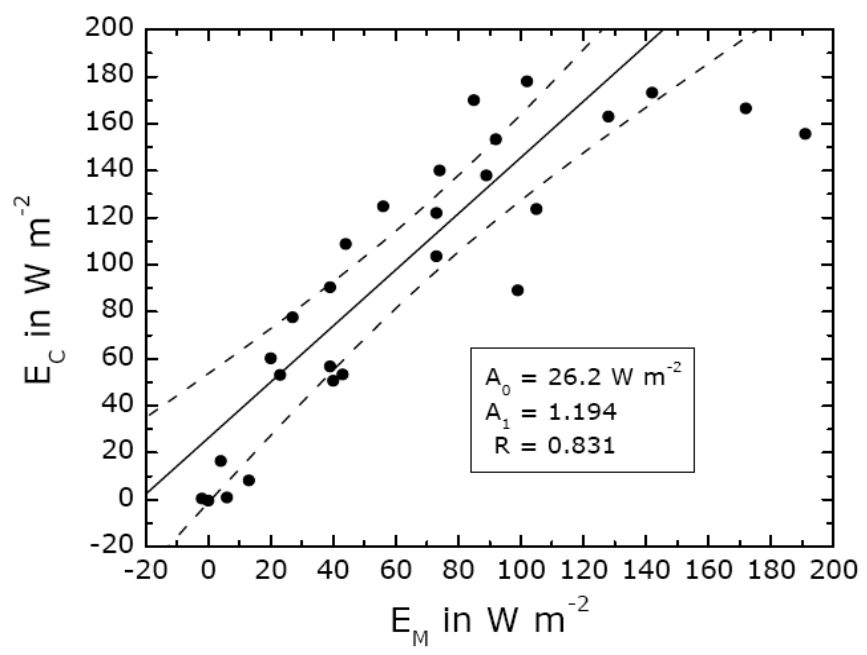

Fig. (14). As in Fig. (12), but for the vertical component of the latent heat flux.

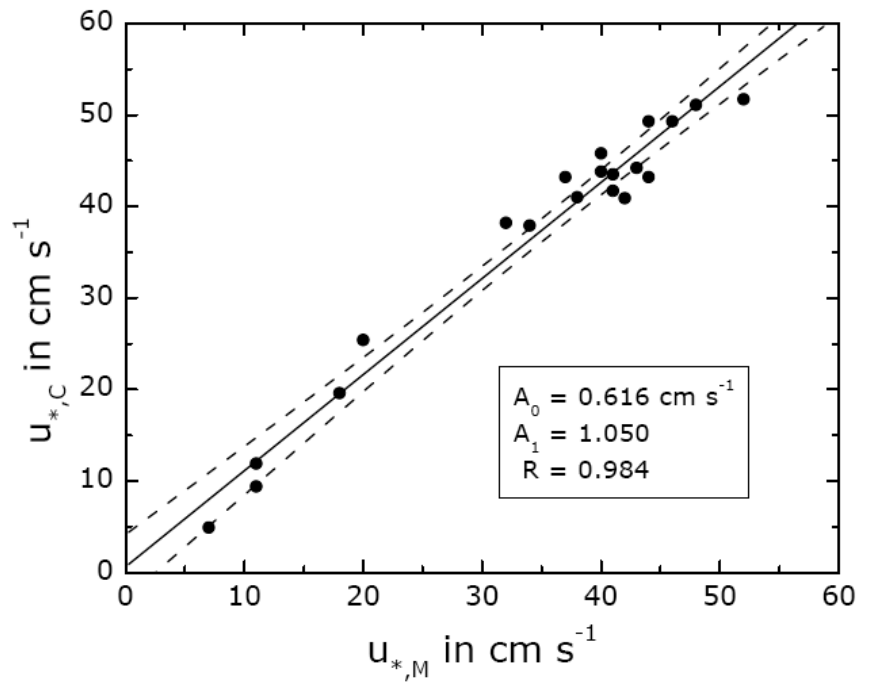

Fig. (15). As in Fig. (12), but Eqs. (7.3) and (7.8) are replaced by Eqs. (7.5) and (7.9), respectively, when unstable stratification is considered.

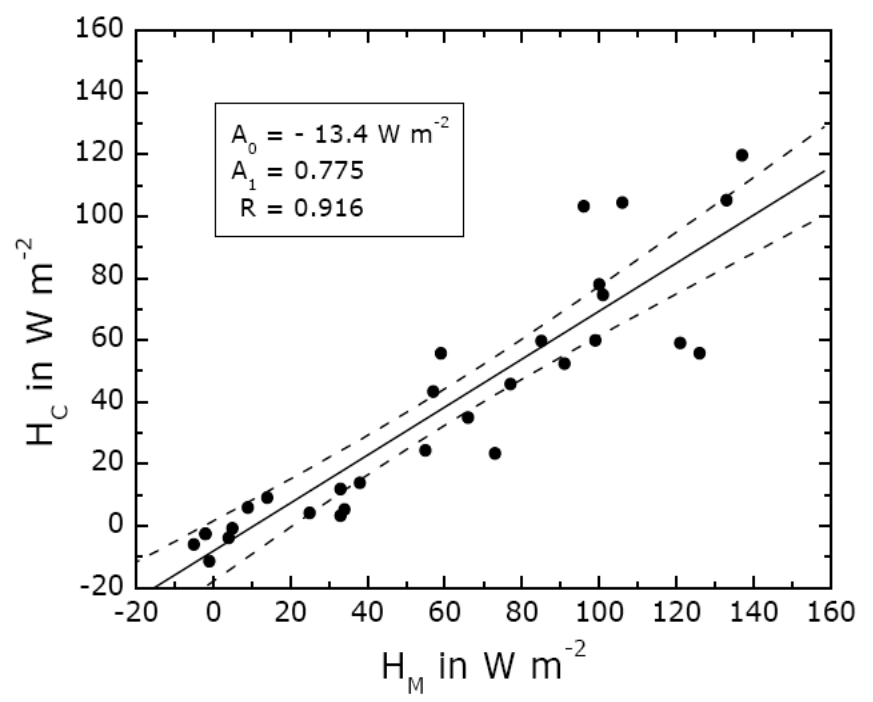

Fig. (16). As in Fig. (15), but for the vertical component of the sensible heat flux.

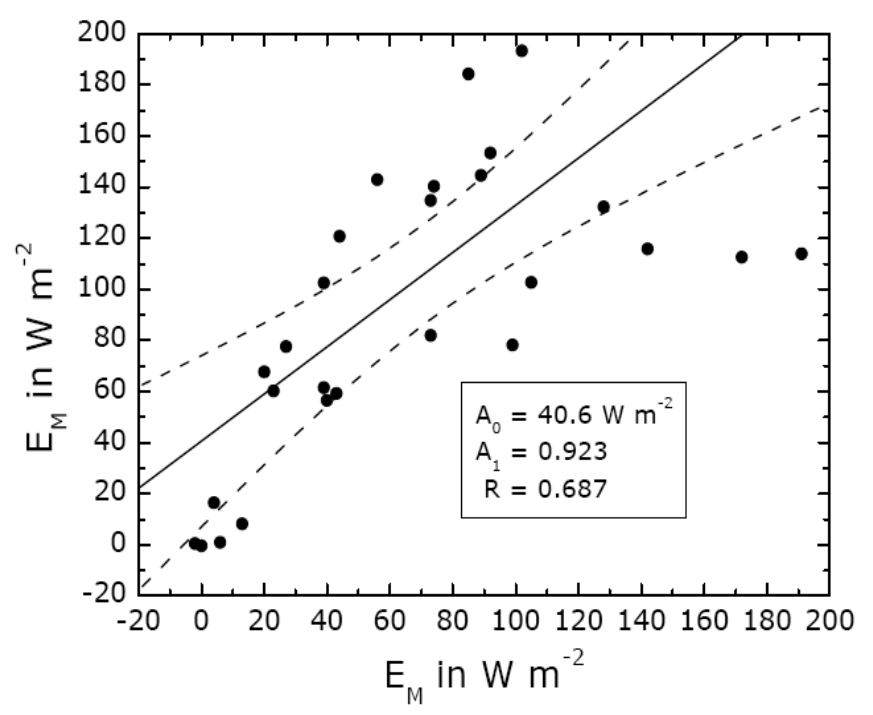

Fig. (17). As in Fig. (15), but for the vertical component of the latent heat flux. 


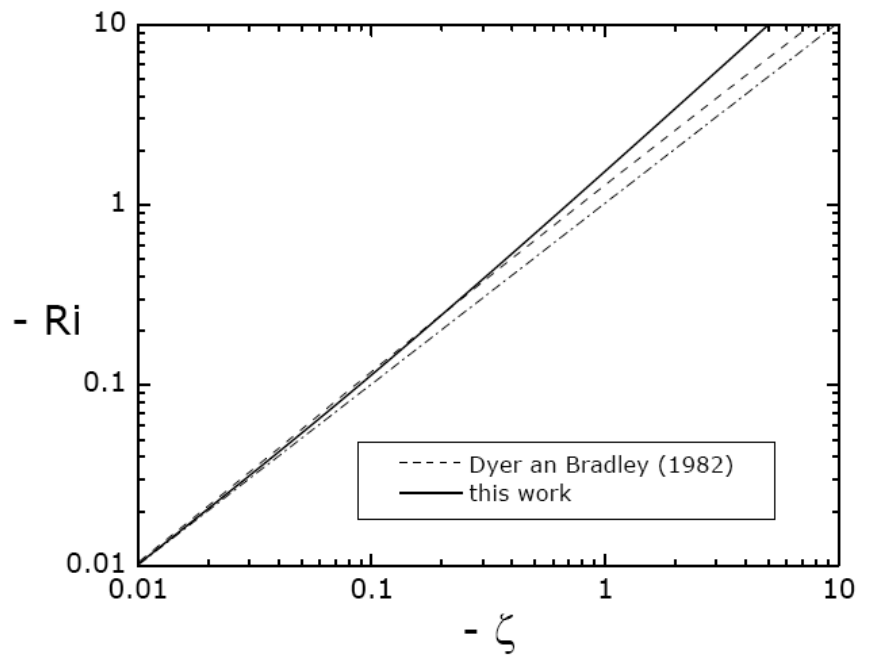

Fig. (18). Gradient Richardson number, Ri, versus Obukhov number, $\zeta$. The one-to-one line represents $\Phi_{\mathrm{h}}(\zeta)=\Phi_{\mathrm{m}}{ }^{2}(\zeta)$ that leads to $\mathrm{Ri}=\zeta$ (see formula (5.17)). For the reference in this figure see [57].

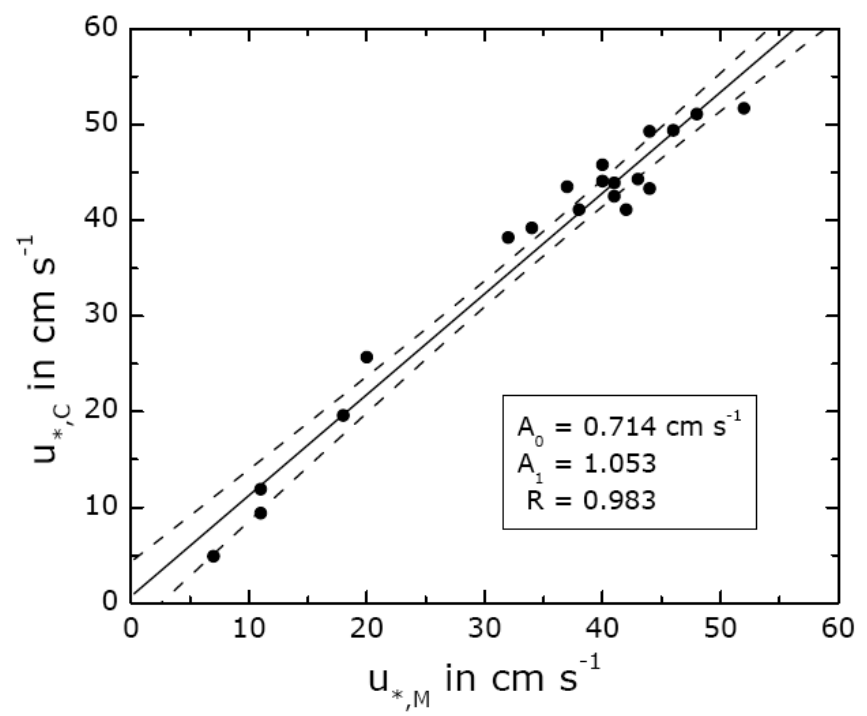

Fig. (19). As in Fig. (12), but Eq. (7.3) is replaced by Eq. (7.5) when unstable stratification is considered.

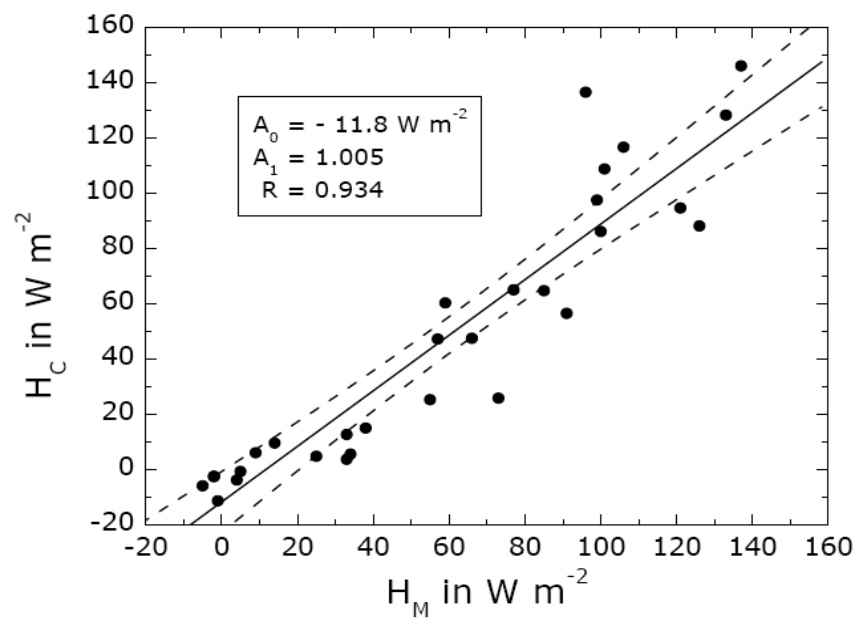

Fig. (20). As in Fig. (19), but for the vertical component of the sensible heat flux.

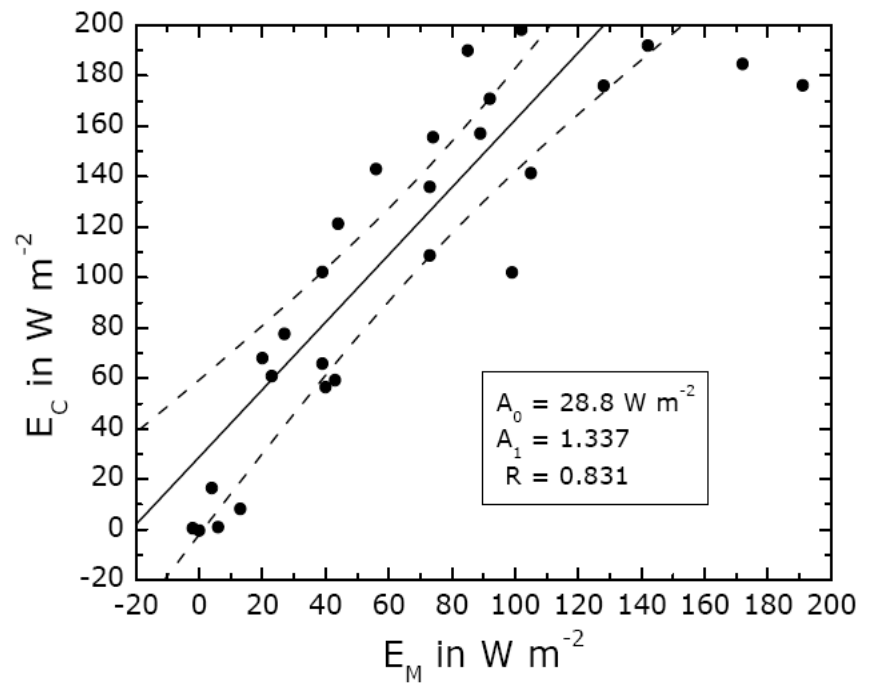

Fig. (21). As in Fig. (19), but for the vertical component of the latent heat flux.

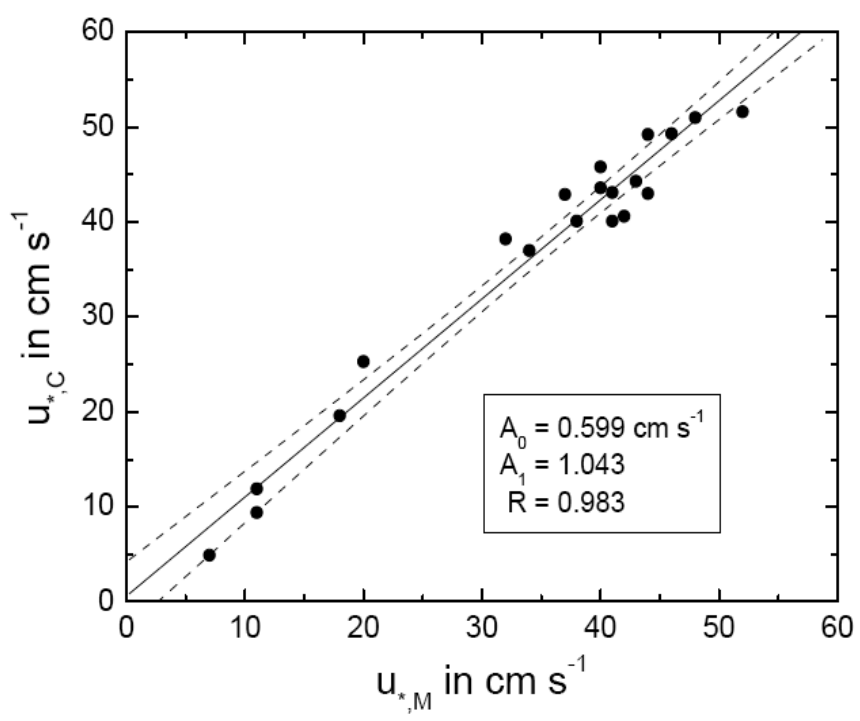

Fig. (22). As in Fig. (12), but Eqs. (7.3) and (7.8) are replaced by Eq. (7.5) when unstable stratification is considered.

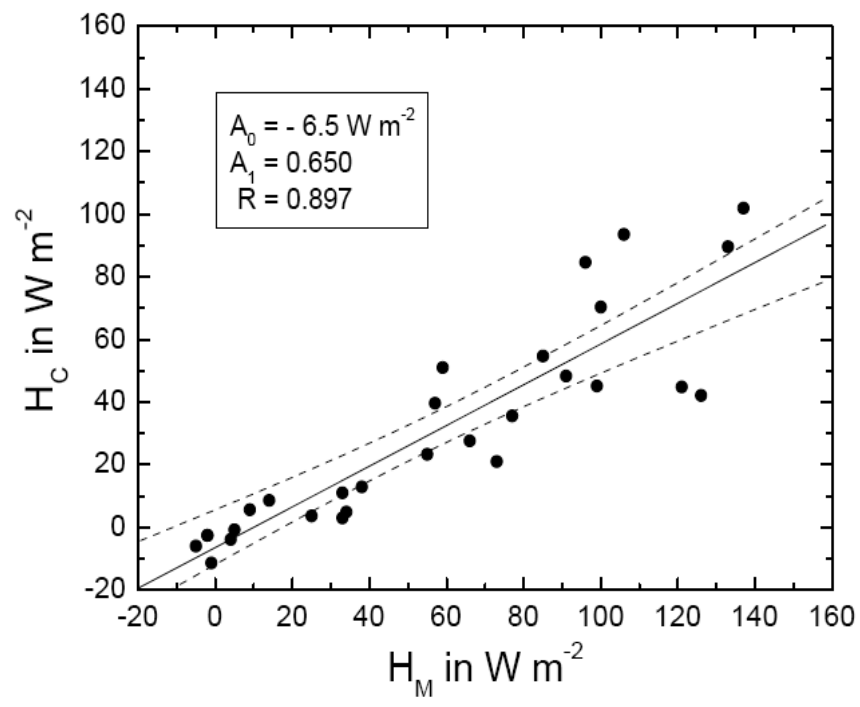

Fig. (23). As in Fig. (22), but for the vertical component of the sensible heat flux. 


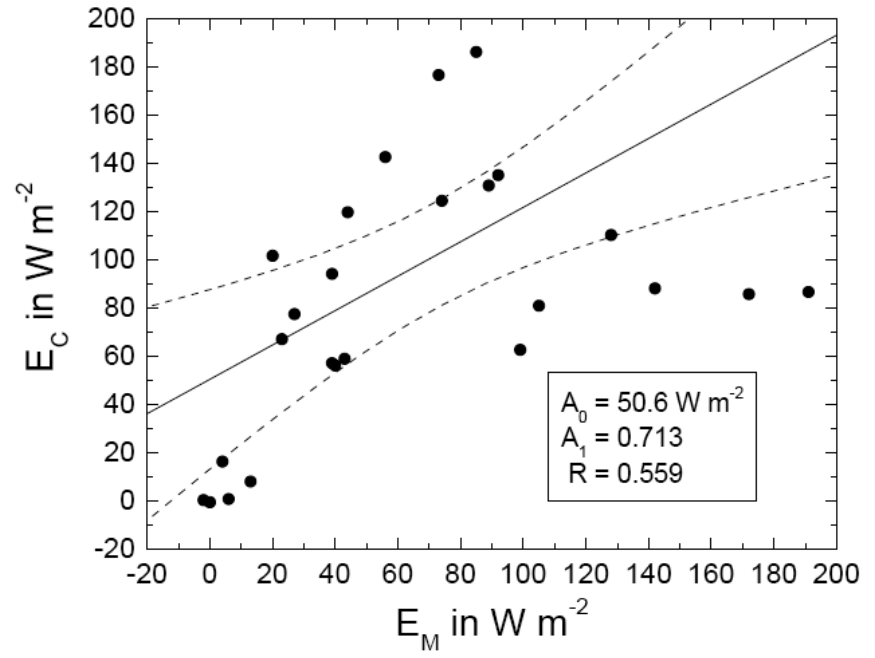

Fig. (24). As in Fig. (22), but for the vertical component of the latent heat flux.

The two instances of different thermal stratification illustrated in Figs. $(\mathbf{1 0}, \mathbf{1 1})$ show that the calculated least squares fits coincide very well with the values observed. General agreement also exist between the eddy flux values of momentum (characterized by $\mathbf{u}_{*}$ ), sensible and latent heat calculated with formulae (7.1) to (7.3), (7.6) to (7.8), (7.10), and (7.11) and those directly measured (see Figs. 12-14). It is called the reference case. Note that the sampling intervals of the vertical profile measurements and the direct measurements of eddy fluxes differ by about $15 \mathrm{~min}$.

As illustrated in Fig. (8), the results provided by formulae (7.4) and (7.5) only differ hardly when $\zeta$ tends to large negative Obukhov numbers that represent free-convective conditions. Since Eq. (7.4) is more bulky than Eq. (7.5), it seems to be reasonable to replace formula (7.3), that does not match free-convective conditions, by formula (7.5) and, with respect to $\Phi_{\mathrm{h}}(\zeta)=\Phi_{\mathrm{m}}{ }^{2}(\zeta) \Leftrightarrow \mathrm{Ri}=\zeta$, Eq. (7.8) by Eq. (7.9) when unstable stratification of air is considered. Compared with the reference case, this combination of formulae provides eddy flux results that more disagree with those directly determined (see Figs. 15-17). In comparison with the reference case, a notably better agreement especially for the eddy flux of sensible heat can be achieved when for unstable stratification only formula (7.3) is replaced by formula (7.5). Consequently, $\mathrm{Ri}=\zeta$ is not longer valid. As illustrated in Fig. (18), this combination leads to $|\operatorname{Ri}| \geq|\zeta|$. The eddy flux results obtained with this combination of equations are shown in Figs. (19-21).

As mentioned before, the local similarity function (5.30) as found, for instance, by Carl et al. [76] as well as Gavrilov and Petrov [77] for unstable stratification and the conventional O'KEYPS formula (5.25) on the one hand and Eq. (6.3) on the other hand suggest that under free-convective conditions the one-thirds law, and, hence, Eq. (7.5) should be valid for both momentum and sensible heat. However, using formula (7.5) for both momentum and sensible heat (and water vapor) only yields rather insufficient results for the vertical eddy fluxes of sensible and latent heat (see Figs. 22-
24). Consequently, Estoque's [123] suggestion that $\Gamma_{\mathrm{u}}=\Gamma_{\mathrm{h}}$ has to be considered with care.

To assess the impact of a value for the von Kármán constant not simultaneously derived with the local similarity functions of momentum, sensible heat and matter, we consider principles of Gaussian error propagation. The deviation, for instance, of the friction velocity owing to the deviation of the von Kármán constant from its original value can be expressed by

$\delta u_{*}= \pm \frac{\partial u_{*}}{\partial \kappa} \delta \kappa$

with

$\frac{\partial \mathrm{u}_{*}}{\partial \kappa}=\frac{\mathrm{u}_{*}}{\kappa}\left(1+\frac{\kappa}{\ln \frac{\mathrm{z}_{\mathrm{R}}-\mathrm{d}}{\mathrm{z}_{\mathrm{r}}-\mathrm{d}}-\Psi_{\mathrm{m}}\left(\zeta_{\mathrm{R}}, \zeta_{\mathrm{r}}\right)} \frac{\partial \Psi_{\mathrm{m}}\left(\zeta_{\mathrm{R}}, \zeta_{\mathrm{r}}\right)}{\partial \kappa}\right)$

The derivative $\partial \Psi_{\mathrm{m}}\left(\zeta_{\mathrm{R}}, \zeta_{\mathrm{r}}\right) / \partial \kappa$ depends on the integral similarity function used (see subsection 7.1). For neutral conditions we simply obtain $\partial \mathrm{u}_{*} / \partial \kappa=\mathrm{u}_{*} / \kappa$ and in a further step for the relative deviation of the friction velocity

$\frac{\delta u_{*}}{u_{*}}= \pm \frac{\delta \kappa}{\kappa}$

Thus, if $\kappa=0.35$ is the value simultaneously derived with the local similarity functions for momentum and sensible heat by Businger et al. [46], but the "true" value of $\kappa=0.387$ derived by Andreas et al. [26] is used, the relative deviation of $\mathrm{u}_{*}$ will amount to $10.6 \%$.

\section{FINAL REMARKS AND CONCLUSIONS}

In this paper, the basic idea of the dimensional $\pi$ invariants analysis was outlined in a mathematically generalized formalism to illustrate the task of this powerful method and how it can be applied to deduce a variety of reasonable solutions by a formalized procedure of nondimensionalization. Various instances were represented that are relevant to the turbulent transfer across the ASL and the prevailing structure of ASL turbulence, in particular, (a) Monin-Obukhov scaling for forced-convective conditions, and (b) Prandtl-Obukhov-Priestley scaling for freeconvective condition.

It was shown that in the case of only one $\pi$ number the derived equations are really applicable if this $\pi$ number can be determined empirically or/and theoretically. Such a $\pi$ number can be considered as a non-dimensional universal constant. This is true in the instances (a) of neutral stratification, when in the case of momentum transfer a logarithmic wind profile prevails and the $\pi$ number is equal to the reciprocal of the von Kármán constant, and (b) of the PrandtlObukhov-Priestley scaling for free-convective condition, for which flux-gradient relationships and the temperature variance relationship were derived. Furthermore, it was shown that in the case of Monin-Obukhov scaling generally two $\pi$ numbers 
occur. In such kind of scaling local similarity functions depending on the Obukhov number, $\zeta$, can be established that may be considered as universal functions within the framework of the various similarity hypotheses. Unfortunately, these universal functions cannot be quantified by the dimensional $\pi$-invariants analysis so that their determination by empirical or/and theoretical work is indispensable. This is true for forced-convective conditions for which local similarity functions of the flux-gradient relationships for the transfer of momentum, sensible heat and water vapor as well as local similarity functions of the energy dissipation and the normalized variances of wind components, potential temperature and specific humidity were derived empirically by several authors during the last five decades. However, especially for strongly stable stratification further research is urgently required because it seems that in this stability range Monin-Obukhov similarity is incomplete. Prandtl-Obukhov-Priestley similarity may be adequate for free-convective conditions, but a sufficient degree of evidence is indispensable. Even though the value of the von Kármán constant, $\kappa=0.387 \pm 0.003$, derived by Andreas et al. [26], is based on the largest, most comprehensive atmospheric data set ever used, this value has to be confirmed for wide ranges of non-neutral stratification.

The eddy flux results provided by the different parameterization schemes substantiate that great uncertainty exists in the prediction of the eddy fluxes of sensible and latent heat. With respect to climate predictions especially for high latitude regions like the Arctic, this uncertainty seems to be too large. Thus, more direct eddy flux measurements are necessary for improving such parameterization schemes and for minimizing their uncertainty.

The great uncertainty, inherent in the universal functions on which the integral similarity functions assessed before are based, is not only reflected by the gradient-Richardson number, but also in the turbulent Prandtl number, $\mathrm{Pr}_{\mathrm{t}}$, the turbulent Schmidt number, $\mathrm{Sc}_{\mathrm{t}, \mathrm{q}}$, and the turbulent LewisSemenov number, $\mathrm{LS}_{\mathrm{t}, \mathrm{q}}$ both for water vapor. Lumley and Panofsky [42] already pointed out that the question of the relative size of $\mathrm{K}_{\mathrm{h}}$ and $\mathrm{K}_{\mathrm{m}}$ has still not been answered satisfactorily. We have to recognize that, even forty years later, their statement is further valid. Hitherto, values of the turbulent Prandtl number, the turbulent Schmidt number and the turbulent Lewis-Semenov number determined for the ASL are still scarce. As these integral similarity functions are frequently used in state-of-the-art weather forecast or climate prediction models, there is an urgent need to reduce this uncertainty by gaining more empirical material either to verify such universal functions or to derive improved universal functions.

\section{APPENDIX: LEAST SQUARES TECHNIQUES}

In this section least squares techniques are presented that are applied to estimate the ASL parameters mentioned above from vertical profiles of wind speed, temperature and humidity.
In order to be able to establish the best approximations for the roughness length, $\mathrm{z}_{0}$, and the zero-plane displacement, $\mathrm{d}$, as well as the relevant reference values $\Theta_{r}$ and $q_{r}$, the following expressions have to be minimized [44]:

$|\rho(\mathbf{x})|^{2}=\sum_{\mathrm{i}=1}^{\mathrm{N}}\left(\mathrm{U}_{\mathrm{M}, \mathrm{i}}-\mathrm{U}_{\mathrm{i}}\left(\mathbf{x}^{\mathrm{T}}\right)\right)^{2}=\min$

and

$\left|\eta\left(\chi_{\mathrm{r}}\right)\right|^{2}=\sum_{\mathrm{i}=1}^{\mathrm{N}}\left(\hat{\chi}_{\mathrm{M}, \mathrm{i}}-\hat{\chi}_{\mathrm{i}}\left(\chi_{\mathrm{r}}\right)\right)^{2}=\min$

with

$\mathbf{x}^{\mathrm{T}}=\left(\mathrm{z}_{0}, \mathrm{~d}\right)$

and

$\chi= \begin{cases}\Theta, & \text { potential temperature } \\ \mathrm{q}, & \text { specific humidity }\end{cases}$

Here, $N \geq 3$ is the number of observation levels, $U_{M, i}$ is the mean wind speed observed at the height $z_{i} \geq z_{1} \quad z_{1}$ is the lowest observation level), $\hat{\Theta}_{\mathrm{M}, \mathrm{i}}$ and $\hat{\mathrm{q}}_{\mathrm{M}, \mathrm{i}}$ are the corresponding mean values of the potential temperature and the specific humidity, respectively.

Appropriate values for the scaling parameters $\mathrm{u} *, \Theta *$ and $\mathrm{q} *$ are provided by the arithmetic averages

$\left\{\begin{array}{c}\mathrm{u}_{*} \\ \Theta_{*} \\ \mathrm{q}_{*}\end{array}\right\}=\frac{1}{\mathrm{~N}-1} \sum_{\mathrm{j}=1}^{\mathrm{N}-1}\left\{\begin{array}{c}\mathrm{u}_{*, \mathrm{j}} \\ \Theta_{*, \mathrm{j}} \\ \mathrm{q}_{*, \mathrm{j}}\end{array}\right\}$

The quantities $u_{*, j}, \Theta_{*, j}$, and $q_{*, j}$ are calculated from the vertical profile data collected at the adjacent observation levels $\mathrm{z}_{\mathrm{i}}$ and $\mathrm{z}_{\mathrm{i}+1}$.

In the case of stable stratification it can be done as follows: Introducing a common local stability function for momentum, sensible heat, and water vapor, $\Phi_{\mathrm{q}}(\zeta)=\Phi_{\mathrm{h}}(\zeta)=\Phi_{\mathrm{m}}(\zeta)$ with $\Phi_{\mathrm{m}}(\zeta)=1+\beta \zeta$, into Eqs. (7.2), (7.7), and (7.11) simply provides:

$$
\begin{aligned}
& \Psi_{\mathrm{q}}\left(\zeta_{\mathrm{i}+1}, \zeta_{\mathrm{i}}\right)=\Psi_{\mathrm{h}}\left(\zeta_{\mathrm{i}+1}, \zeta_{\mathrm{i}}\right)=\Psi_{\mathrm{m}}\left(\zeta_{\mathrm{i}+1}, \zeta_{\mathrm{i}}\right) \\
& =-\beta\left(\zeta_{\mathrm{i}+1}-\zeta_{\mathrm{i}}\right)
\end{aligned}
$$

where $z_{R}$ and $z_{r}$ were replaced by $z_{i+1}$ and $z_{i}$, respectively. Thus, combining Eqs. (7.1) to (7.6) and Eq. (7.10) yields then [24, 44]

$$
\left\{\begin{array}{l}
u_{*, j} \\
\Theta_{*, j} \\
q_{*, j}
\end{array}\right\}=C_{j}\left\{\begin{array}{l}
U\left(z_{i+1}\right)-U\left(z_{i}\right) \\
\hat{\Theta}\left(z_{i+1}\right)-\hat{\Theta}\left(z_{i}\right) \\
\hat{q}\left(z_{i+1}\right)-\hat{q}\left(z_{i}\right)
\end{array}\right\}
$$




$$
C_{j}=\frac{\kappa\left(1-\beta R_{B, j}\right)}{\ln \frac{z_{i+1}-d}{z_{i}-d}}
$$

where $\mathrm{Ri}_{\mathrm{B}}$ is the so-called bulk-Richardson number for the layer $\left[z_{i}, z_{i+1}\right]$ given by (e.g., $\left.[44,75]\right)$

$\operatorname{Ri}_{B, j}=\frac{g}{\Theta_{m}} \frac{\hat{\Theta}\left(z_{i+1}\right)-\hat{\Theta}\left(z_{i}\right)+0.61 \Theta_{m}\left(\hat{q}\left(z_{i+1}\right)-\hat{q}\left(z_{i}\right)\right)}{\left(U\left(z_{i+1}\right)-U\left(z_{i}\right)\right)^{2}}\left(z_{i+1}-z_{i}\right)$

In contrast to the exact solution for stable stratification, the scaling parameters $\mathrm{u}_{*, \mathrm{j}}, \Theta_{*, \mathrm{j}}$, and $\mathrm{q}_{*, \mathrm{j}}$ and the related quantities have to be determined by a method of successive approximations. Following iteration scheme may be used [44]:

$\mathrm{u}_{*, \mathrm{j}}{ }^{(\mathrm{i}+1)}=\mathrm{C}_{\mathrm{m}, \mathrm{j}}{ }^{(\mathrm{i})}\left(\mathrm{U}\left(\mathrm{z}_{\mathrm{i}+1}\right)-\mathrm{U}\left(\mathrm{z}_{\mathrm{i}}\right)\right)$

$$
\begin{aligned}
& \left\{\begin{array}{c}
\Theta_{*, j}{ }^{(i+1)} \\
\mathrm{q}_{*, j}^{(i+1)}
\end{array}\right\}=C_{h, j}{ }^{(i)}\left\{\begin{array}{c}
\hat{\Theta}\left(z_{i+1}\right)-\hat{\Theta}\left(z_{i}\right) \\
\hat{q}\left(z_{i+1}\right)-\hat{q}\left(z_{i}\right)
\end{array}\right\} \\
& C_{m, j}^{(i)}=\frac{\kappa}{\ln \frac{z_{i+1}-d}{z_{i}-d}-\Psi_{m}^{(i)}\left(\zeta_{i+1}, \zeta_{i}\right)}
\end{aligned}
$$

$$
\mathrm{C}_{\mathrm{h}, \mathrm{j}}{ }^{(\mathrm{i})}=\frac{\kappa}{\ln \frac{\mathrm{z}_{\mathrm{i}+1}-\mathrm{d}}{\mathrm{z}_{\mathrm{i}}-\mathrm{d}}-\Psi_{\mathrm{h}}^{(\mathrm{i})}\left(\zeta_{\mathrm{i}+1}, \zeta_{\mathrm{i}}\right)}
$$

and

$$
\mathrm{L}^{(\mathrm{i})}=\frac{\left(\mathrm{u}_{*}^{(\mathrm{i})}\right)^{2}}{\kappa \frac{\mathrm{g}}{\Theta_{\mathrm{m}}}\left(\Theta_{*}^{(\mathrm{i})}+0.61 \Theta_{\mathrm{m}} \mathrm{q}_{*}^{(\mathrm{i})}\right)}
$$

The integral similarity functions $\Psi_{\mathrm{m}}^{(\mathrm{i})}\left(\zeta_{\mathrm{i}+1}, \zeta_{\mathrm{i}}\right)$ and $\Psi_{\mathrm{h}}{ }^{(\mathrm{i})}\left(\zeta_{\mathrm{i}+1}, \zeta_{\mathrm{i}}\right)$ may be calculated using either formulae (7.3) and (7.8), formulae (7.5) and (7.9), or formulae (7.5) and (7.8), i.e.,

$$
\begin{aligned}
& \Psi_{\mathrm{m}, \mathrm{j}}^{(\mathrm{i})}\left(\zeta_{\mathrm{i}+1}, \zeta_{\mathrm{i}}\right)=2 \ln \frac{1+\mathrm{y}_{\mathrm{i}+1}^{(\mathrm{i})}}{1+\mathrm{y}_{\mathrm{i}}^{(\mathrm{i})}} \\
& +\ln \frac{1+\left(\mathrm{y}_{\mathrm{i}+1}{ }^{(\mathrm{i})}\right)^{2}}{1+\left(\mathrm{y}_{\mathrm{i}}^{(\mathrm{i})}\right)^{2}}-2 \arctan \frac{\mathrm{y}_{\mathrm{i}+1}{ }^{(\mathrm{i})}-\mathrm{y}_{\mathrm{i}}^{(\mathrm{i})}}{1+\mathrm{y}_{\mathrm{i}+1}^{(\mathrm{i})} \mathrm{y}_{\mathrm{i}}^{(\mathrm{i})}} \\
& \Psi_{\mathrm{h}, \mathrm{j}}^{(\mathrm{i})}\left(\zeta_{\mathrm{i}+1}, \zeta_{\mathrm{i}}\right)=2 \ln \frac{1+\left(\mathrm{y}_{\mathrm{i}+1}^{\left({ }^{(i)}\right.}\right)^{2}}{1+\left(\mathrm{y}_{\mathrm{i}}^{(\mathrm{i})}\right)^{2}} \\
& \mathrm{y}_{\mathrm{i}}^{(\mathrm{i})}=\left(1-\frac{\gamma_{2}}{\mathrm{~L}^{(\mathrm{i})}}\left(\mathrm{z}_{\mathrm{i}}-\mathrm{d}\right)\right)^{\frac{1}{4}}
\end{aligned}
$$

$$
\mathrm{y}_{\mathrm{i}+1}^{(\mathrm{i})}=\left(1-\frac{\gamma_{2}}{\mathrm{~L}^{(\mathrm{i})}}\left(\mathrm{z}_{\mathrm{i}+1}-\mathrm{d}\right)\right)^{\frac{1}{4}}
$$

or

$$
\begin{aligned}
& \Psi_{\mathrm{m}, \mathrm{j}}^{(\mathrm{i})}\left(\zeta_{\mathrm{i}+1}, \zeta_{\mathrm{i}}\right)=\frac{3}{2} \ln \frac{\left(\mathrm{y}_{\mathrm{i}+1}{ }^{(\mathrm{i})}\right)^{2}+\mathrm{y}_{\mathrm{i}+1}{ }^{(\mathrm{i})}+1}{\left(\mathrm{y}_{\mathrm{i}}^{(\mathrm{i})}\right)^{2}+\mathrm{y}_{\mathrm{i}}^{(\mathrm{i})}+1} \\
& -\sqrt{3} \arctan \frac{\mathrm{x}_{\mathrm{i}+1}{ }^{(\mathrm{i})}-\mathrm{x}_{\mathrm{i}}^{(\mathrm{i})}}{1+\mathrm{x}_{\mathrm{i}+1}{ }^{(\mathrm{i})} \mathrm{x}_{\mathrm{i}}^{(\mathrm{i})}}
\end{aligned}
$$

$\mathrm{x}_{\mathrm{i}}^{(\mathrm{i})}=\frac{2 \mathrm{y}_{\mathrm{i}}^{(\mathrm{i})}+1}{\sqrt{3}}$

and

$\mathrm{x}_{\mathrm{i}+1}{ }^{(\mathrm{i})}=\frac{2 \mathrm{y}_{\mathrm{i}+1}^{(\mathrm{i})}+1}{\sqrt{3}}$

From the minimum condition (A2) one obtains the optimum reference values $\Theta_{\mathrm{r}}$ and $\mathrm{q}_{\mathrm{r}}$ as follows

$$
\left\{\begin{array}{c}
\Theta_{\mathrm{r}} \\
\mathrm{q}_{\mathrm{r}}
\end{array}\right\}=\frac{1}{\mathrm{~N}}\left[\sum_{\mathrm{i}=1}^{\mathrm{N}}\left\{\begin{array}{c}
\hat{\Theta}_{\mathrm{M}, \mathrm{i}} \\
\hat{\mathrm{q}}_{\mathrm{M}, \mathrm{i}}
\end{array}\right\}-\frac{1}{\kappa}\left\{\begin{array}{c}
\Theta_{*} \\
\mathrm{q}_{*}
\end{array}\right\} \sum_{\mathrm{i}=1}^{\mathrm{N}}\left(\ln \frac{\mathrm{z}_{\mathrm{i}}-\mathrm{d}}{\mathrm{z}_{0}}-\Psi_{\mathrm{h}}\left(\zeta_{\mathrm{i}}, \zeta_{\mathrm{r}}\right)\right)\right]
$$

The nonlinear least squares equation (A1) can only be solved by a method of successive approximation. This procedure can be derived from the approximation of the nonlinear least squares formula by series of linear least squares equations, i.e., if $\mathbf{x}$ is an approximation for the optimum solution, then the optimum solution

$$
\mathbf{x}^{*}=\mathbf{x}+\left(\operatorname{Df}(\mathbf{x})^{\mathrm{T}} \cdot \operatorname{Df}(\mathbf{x})\right)^{-1} \cdot \operatorname{Df}(\mathbf{x})^{\mathrm{T}} \cdot \rho(\mathbf{x})
$$

of the linear least squares expression

$$
\min |\rho(\mathbf{x})-\operatorname{Df}(\mathbf{x}) \cdot(\mathbf{x} *-\mathbf{x})|^{2}
$$

is, in general, a better approximation of the nonlinear least squares formula than $\mathbf{x}$ expressed by $|\rho(\mathbf{x} *)|^{2}<|\rho(\mathbf{x})|^{2}$ $[44,125]$. The quantity $\operatorname{Df}(\mathbf{x})$ is the Jacobian given by 


$$
\operatorname{Df}(\mathbf{x})=\left\{\begin{array}{cc}
\frac{\partial \mathrm{U}_{1}}{\partial \mathrm{z}_{0}} & \frac{\partial \mathrm{U}_{1}}{\partial \mathrm{d}} \\
\cdots & \cdots \\
\frac{\partial \mathrm{U}_{\mathrm{N}}}{\partial \mathrm{z}_{0}} & \frac{\partial \mathrm{U}_{\mathrm{N}}}{\partial \mathrm{d}}
\end{array}\right\}
$$

and $\operatorname{Df}(\mathbf{x})^{\mathrm{T}}$ is its transpose. The elements of the Jacobian are given by

$$
\frac{\partial \mathrm{U}_{\mathrm{i}}}{\partial \mathrm{z}_{0}}=-\frac{\mathrm{u}_{*}}{\kappa \mathrm{z}_{0}} \Phi_{\mathrm{m}}\left(\zeta_{\mathrm{r}}\right)+\frac{1}{\kappa}\left(\ln \frac{\mathrm{z}_{\mathrm{i}}-\mathrm{d}}{\mathrm{z}_{0}}-\Psi_{\mathrm{m}}\left(\zeta_{\mathrm{i}}, \zeta_{\mathrm{r}}\right)\right) \frac{\partial \mathrm{u}_{*}}{\partial \mathrm{z}_{0}}
$$

and

$$
\frac{\partial \mathrm{U}_{\mathrm{i}}}{\partial \mathrm{d}}=-\frac{\mathrm{u}_{*}}{\kappa\left(\mathrm{z}_{\mathrm{i}}-\mathrm{d}\right)} \Phi_{\mathrm{m}}\left(\zeta_{\mathrm{i}}\right)+\frac{1}{\kappa}\left(\ln \frac{\mathrm{z}_{\mathrm{i}}-\mathrm{d}}{\mathrm{z}_{0}}-\Psi_{\mathrm{m}}\left(\zeta_{\mathrm{i}}, \zeta_{\mathrm{r}}\right)\right) \frac{\partial \mathrm{u}_{*}}{\partial \mathrm{d}}(
$$

The derivations of $u_{*}$ with respect to $z_{0}$, and $d$, respectively, can be approximated by

$$
\frac{\partial \mathrm{u}_{*}}{\partial \mathrm{z}_{0}} \cong 0
$$

and

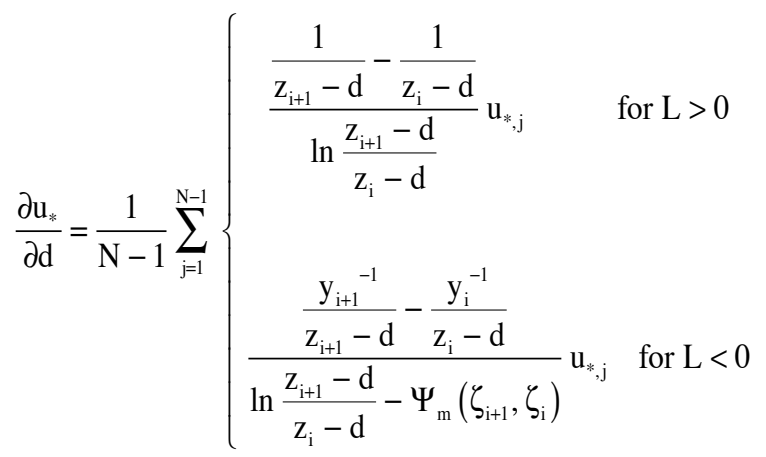

The iteration procedure may be started with the conditions of a neutrally stratified ASL for which $\mathrm{L}(1) \rightarrow \infty$. Thus, $\Psi_{\mathrm{m}}^{(1)}\left(\zeta_{\mathrm{i}+1}, \zeta_{\mathrm{i}}\right)$ and $\Psi_{\mathrm{h}}^{(1)}\left(\zeta_{\mathrm{i}+1}, \zeta_{\mathrm{i}}\right)$ are equal to zero. With these first approximations we may obtain the second approximations, and so on. At the beginning, the roughness length and the zero-plane-displacement have to fulfill the conditions: $\mathrm{z}_{0}^{(1)}>0$ and $\mathrm{d}^{(1)}<\mathrm{z}_{1}$ The iteration procedure will be stopped if after the $\mathrm{k}^{\text {th }}$ iteration step the scaling parameters are computed with an accuracy of

$$
\begin{gathered}
\left|\mathbf{u}_{*}^{(\mathrm{k}+1)}-\mathrm{u}_{*}{ }^{(\mathrm{k})}\right|<10^{-4} \mathrm{~m} \mathrm{~s}^{-1}, \\
\left|\Theta_{*}^{\left({ }^{(k+1)}\right.}-\Theta_{*}^{(\mathrm{k})}\right|<10^{-6} \mathrm{~K}
\end{gathered}
$$

and

$$
\left|\mathrm{q}_{*}{ }^{(\mathrm{k}+1)}-\mathrm{q}_{*}{ }^{(\mathrm{k})}\right|<10^{-7}
$$

that may be considered as sufficient. Usually, three or four iteration steps are required [63].

\section{ACKNOWLEDGEMENTS}

We are grateful to Professor Dr. Klaus D. Beheng, Universität Karlsruhe (TH), Germany, for his thorough review and constructive recommendations. Appreciation is also expressed to the two other reviewers and to Dr. Ralph Dlugi, Universität München, Germany, for fruitful discussions and helpful suggestions.

\section{REFERENCES}

[1] Barenblatt GI. Similarity, self-similarity, and intermediate asymptotics. Cambridge University Press, Cambridge, UK 1996.

[2] Huntley HE. Dimensional analysis. MacDonald \& Co (Publishers), London, UK 1952.

[3] Kitaigorodskij SA. Zur Anwendung der Ähnlichkeitstheorie für die Beschreibung der Turbulenz in der bodennahen Schicht der Atmosphäre. Z Meteorologie 1976, 26: 185-205 (in German).

[4] Barenblatt GI. Similarity, self-similarity, and intermediate asymptotics. Consultants Bureau, New York/London 1979.

[5] Barenblatt GI. Scaling phenomena in fluid mechanics. Inaugural lecture delivered before the University of Cambridge, May 3, 1993. Cambridge University Press, Cambridge, UK 1994.

[6] Barenblatt GI. Scaling. Cambridge University Press, Cambridge, UK 2003.

[7] Zdunkowski W, Bott A. Dynamics of the atmosphere. Cambridge University Press, Cambridge, UK 2003.

[8] Kramm G, Herbert F. The structure functions for velocity and temperature fields from the perspective of dimensional scaling. Flow Turbul Combust 2006; 76: 23-60.

[9] Sommerfeld A. Thermodynamics and statistical mechanic, lectures on theoretical physics, Vol. V. Academic Press, New York 1956.

[10] Kramm G, Herbert F. Heuristic derivation of blackbody radiation laws using principles of dimensional analysis. J Calcutta Math Soc 2006; 2(2): 1-20.

[11] Brown RA. Fluid mechanics of the atmosphere. Academic Press, San Diego, CA 1991.

[12] Buckingham E. On physically similar systems; illustrations of the use of dimensional equations. Phys Rev 1914; 4: 345-76.

[13] Foken T. 50 years of Monin-Obukhov similarity theory. Bound Layer Meteorol 2006; 119: 431-447.

[14] Monin AS, Obukhov AM. Osnovnye zakonomernosti turbulentnogo peremešivanija $\mathrm{v}$ prizemnom sloe atmosfery. Trudy Geofiz Inst AN SSSR 1954; 24 (151): 163-87 (in Russian).

Prandtl L. Meteorologische Anwendungen der Strömungslehre. Beitr Phys fr Atmosph (Bjerknes-Festband) 1932; 19: 188-202 (in German).

[16] Obukhov AM. Turbulentnost' $\mathrm{v}$ temperaturno-neodnorodnoj atmosphere. Trudy Inst Teoret Geofiz AN SSSR 1946; 1 (in Russian; English translation in Boundary-Layer Meteorol 1971; 2: 7-29).

[17] Priestley CHB. Turbulent transfer in the lower atmosphere. The University of Chicago Press 1959

[18] Beyer R, Roth R. GREIV I 1974 - Meßdaten. Berichte Inst. Meteor. Klimat. 16, TU Hannover, Germany 1976.

[19] Herbert F. Vorlesung zur Physik der planetarischen Grenzschicht Vorlesungskriptum, JW Goethe-Universität, Frankfurt/Main, Germany 1980 (in German).

[20] Pal Arya S. Introduction to micrometeorology. Academic Press, San Diego, CA 1988.

[21] Sorbjan Z. Structure of the atmospheric boundary layer. Prentice Hall, Englewood Cliffs, NJ 1989.

[22] Nikuradse J. Gesetzmäßigkeit der turbulenten Strömung in glatten Rohren. Forsch Arb Ing.-Wes 1932; 356 (in German).

[23] Schlichting H. Grenzschicht-Theorie. Braun, Karlsruhe, 1965 (in German).

[24] Businger JA. Turbulent transfer in the atmospheric surface layer. In: Haugen DA, Ed. Workshop on micrometeorology. Am Meteor Soc, Boston, MA, 1973; pp. 67-100.

Raupach MR, Antonia RA, Rajagopalan S. Rough-wall turbulent boundary layers. Appl Mech Rev 1991; 44: 1-25.

Andreas EL, Claffey KJ, Jordan RE, et al. Evaluations of the von Kármán constant in the atmospheric surface layer. J Fluid Mech 2006; 559: 117-149. 
[27] Eliassen A, Kleinschmidt E, jr. Dynamic meteorology. In: Flügge S, Ed. Handbuch der Physik, Bd. XLVIII. Springer, Berlin/Heidelberg/New York, 1957, pp. 1-154.

[28] van Mieghem J. Atmospheric energetics. Clarendon Press, Oxford 1973.

[29] Herbert F. Irreversible Prozesse der Atmosphäre - 3. Teil (Phänomenologische Theorie mikroturbulenter Systeme). Beitr Phys Atmosph 1975; 48: 1-29 (in German).

[30] Pichler H. Dynamik der Atmosphäre. Bibliographisches Institut, Zürich 1984 (in German).

[31] Dutton JA. Dynamics of atmospheric motion. Dover, New York 1995.

[32] Kramm G, Dlugi R, Lenschow DH. A re-evaluation of the Webbcorrection using density-weighted averages. J Hydrol 1995; 166: 283-92.

[33] Kramm G, Meixner FX. On the dispersion of trace species in the atmospheric boundary layer: a re-formulation of the governing equations for the turbulent flow of the compressible atmosphere. Tellus 2000; 52A: 500-22.

[34] Kramm G, Dlugi R. On the correction of eddy fluxes of water vapour and trace gases. J Calcutta Math Soc 2006; 2(1): 29-54.

[35] Landau LD, Lifshitz EM. Course of theoretical physics - Vol. 6) Fluid Mechanics. Pergamon Press, Oxford/New York/Toronto/ Sydney/Paris/Frankfurt 1959

[36] Hesselberg T. Die Gesetze der ausgeglichenen atmosphärischen Bewegungen. Beitr Phys fr Atmosph 1926; 12: 141-60 (in German).

[37] Busch NE. On the mechanics of atmospheric turbulence. In: Haugen DA, Ed. Workshop on micrometeorology. Amer Meteor Soc, Boston, MA, 1973, 1-65.

[38] Stull RB. An introduction to boundary layer meteorology. Kluwer Academic Publishers, Dordrecht/Boston/London 1988.

[39] Zilitinkevič SS. Effects of humidity stratification on hydrostatic stability. Izv Atmos Ocean Phys 1966; 2: 655-8.

[40] Barenblatt GI, Monin AS. Similarity laws for stratified turbulent shear flows. Report of the Fourth All-Union Congress on Theoretical and Applied Mechanics, 41, Naukova, Dumka, Kiev 1976, USSR.

[41] Barenblatt GI, Monin AS. Similarity laws for stratified turbulent shear flows. Arch Rat Mech Anal, 1979; 70, 307-17.

[42] Lumley JL, Panofsky HA. The structure of atmospheric turbulence. Interscience Publishers (Wiley \& Sons), New York/London/ Sydney 1964.

[43] Stearns CR. Determining surface roughness and displacement height. Bound-Layer Meteorol 1970; 1: 102-11.

[44] Kramm G. The estimation of the surface layer parameters from wind velocity, temperature and humidity profiles by least squares methods. Bound-Layer Meteorol 1989; 48: 315-27.

[45] Foken T. Angewandte Meteorologie. Springer, Berlin/Heidelberg/ NewYork 2003 (in German).

[46] Businger JA, Wyngaard JC, Izumi Y, Bradley EF. Flux-profile relationships in the atmospheric surface layer. J Atmos Sci 1971; 28: 181-9

[47] Zilitinkevič SS, Čalikov DV. Opredelenie universal'nych profilej skorosti vetra i temperatury v prizemnom sloe atmosfery. Izv AN SSSR, Fiz Atm i Okeana 1968; 4: 294-302 (in Russian).

[48] Dyer AJ, Hicks BB. Flux-gradient relationships in the constant flux layer. Quart J R Met Soc 1970; 96: 715-21.

[49] Businger JA. Transfer of momentum and heat in the planetary boundary layer. In: Proceedings of the Symposium on Arctic Heat Budget and Atmospheric Circulation. The Rand Corporation 1966; pp. 305-32.

[50] Pandolfo J. Wind and temperature profiles for a constant flux boundary layer in lapse conditions with a variable eddy conductivity to eddy viscosity ratio. J Atmos Sci 1966; 23: 495-502.

[51] Businger JA. A note on the businger-dyer profiles. Bound-Layer Meteorol 1988; 42: 145-51.

[52] Panofsky HA, Dutton JA. Atmospheric turbulence. John Wiley \& Sons, New York/ Chichester/Brisbane/Toronto/Singapore, 1984.

[53] Högström U. Non-dimensional wind and temperature profiles in the atmospheric surface layer: a re-evaluation. Bound-Layer Meteorol 1988; 42: 55-78.

[54] Čalikov DV. O profilja vetra i temperatury v prizemnom sloe atmosfery pri ustojcivoj stratifikacii. Trudy GGO 1968; 207: 170-3 (in Russian).
[55] Webb EK. Profile relationships: the log-linear range, and extension to strong stability. Quart J R Met Soc 1970; 96: 67-90.

[56] Pai Mazumder D. On the kinetic energy spectra of turbulence in the thermally stratified atmospheric surface layer. Proc. Indian Natn Sci Acad 2006; 72: 125-33.

[57] Dyer AJ, Bradley EF. An alternative analysis of flux-gradient relationships at the 1976 ITCE. Bound-Layer Meteorol 1982; 22: 3-19.

[58] Webb EK. Profile relationships in the super adiabatic surface layer. Quart J R Met Soc 1982; 108: 661-88.

[59] Kramm G, Herbert F, Bernhardt K, et al. Stability functions for momentum, heat and water vapour and the vertical transport of TKE and pressure fluctuations estimated from measured vertical profiles of wind speed, temperature, and humidity. Beitr Phys Atmosph 1996; 69: 463-75.

[60] Cheng Y, Brutsaert W. Flux-profile relationships for wind speed and temperature in the stable atmospheric boundary layer. BoundLayer Meteorol 2005; 114: 519-38.

[61] Kondo J, Kanechika O, Yasuda N. Heat and momentum transfer under strong stability in the atmospheric surface layer. J Atmos Sci 1978; 35: 1012-21.

[62] Okamoto M, Webb EK. The temperature fluctuations in stable stratification. Quart J R Met Soc 1970; 96: 591-600.

[63] Poulos GS, Burns SP. An evaluation of bulk Ri-based surface layer flux formulas for stable and very stable conditions with intermittent turbulence. J Atmos Sci 2003; 60: 2523-37.

[64] Kazansky AB, Monin AS. Turbulence in the inversion layer near the surface. Izv Acad Nauk SSSR Ser Geophys 1956; 1: 79-86.

[65] Ellison TH. Turbulent transport of heat and momentum from an infinite rough plane. J Fluid Mech 1957; 2: 456-66.

[66] Yamamoto G. Theory of turbulent transfer in non-neutral conditions. J Meteor Soc Japan 1959; 37: 60-7.

[67] Panofsky HA. An alternative derivation of the diabatic wind profile. Quart J R Met Soc 1961; 87: 109-10.

[68] Sellers WD. Simplified derivation of the diabatic wind profile. J Atmos Sci 1962; 19: 180-1.

[69] Heisenberg W. Zur statistischen Theorie der Turbulenz. Z Physik 1948; 124: 628-57 (in German).

[70] von Weizsäcker CF. Das Spektrum der Turbulenz bei großen Reynoldsschen Zahlen. Z Physik 1948; 124: 614-27 (in German).

[71] Fortak H. Berechnung des charakteristischen „Scales“ der Turbulenz der bodennahen Grenzschicht aus Windprofilmessungen. Beitr Phys Atmosph 1969; 42: 245-50 (in German).

[72] Herbert F, Panhans WG. Theoretical studies of the parameterization of the non-neutral surface boundary layer - Part I: governing physical concepts. Bound-Layer Meteorol 1979; 16: 155-67.

[73] Panhans WG, Herbert F. Theoretical studies of the parameterization of the non-neutral surface boundary layer - Part II: an improved similarity model. Bound-Layer Meteorol 1979; 16: 169-79.

[74] Wyngaard JC, Coté OR. The budget of turbulent kinetic energy and temperature variance in the atmospheric surface layer. J Atmos Sci 1971; 28: 190-201.

[75] Garratt JR. The atmospheric boundary layer. Cambridge University Press, Cambridge, UK 1994

[76] Carl DM, Tarbell TC, Panofsky HA. Profiles of wind and temperature from towers over homogeneous terrain. J Atmos Sci 1973; 30: 788-94.

[77] Gavrilov AS, Petrov JS. Ocenka tocnosti opredelenija turbulentych potokov po standartnym gidrometeorologiceskim izmerenijam nad morem. Meteorol i Gidrol 1981; 4: $52-9$ (in Russian).

[78] McNaughton K. On the kinetic energy budget of the unstable atmospheric surface layer. Bound-Layer Meteorol 2006; 118: 83107.

[79] Högström U. Turbulent water vapour transfer at different stability conditions. Phys of Fluids 1967; 10 (Suppl): 247-54.

[80] Swinbank WC, Dyer AJ. An experimental study in micrometeorology. Quart J R Met Soc 1967; 93: 494-500.

[81] Businger JA. Evaluation of the accuracy with which dry deposition can be measured with current micrometeorological techniques. J Appl Meteor 1986; 25: 1100-124.

[82] Businger JA, Delany AC. Chemical sensor resolution required for measuring surface fluxes by three common micrometeorological techniques. J Atmos Chem 1990; 10: 399-410.

[83] Droppo JG Jr. Concurrent measurements of ozone dry deposition using eddy correlation and profile flux methods. J Geophys Res 1985; 90 (D1): 2111-8. 
[84] Reichardt H. Der Einfluß der wandnahen Strömung auf den turbulenten Wärmeübergang. Mitt MPI Ström Forsch Nr 31950 (in German).

[85] Fage A, Faulkner VM. Note on experiments on the temperature and velocity in the wake of a heated cylindrical obstacle. Appendix to: Taylor GI, The transport of vorticity and heat through fluids in turbulent motion. Proc R Soc 1932; A 135: $702-5$ (as cited by [23, 93]).

[86] Ludwieg H. Bestimmung des Verhältnisses der Austauschkoeffizienten für Wärme und Impuls bei turbulenten Grenzschichten. Z Flugwiss 1956; 4 (the A. Betz Volume): $73-81$ (in German, abstracts in English and French).

[87] Johnson DS. Velocity and temperature fluctuation measurements in a turbulent boundary layer downstream of a stepwise discontinuity in wall temperature. J Appl Mech, Trans ASME Ser E 1959; 26: 325-36.

[88] Fulachier L, Dumas R. Spectral analogy between temperature and velocity fluctuations in a turbulent boundary layer. J Fluid Mech 1976; 77: 257-77.

[89] Lesieur M. Turbulence in fluids. Kluwer Academic Publishers, Dordrecht/Boston/London 1993.

[90] Lesieur M. Recent approaches in large-eddy simulations of turbulence. In: Métais O, Ferziger J, Eds. New tools in turbulence modeling. Springer, Berlin/Heidelberg/ New York, and Les Éditions de Physique, Les Ulis 1997; pp. 1-28.

[91] Rotta JC. Temperaturverteilungen in der turbulenten Grenzschicht an der ebenen Platte. Int J Heat Mass Transfer 1964; 7: 215-28 (in German, abstracts in English, French, and Russian).

[92] Deissler RG. Turbulent heat transfer and temperature fluctuations in a field with uniform velocity and temperature gradients. Int $\mathrm{J}$ Heat Mass Transfer 1963; 6: 257-70.

[93] Kestin J, Richardson PD. Heat transfer across turbulent, incompressible boundary layers. Int. J. Heat Mass Transfer 1963, 6: 14789.

[94] Kramm G, Dlugi R, Mölders N. Sublayer-Stanton numbers of heat and matter for aerodynamically smooth surfaces: Basic considerations and evaluation. Meteorol Atmos Phys 2002; 79: 173-94.

[95] Kraus EB, Businger JA. Atmosphere-ocean interaction. Oxford University Press, New York 1994.

[96] von Kármán T. Mechanische Ähnlichkeit und Turbulenz. Nachr Ges Wiss Göttingen, Math Phys Klasse 1930; 58 (in German).

[97] Frenzen P, Vogel CA. A further note 'On the magnitude and apparent range of variation of the von Karman constant'. Bound-Layer Meteorol 1995; 73: 315-7.

[98] Frenzen P, Vogel CA. On the magnitude and apparent range of variation of the von Karman constant in the atmospheric surface layer. Bound-Layer Meteorol 1995; 72: 371-92.

[99] Wilson JD. Monin-Obukhov functions for standard deviations of velocity. Bound-Layer Meteorol 2008; 129: 353-69.

[100] Panofsky HA, Tennekes H, Lenschow DH, Wyngaard JC. The characteristics of turbulent components in the surface layer under convective conditions. Boundary-Layer Meteorol 1977; 11: 355-61.

[101] Johansson C, Smedman AS, Högström U, Brasseur JG, Khanna S. Critical test of the validity of Monin-Obukhov similarity during convective conditions. J Atmos Sci 2001; 58: 1549-66.

[102] Andreas EL, Hicks BB. Comments on "Critical test of the validity of Monin-Obukhov similarity during convective conditions". J Atmos Sci 2002; 59: 2605-7.

[103] Wyngaard JC, Coté OR, Izumi Y. Local free convection, similarity and budgets of shear stress and heat flux. J Atmos Sci 1971; 28: 1171-82.

[104] Monji N. Budgets of turbulent energy and temperature variance in the transition zone from forced to free convection. J Meteor Soc Japan 1973; 2: 133-45.
[105] Tillman JE. The indirect determination of stability, heat and momentum fluxes in the atmospheric boundary layer from simple scalar variables during dry unstable conditions. J Appl Meteor 1972; 11: 783-92.

[106] Högström U, Smedman-Högström AS. Turbulence mechanism at an agricultural site. Boundary-Layer Meteorol 1974, 7: 373-89.

[107] Kaimal JC, Finnigan JJ. Atmospheric boundary layer flows. Oxford University Press, New York/Oxford 1994.

[108] Kaimal JC, Wyngaard JC, Izumi Y, Coté OR. Spectral characteristics of surface layer turbulence. Quart J R Met Soc 1972; 98: 56389.

[109] Prenosil T. Prediction of the Monin-Obukhov similarity functions from a second-order closure model. Bound-Layer Meteorol 1979; 17: 495-516

[110] Claussen M. Estimation of the Monin-Obukhov functions from a spectral model. Bound-Layer Meteorol 1985; 33: 233-43.

[111] Khanna S, Brasseur JG. Analysis of Monin-Obukhov similarity from large-eddy simulation. J Fluid Mech 1997; 345: 251-86.

[112] Lewellen W, Teske M. Prediction of the Monin-Obukhov similarity functions from an invariant model of turbulence. J Atmos Sci 1973; 30: $1340-45$.

[113] Panofsky HA. Determination of stress from wind and temperature measurements. Quart J R Met Soc 1963; 89: 85-94.

[114] Kramm G, Herbert F. Ein numerisches Modell zur Deposition von Schadstoffen in der bodennahen Luftschicht. In: Reuter H, Ed. Probleme der Umwelt- und Medizinmeteorologie im Gebirge. Symposium Rauris/Österreich, September 23-25, 1983. Zentralanstalt f Meteorologie u Geodynamic, Wien, Nr 288, 1984; pp. 22-38 (in German).

[115] Paulson CA. The mathematical representation of wind speed and temperature profiles in the unstable atmospheric surface layer. J Appl Meteor 1970; 9: 857-61.

[116] Lettau HH. Wind and temperature profile predictions for diabatic surface layers including strong inversion cases. Bound-Layer Meteorol 1979; 17: 443-64.

[117] Dyer AJ. A review of flux-profile relationships. Bound-Layer Meteorol 1974; 7: 363-72.

[118] Bernhardt K. Zur Interpretation der Monin-Obuchovschen Länge. Meteorol Zeitschrift, NF, 1995; 4: 81-2 (in German).

[119] Yaglom AM. Comments on wind and temperature flux-profile relationships. Bound-Layer Meteorol 1977; 11: 89-102.

[120] Haenel HD. Surface-layer profile evaluation using a generalization of Robinson's method for the determination of $\mathrm{d}$ and $\mathrm{z}_{\mathrm{o}}$. BoundLayer Meteorol 1993; 65: 55-67.

[121] Lo AK. An analytical-empirical method for determining the roughness length and zero-plane displacement. Bound-Layer Meteorol 1977; 12: 141-51.

[122] Nieuwstadt F. The computation of the friction velocity $\mathrm{u} *$ and the temperature scale $\mathrm{T} *$ from temperature and wind velocity profiles by least-square methods. Boundary-Layer Meteorol 1978; 14: 23546.

[123] Estoque MA. Numerical modeling of the planetary boundary layer. In: Haugen DA, Ed. Workshop on micrometeorology. Am Meteor Soc, Boston, MA, 1973, pp. 217-70.

[124] Herbert F, Kramm G. A discussion of approximate relations for transfer and deposition of trace constituents in the ABL. In: Herbert F, Ed. Atmospheric trace constituents. Friedr.Vieweg \& Sohn, Braunschweig/Wiesbaden, Germany 1982; pp. 27-40.

[125] Stoer J. Einführung in die numerische Mathematik I. Springer, Berlin/Heidelberg/New York/Tokyo 1972 (in German).

[126] Foken T, Skeib G. Profile measurements in the atmospheric nearsurface layer and the use of suitable universal functions for the determination of the turbulent energy exchange. Boundary-Layer Meteorol 1983; 25: 55-62. 